\title{
Hypoxia, oxidative stress, and benzo[a]pyrene induced carcionogenesis
}

Citation for published version (APA):

Schults, M. A. C. (2012). Hypoxia, oxidative stress, and benzo[a]pyrene induced carcionogenesis.

[Doctoral Thesis, Maastricht University]. BOXPress. https://doi.org/10.26481/dis.20121211ms

Document status and date:

Published: 01/01/2012

DOI:

10.26481/dis.20121211ms

Document Version:

Publisher's PDF, also known as Version of record

\section{Please check the document version of this publication:}

- A submitted manuscript is the version of the article upon submission and before peer-review. There can be important differences between the submitted version and the official published version of record.

People interested in the research are advised to contact the author for the final version of the publication, or visit the DOI to the publisher's website.

- The final author version and the galley proof are versions of the publication after peer review.

- The final published version features the final layout of the paper including the volume, issue and page numbers.

Link to publication

\footnotetext{
General rights rights.

- You may freely distribute the URL identifying the publication in the public portal. please follow below link for the End User Agreement:

www.umlib.nl/taverne-license

Take down policy

If you believe that this document breaches copyright please contact us at:

repository@maastrichtuniversity.nl

providing details and we will investigate your claim.
}

Copyright and moral rights for the publications made accessible in the public portal are retained by the authors and/or other copyright owners and it is a condition of accessing publications that users recognise and abide by the legal requirements associated with these

- Users may download and print one copy of any publication from the public portal for the purpose of private study or research.

- You may not further distribute the material or use it for any profit-making activity or commercial gain

If the publication is distributed under the terms of Article $25 \mathrm{fa}$ of the Dutch Copyright Act, indicated by the "Taverne" license above, 


\section{Hypoxia, oxidative stress, and benzo[a]pyrene induced carcinogenesis}

Marten Schults 
(C) Marten Schults, Nijmegen 2012

ISBN: 978-90-8891-502-4

Cover design: $\quad$ Esther Ris, www.proefschriftomslag.nl

Lay-out: Marten Schults

Production: $\quad$ Proefschriftmaken.nl || Uitgeverij BOXPress, 's-Hertogenbosch

The research presented in this thesis was performed at the Department of Toxicology (formerly Health Risk Analysis and Toxicology), Maastricht University, within NUTRIM School for Nutrition, Toxicology and Metabolism, which participates in the Graduate School VLAG (Food Technology, Agrobiotechnology, Nutrition, and Health Sciences, accredited by the Royal Netherlands Academy of Arts and Sciences (KNAW) 


\title{
Hypoxia, oxidative stress, and benzo[a]pyrene induced carcinogenesis
}

\author{
Proefschrift \\ Ter verkrijging van de graad van doctor aan de Universiteit Maastricht, \\ op gezag van Rector Magnificus, Prof. Dr. L.L.G. Soete, \\ volgens het besluit van het College van Decanen, \\ in het openbaar te verdedigen \\ op 11 december 2012 om 16:00 uur. \\ door
}

Martinus Alphonsus Cornelis Schults

Geboren te Tilburg op 25 juli 1983 


\section{Promotor}

Prof. Dr. F.J. van Schooten

\section{Co-promotoren}

Dr. R.K. Chiu

Dr. R.W.L. Godschalk

\section{Beoordelingscommissie}

Prof. Dr. A. Bast (voorzitter)

Prof. Dr. F.C.R. Ramaekers

Prof. Dr. M.A.G.G. Vooijs

Dr. R.C.J. Langen 


\section{CONTENTS}

Chapter 1 General introduction 7

Chapter 2 Diminished carcinogen detoxification is a novel mechanism for $\quad 29$ hypoxia-inducible factor 1-mediated genetic instability.

Chapter 3 Hypoxia diminishes the detoxification of the environmental mutagen benzo[a]pyrene.

Chapter 4 Loss of von Hippel-Lindau affects benzo[a]pyrene induced genotoxic responses and reduces its repair in renal-cell carcinoma in vitro.

Chapter 5 Genetic polymorphisms in catalase and CYP1B1 determine

DNA-adduct formation by benzo[a]pyrene ex vivo.

Chapter 6 Decreased nucleotide excision repair in steatotic livers: associates with myeloperoxidase-immunoreactivity.

Chapter 7 Summary and general discussion

Nederlandse samenvatting

Dankwoord

Curriculum vitae

List of publications 



\section{Chapter 1}

General introduction 
It was estimated that about 12.7 million cancer cases and 7.6 million cancer deaths have occurred in 2008. Because of the aging and growth of the world population and increased adoption of cancer-causing behaviors, such as smoking, in the developing world, this number will increase (1). For many years it has been known that environmental factors, such as tobacco, alcohol, diet, and occupational exposures account for a great majority of cancer deaths (2). The great majority of the chemical carcinogens present in these environmental factors require metabolic activation to elicit detrimental effects (3). Therefore, alterations in the metabolism could influence the carcinogenicity of those compounds. A lot is known about the effect of polymorphisms on carcinogen metabolism; however there are more endogenous factors that could influence one's susceptibility to carcinogens such as inflammation and oxidative stress. Moreover these factors might also alter the repair of the damage induced by the same carcinogens. In this thesis we focus on two endogenous oxygenrelated factors (hypoxia and oxidative stress) since previous research suggests that both factors might have an influence on carcinogen metabolism (4) and repair (5). Our goal was to further elucidate these mechanisms, and to prove the biological significance of these factors influencing the carcinogenic capabilities of carcinogens and subsequent genetic instability.

\section{Carcinogen-induced DNA damage}

Cancer induction is a multi-stage, multi-step process and includes multiple molecular and cellular events to transform a normal cell to a malignant neoplastic cell. However, three general steps can be identified in carcinogenesis; initiation, promotion, and progression. Initiation is the step where irreversibly, DNA of a normal cell is changed and a mutated cell is formed. During the next step, this single cell is encouraged to proliferate and form a population of mutated cells. This tumor promotion process is not necessarily a direct DNA reactive or damaging process, but involves modulation of gene expression that results in the increase in cell number through cell division and/or decrease in apoptotic cell death. The third step, progression, involves additional damage to the genome, and invasive expansion of the neoplastic cells.

A cell or tissue has to acquire certain capabilities to follow this above mentioned multistep process of human tumor pathogenesis. In 2000, Hanahan and Weinberg described six capabilities (hallmarks) that enable cells to eventually form a tumor; cells have to become self-sufficient in growth signals, insensitive to anti-growth signals, cells must be able to avoid apoptosis, to induce angiogenesis, to invade local tissue and metastasize, and they must acquire limitless replicative potential (6). Eleven years later additional hallmarks were proposed such as the ability of cells to evade immune destruction and the deregulation of the energy metabolism inside the cell (7).

To affect these hallmarks, expression of genes that are involved in pathways influencing these hallmarks of cancer, have to change. These changes can be a result of an alteration in the microenvironment of the cell due to for instance hypoxia or inflammation, or as a result of gene mutations. There is however a continuous surveillance of the genetic material to find and repair any DNA damage. The mechanisms involved are known as the DNA damage response pathways. Cells 
respond to DNA damage by activating checkpoint pathways to delay the cell-cycle progression and repair the defects before the damage is converted into permanent mutations $(8,9)$. When a cell is however not able to correct the damage properly or is not going into apoptosis, an irreversible DNA damage is formed and a hallmark can be acquired.

\section{Chemical carcinogenesis}

Chemical carcinogens have an impact on all three stages of carcinogenesis. The mechanisms by which carcinogens induce their effects and how they are involved in carcinogenesis have been studied extensively and can be divided into two main groups; genotoxic and non-genotoxic effects.

A genotoxic carcinogen is capable, mostly after metabolic activation, of directly altering the genetic material of target cells by for instance inducing DNA breakage or binding to the DNA and form DNA-adducts. Non-genotoxic carcinogens on the other hand are chemicals that induce cancer without altering the DNA, but instead alter mechanisms involved in cell-cell communication, receptors activation, DNA methylation and DNA repair, among others $(3,10,11)$. Therefore, investigating the consequences of these factors or the mechanisms inducing cancer is of great importance to come up with preventive measurements or treatments.

\section{Exposure to polycyclic hydrocarbons}

One of the most studied carcinogens is the polycyclic aromatic hydrocarbons (PAHs). PAHs are widely distributed environmental contaminants produced as by-products of a variety of combustion processes such as diesel exhaust, cigarette smoking, and charcoal grilling of food. The ability of PAH-containing mixtures to induce cancer has been known since 1775, when the British surgeon Sir Percival Pott demonstrated a relation between scrotal cancer incidence and the exposure of chimney sweepers to soot. The most studied PAH in the human population is benzo[a]pyrene (BaP), which has often been regarded as the prototypical PAH. There are three major exposure routes to BaP: skin exposure, dietary intake which is estimated to be around $76 \mathrm{ng}$ per day and associated with colorectal adenomas (12), and inhalation by for instance smoking, which is estimated to be around $9 \mathrm{ng}$ BaP per cigarette (13), or exposure to air pollution. In Berlin outdoor BaP levels were reported to be around $0.1 \mathrm{ng} / \mathrm{m}^{3}$ due to for instance motor vehicle traffic (14), while BaP concentrations in the developing world are much higher especially in urban areas. In La Plata (Argentina) almost 4 times higher levels of $\mathrm{BaP}\left(0.38 \mathrm{ng} / \mathrm{m}^{3}\right)$ were observed compared to the rural area $(0.11$ $\mathrm{ng} / \mathrm{m}^{3}$ ), while in industrial areas 7.5 fold higher levels were observed. (15). Similar concentrations were observed in the city of Curitiba (southern Brazil), where BaP concentration ranges between $0.36-0.97 \mathrm{ng} / \mathrm{m}^{3}$ (16). Although smoking and air pollution are decreased in the developed world in the last few decades, in the developing world exposure to PAHs is still of great concern. 


\section{Cellular response to $B a P$}

Exposure to $\mathrm{BaP}$ is of major concern because, once entered into the body, BaP easily crosses the cell membrane as it is a lipophilic compound. In the cytoplasm, it binds to the aryl hydrocarbon receptor (AhR), which forms a complex with chaperone proteins: heat shock protein 90, XAP2 and p23 (17). Upon ligand binding, AhR translocates into the nucleus, dimerizes with the aryl hydrocarbon receptor nuclear translocator (ARNT), and activates gene expression by binding to the TNGCGTG consensus sequence in the xenobiotic-responsive elements of target genes (18). This leads to the up-regulation of a multitude of genes as has been shown in multiple gene expression studies in different cell types (19-21). BaP is mostly known for its capacity to stimulate its own metabolism by inducing the expression of the cytochrome P450 isoforms CYP1A1 (22) and CYP1B1 (23) which are two of the most important enzymes in the detoxification and bioactivation of $\operatorname{BaP}(24,25)$.

The detoxification process of BaP (Figure 1.1) starts with the addition of an epoxide group to $\mathrm{BaP}$ by these mono-oxygenases (phase I). The resulting metabolites (e.g. BaP7,8-epoxide and BaP-9,10-epoxide) can be converted into BaP-glutathion conjugates, a reaction catalyzed by glutathione S-transferase (GST) (phase II). BaP-epoxides can also be converted nonenzymatically to phenols (e.g. BaP-3-phenol), or to dihydrodiols (e.g. $\mathrm{BaP}-7,8-\mathrm{diOH}$ or BaP-9,10-diOH) by epoxide hydrolase. Phenols can be converted to water-soluble sulphate or glucuronide conjugates by sulfonyl transferase (SULT) and uridine diphosphate glucuronosyl transferase (UGT), respectively. Dihydrodiols can be glucuronidated (26) or transformed by CYP1A1 or CYP1B1 to diol epoxides (e.g. BaP7,8-diol-9,10-epoxide (BPDE)) (25).

The last phase in the metabolism of BaP is the active transport over the membrane. Certain ATP binding cassette transporter proteins are able to transport BaP and other xenobiotics and their metabolites across the cell membranes (27). For instance, Pglycoprotein mediates the efflux of BaP in human breast cancer cells (28) and the breast cancer resistance protein can actively transport BaP glutathione, glucuronide, and sulfate-conjugates (29). Changes in the activity of these transport proteins could have an effect on the carcinogenicity of a compound as for example a reduced BPDE glutathione conjugate removal resulted in an increased BPDE-DNA adduct formation (30). In addition BaP can be metabolized to o-quinones catalyzed by dihydrodiol dehydrogenases, which can undergo redox cycling. Redox cycling of these metabolites leads to the formation of large amounts of reactive oxygen species (ROS), which cause the formation of oxidative DNA damage which results in elevated levels of lipid peroxidation (31).

\section{BaP-induced DNA damage}

There are four isoforms of BPDE of which the (+)-anti-isomer is the most predominant and the most potent tumor initiator (24). BPDE can covalently bind to DNA, preferentially to the nucleotide guanine at the N2 position. This covalent binding result in the formation of highly mutagenic DNA adducts (BPDE-N2-dG lesion), which can become mutations, predominantly $\mathrm{G}$ to $\mathrm{T}$ transversions, when these adducts are not removed (32). Unrepaired damage can result in apoptosis or transcriptional changes, and mutations acquired in the process of DNA repair may lead to unregulated cell 
growth and cancer. It is for instance known that these BPDE-induced $G$ to $T$ transversions in the p53 tumor suppressor gene are involved in lung cancer development (33). Furthermore, isothiocyanate, which is very effective against lung tumor development in a mouse model, caused a decrease in BPDE-DNA adduct levels in the mouse lung (34).

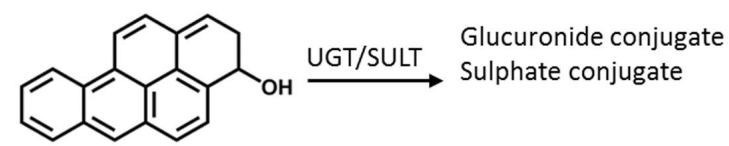

3-hydroxy BaP

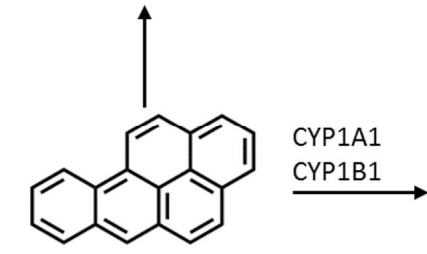

Benzo(a)pyrene (BaP)<smiles>CCOC(=O)C(C)(C)C</smiles>

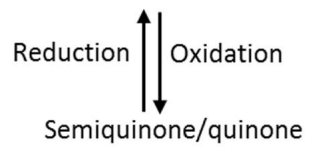

Glucuronide conjugate Sulphate conjugate

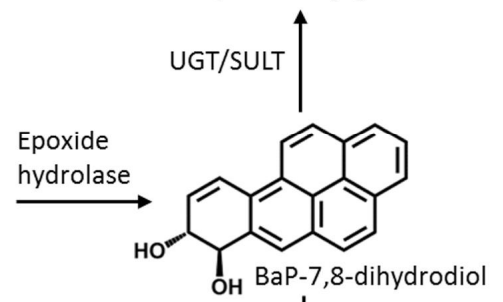

BaP-7,8-epoxide

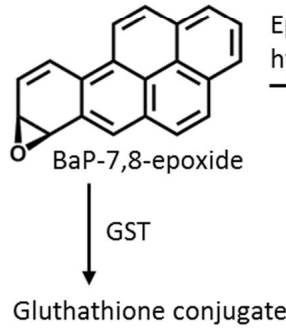

Gluthathione conjugate (1)

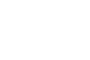<smiles>OC1C=C2C3=c4ccc(cccc5ccc6cc1c4c5-6)C(O3)C(O)C2O</smiles>

BaP-7,8-dihydrodiol-9,10-epoxide (BPDE)

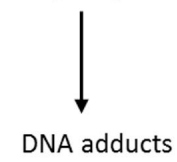

Figure 1.1: Schematic overview of the metabolism of BaP by the phase I enzymes cytochrome P450 (CYP1A1 and CYP1B1) and phase II enzymes; glutathione S-transferase (GST), uridine diphosphate glucuronosyl transferase (UGT), and sulfonyl transferase (SULT). Adapted from Baird et al and Zhou et al $(25,35)$.

\section{Polymorphisms affecting BaP metabolism}

These bulky DNA adducts formed after BaP exposure are considered to be markers of exposure to genotoxic aromatic compounds and of the ability of the individual to metabolically activate carcinogens and to repair DNA damage (36). Nevertheless, individuals with approximately similar exposures may have different DNA adduct levels as was for instance found by Rojas et al, who observed a 4-fold and 3-fold interindividual difference in smoker and non-smokers, respectively (37). These differences could be explained by polymorphisms in genes involved in the process of DNA adduct formation and repair. These variations have been studied extensively for both BPDEadduct formation as cancer risk and multiple polymorphisms have been found. Polymorphisms affecting BPDE-DNA adduct formation have been identified in phase I and II enzymes linked to BaP metabolism, including CYP1A1, GSTM1, GSTT1, GSTP1 
(38-40). However, no CYP1B1 polymorphisms affecting BPDE-DNA adduct formation have been identified so far.

Even more research has been performed on the effect of these polymorphisms on susceptibility to various kinds of cancers. Some of these polymorphisms have been shown to be a risk factor, however, factors as gender, ethnic background or smoking habits can have a tremendous influence on the effect of a polymorphism and cancer development. Polymorphisms of both phase I enzymes involved in BaP metabolism have been linked to cancer risk. For instance, the CYP1A1 lle462Val polymorphism has been associated with the development of lung cancer, especially in Asians (41) and with risk of colorectal cancer in both Asians and Caucasians (42). Also the CYP1A1 Mspl gene polymorphism, is associated with increased lung cancer risk (43). Both these polymorphisms have also been associated with increases in CYP1A1 catalytic activity $(44,45)$. The CYP1B1 polymorphism Leu432Val, which results in an increased catalytic activity of CYP1B1, is associated with increased lung cancer among smokers $(46,47)$. Phase II enzymes have also been studied and polymorphisms in GSTM1, GSTP1, and GSTT1 have been associated with altered catalytic activity, but concluding from numerous datasets, GSTs do not show to have a link with cancer risk $(48,49)$. Overall, polymorphisms in genes of xenobiotic enzymes are of influence to adduct formation and associated with cancer risk.

\section{Repair of BaP-induced DNA damage}

To cope with DNA lesions, cells have specific mechanisms for tolerating and repairing the damage. There are 6 major DNA repair pathway involved in DNA repair, which can be subdivided into those who repair single-strand damage and those involved in the repair of double-strand breaks (DSBs). DSBs are usually repaired through two main pathways; homologous recombination (HR) and non-homologous end joining (NHEJ), while the single strand damages are repaired by direct reversal that corrects alkylated bases, mismatch repair (MMR) that corrects small insertions and deletions that take place during DNA replication, base excision repair (BER), which repairs damage to single bases, and nucleotide excision repair (NER), which repairs bulky helix-distorting lesions (50). The main repair mechanism of bulky adducts caused by for instance BaP is NER (51). The importance of NER can be observed in xeroderma pigmentosum (XP), where a mutation in one of the XP genes results in a non-functional NER and a subsequent increased cancer risk due to the inability to restore UV-induced DNA damage (52). Furthermore, reduced expression of NER related genes, such as ERCC1, has been linked to the development of lung cancer (53). NER is therefore an essential repair pathway responsible for the repair of bulky DNA adducts and UV-induced lesions. However, when these bulky DNA-adduct are not repaired, replication forks will stall during replication. To prevent DNA replication fork stalling, specific DNA repair mechanism called post-replication repair pathways are activated to simply bypass DNA damage. The stalling of a replication fork triggers monoubiquitination of proliferating cell nuclear antigen (PCNA) at Lys164, which is catalyzed by the Rad6/Rad18 complex and activates the predominately error-prone translesion synthesis (TLS). In contrast, polyubiquitination of PCNA by the Ubc13/Mms2/Rad5 complex triggers the error-free lesion bypass. (54-56). 


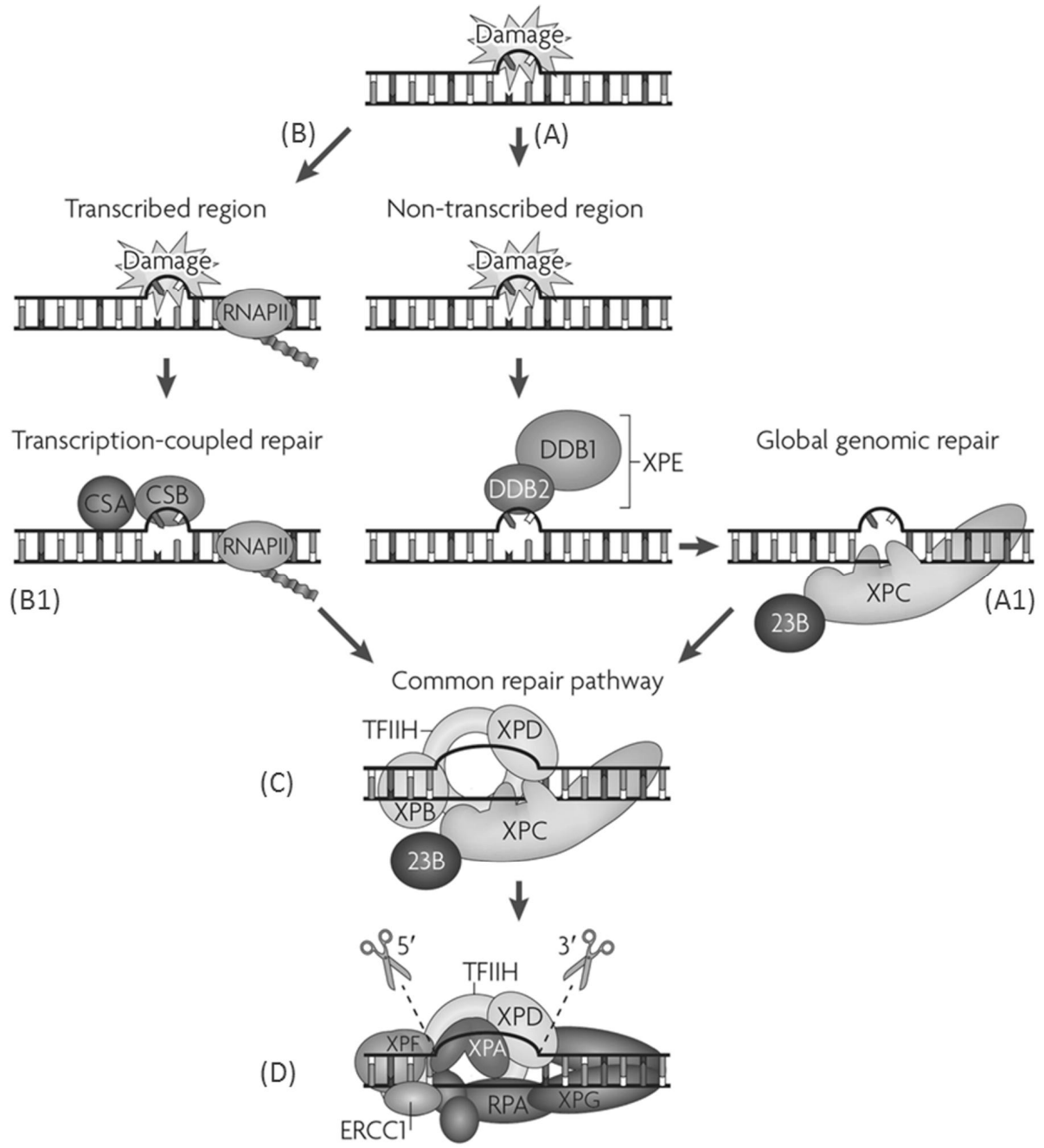

Figure 1.2: Overview of the nucleotide excision pathway adapted from cleaver et al (52).

\section{Nucleotide excision repair pathway}

The repair of DNA damage by NER (Figure 1.2) can be divided in three steps: firstly, the recognition of the damage and a subsequent formation of a pre-incision complex; the excision of the damaged strand; and finally the gap is filled during DNA synthesis. There are two NER sub-pathways: the global genome NER (GG-NER) that detects and removes lesions in non-transcribed regions (A); and the transcription-coupled NER (TCNER), which repairs actively transcribed genes (B) $(51,57)$. The difference between the two sub-pathways is in the damage recognition step. Where in the GG-NER pathway damage in transcriptionally inactive regions is detected by XPC and the XPE complex (A1), the TC-NER pathway recognizes the damage through the arrest of RNA polymerase I (RNAPI) and RNAPII. Subsequently, Cockayne syndrome A (CSA/ERCC8) and CSB (also known as ERCC6) proteins bind to the DNA. Arrested polyubiquitylated 
RNAPII is removed and degraded, leaving the active gene accessible for repair (B1). Damage recognition of both pathways is followed by binding of XPA to the damaged DNA strand and RPA envelops the undamaged strand. XPB (also known as ERCC3) and XPD (also known as ERCC2), both part of transcription factor TFIIH bind to the DNA and unwind it $(C)$. The DNA around the damaged site is then cleaved for 24-32 bases long by the XPG (ERCC5) and the XPF (ERCC4)-ERCC1 heterodimer (D). DNA polymerases $\delta$ or $\varepsilon$ fills the gap and ligase connects the newly formed and original DNA strand $(51,52)$. The rate limiting steps in NER are damage recognition and incision, as ATP is required for the cleavage and opening of the damaged DNA strand (58).

\section{Hypoxia and cancer}

Cellular responses to hypoxia, a reduction in normal oxygen tension, occur as a regulatory process in normal physiologic conditions. For instance under high altitude where hypoxic responses results in the increase of respiration rate while due to local hypoxia at for instance a site of injury, blood vessels are recruited.

Hypoxia is also an important factor in cancer where it has an influence on the hallmarks of cancer. It stimulates for instance cells to express various growth signals. To evade apoptosis, hypoxia is able to induce the expression of anti-apoptosis proteins and it provides a physiological selective pressure in tumors for the expansion of cells that have lost their apoptotic potential. Furthermore, tissue hypoxia can induce a number of angiogenic factors that promote angiogenesis, such as VEGF and IL-8, but it can also decrease the activity of the angiogenic inhibitor thrombospondin, which will result in a sustained angiogenesis.(See (59) for a more extensive review on this topic). Due to abnormal vasculature of tumors, hypoxia is a characteristic feature in the vast majority of solid tumors and remains of therapeutic concern due to the reduction in the efficacy of conventional therapies. Resistance of hypoxic cells to chemotherapy is caused by the limited delivery of the agent to the cells due to the limited vasculature in the tumor and by the immunity of slowly proliferating cells at increasing distances from tumor blood vessels to agents that target cell proliferation, while resistance to radiotherapy is a result of the reduced formation of ROS targeting the DNA after irradiation (60-62). Overall, hypoxia plays a central role in mutagenesis and carcinogenesis.

\section{Molecular responses to hypoxia}

Hypoxia inducible factor $\alpha$ ( $\mathrm{HIF} \alpha)$ is regarded as the primary molecular switch to alter gene expression in response to reduced oxygen tension (Figure 1.3). There are three known family members (HIF-1 $\alpha$, HIF- $2 \alpha$, and HIF-3 $\alpha$ ). Under normoxic conditions, hydroxyl groups are attached to HIF $\alpha$ by prolyl-4-hydroxylase (PHD), which requires oxygen, iron and 2-oxoglutarate for enzymatic activity (63). The hydroxylated HIF $\alpha$ is recognized by an ubiquitin ligase complex, which contains the von Hippel-Lindau protein (VHL). VHL binding of HIF $\alpha$ targets it for ubiquitination (64) and subsequent degradation by the $26 \mathrm{~S}$ proteasome (65). Hypoxia prevents hydroxylase activity and the consequently stabilized HIF $\alpha$ subunit is translocated into the nucleus, where it forms HIF1, a heterodimer with HIF-1 $\beta$ also known as ARNT (66). In contrast to HIF $\alpha$, 
HIF-1ß/ARNT is constitutively present irrespective of oxygen tension (67). After dimerization, HIF1 binds to the (A/G)CGTG consensus sequence in the hypoxiaresponsive elements of the promoter/enhancer regions in the DNA (68), where it promotes the transcription of a wide array of hypoxia-inducible genes, including genes involved in angiogenesis (vascular endothelial growth factor (VEGF)), glucose metabolism (glucose transporter 1 ), $\mathrm{pH}$ regulation (carbonic anhydrase IX (CA-IX)), and cell growth (insulin-like growth factor 2) (69). These proteins encoded by these genes are crucial in mediating the cellular adaptation or tolerance to hypoxia and in the survival of the cell.

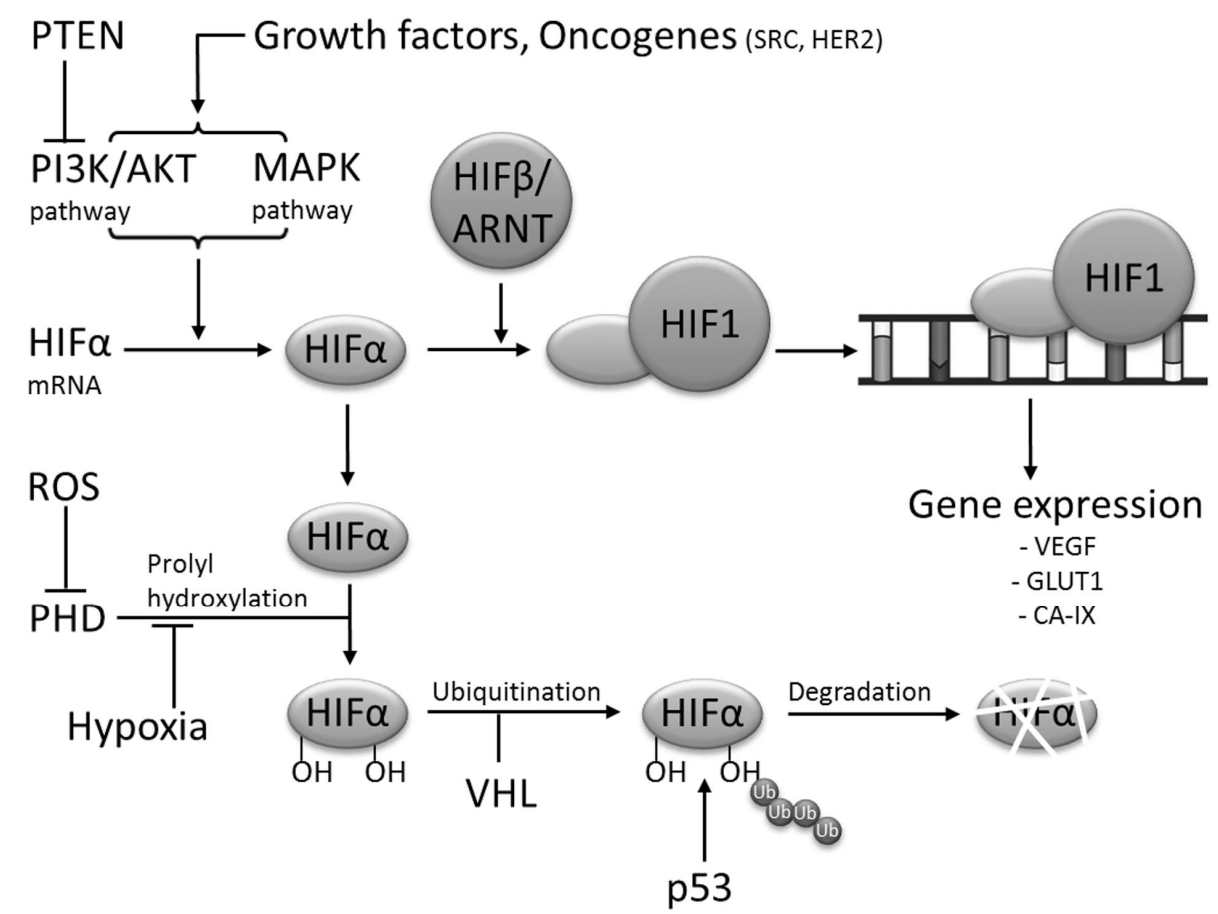

Figure 1.3: Schematic overview of the HIF pathway. Adapted from Baldewijns et al and Semenza et al $(70,71)$. HIF $\alpha$ protein levels are regulated by the amount of synthesis and stabilitzation. Activation of the PI3K/AKT and MAPK pathway results in increased translation of HIFa mRNA. Oxygen-dependent prolyl hydroxylation by prolyl-4-hydroxylase (PHDs) on the other hand regulates the binding of the von Hippel-Lindau protein (VHL) that targets HIFa for ubiquitination and proteasomal degradation.

\section{Hypoxia independent HIF $\alpha$ stabilization}

In addition to changes in oxygen tension, various other stimuli can induce a HIF $\alpha$ response (Figure 1.3). The transition metal cobalt can inactivate the hydroxylases by occupying an iron-binding site on the proline hydroxylases (72) and by occupying the VHL-binding domain of HIF $\alpha$, preventing the degradation of HIF $\alpha$ (73). HIF1 may also be activated by interaction with ROS, probably via inhibition of hydroxylation by PHDs (74). Growth factors such as insulin and TNFa have also been shown to generate a HIF1 
response (75) by stimulating HIFa synthesis via activation of the phosphatidylinositol 3kinase (PI3K) or mitogen-activated protein kinase (MAPK) pathways (76). HIF expression can also be induced by oncogenic activation (HRAS, HER2, or SRC) and tumorsupressor (VHL, PTEN, or p53) deactivation (76). For instance, mutations in the $\mathrm{VHL}$ gene result in constitutive HIF $\alpha$ activation since $\mathrm{VHL}$ is unable to recognize the hydroxylated HIF $\alpha$ and appear to be responsible for about 60 to 70 percent of the cases of sporadic clear-cell renal-cell carcinoma, which represents a major portion of all cases of renal-cell carcinoma (77). Since the stabilization of HIF $\alpha$ may already occur in the early phases of disease development, it could be of major relevance for the preclinical stages of carcinogenesis and studying HIF $\alpha$ stabilization should not be limited to hypoxia.

\section{Cancer therapies targeting hypoxia}

As hypoxia has a major influence on cancer development, studies in the recent years have come up with therapies targeting hypoxia through a variety of molecular mechanisms. The major mechanisms of action are reducing HIF $\alpha$ mRNA or protein levels, HIF1 DNA-binding activity, or HIF1-mediated transactivation of target genes. (See $(78,79)$ for a more extensive review of this topic). These drugs can improve cancer treatment outcomes or prevent further cancer development in the early stages of carcinogenesis.

A second group of possible therapies are the bioreductive drugs. These drugs do not overcome hypoxia, but they are designed in such a way that they become active in the absence of oxygen and make it possible to target hypoxic cells. There are five different chemical groups (nitro groups, quinones, aromatic $\mathrm{N}$-oxides, aliphatic $\mathrm{N}$-oxides and transition metals) with the potential to be metabolized under hypoxic conditions. The general mechanism involves a one-electron reduction generating a prodrug radical that can be re-oxidized by oxygen in normoxic cells, but become active under hypoxic conditions, either by fragmentation of the prodrug radical or by its further reduction. The use of these drugs in combination with traditional therapies has the potential to improve treatment outcome of anticancer therapies $(80,81)$.

A third group is the bacterial-mediated cancer therapies. Anaerobic bacteria carrying a recombinant protein specifically targets hypoxic regions in solid tumors. These bacteria can either deliver proteins that have a direct cytotoxic effect, such as toxins and cytokines but also enzymes that convert a non-toxic prodrug into a toxic agent. Since the hypoxic environment supports the growth and proliferation of anaerobic bacteria, this therapy is very specific (82).

\section{Nucleotide excision repair and hypoxia}

There is a growing body of evidence showing that pathways involved in single-strand damage repair; BER and MMR, as well as those involved in DSB repair; HR and NHEJ, are inhibited by hypoxia. Hypoxia has also been linked with NER. (83). Yuan et al. were the first to show that NER is inhibited by hypoxia. They showed that mouse fibroblast cells under hypoxic conditions ( $0 \%$ oxygen for 24 hours) combined with low pH (6.5) had a decreased repair of UV damaged DNA that was transfected into the mouse fibroblast cells (84). However, more recently Dregoesc et al. showed a differential 
pattern in 5 different cell lines, where in human fibroblasts under conditions of hypoxia (1\% oxygen for 12 to 24 hours) or hypoxia and low $\mathrm{pH}$ (6.5) an increase in repair was observed, while at longer time periods a reduced repair was observed. In the tumor derived cells, a decrease was observed in repair, which increased after 30 hours of hypoxic conditions (85). It is also known that HIF- $1 \alpha$ and NER are linked since HIF-1 $\alpha$ regulates the gene expression of XPC and XPD by binding to the hypoxiaresponsive elements within their promoter sites (86). Furthermore, miR-373 is upregulated in a HIF-1 $\alpha$ dependent manner and downregulates the NER protein RAD23B (87). Considering the contradictory results, probably due to different experiment conditions and cell lines used, more research is needed, especially on the actual phenotypic effects of hypoxia on NER activity.

\section{Crosstalk between the HIF and AhR pathway}

HIF-1ß/ARNT is a component of both the AhR and HIF1 signaling pathways and therefore HIF stabilization could reduce the availability of Hif-1ß/ARNT for the metabolism of carcinogens. This cross-talk between the two pathways has previously been demonstrated; however, these studies revealed inconsistent interactive results and did not determine biological significance.

In 1996, Gradin et al. were the first to demonstrate in HepG2 cells that both the AhRpathway and HIF1-pathway required ARNT. An excess of activated AhR by 2,3,7,8tetrachlorodibenzofuran (TCDF) did not compete with HIF-1 $\alpha$ for recruitment of ARNT, while $\mathrm{CoCl}_{2}$ had an inhibitory effect on CYP1A1 mRNA expression (88). This conclusion was confirmed by Gassmann et al. who showed that VEGF expression was independent of HIF1 activation by indolo[3,2-b]carbazole (ICZ)-treatment in mouse Hepa1 hepatoma cells (89). Also the AhR-ligand 2,3,7,8-tetrachlorodibenzodioxin (TCDD) showed in Hepa1 cells that hypoxic agents including $\mathrm{CoCl}_{2}$ inhibited dioxin-induced CYP1A1 transcription (90). These studies indicated that the HIF1-pathway activation inhibits the AhR pathway but not vice versa.

Conversely, a number of reports have demonstrated an opposing effect stating that AhR pathway activation affects hypoxic response. For instance, Takacova et al. showed in Hela cells that TCDD-induced activation of the AhR pathway interfered with CA-IX mRNA and protein expression (91). The two-way competition was shown by Chan et al, who determined that in HepG2 and Hep3B cells, AhR driven transcription was inhibited by $\mathrm{CoCl}_{2}$ and the hypoxia enhancer driven transcription was inhibited by AhR agonists (92). These results were confirmed by Nie et al. showing that TCDD significantly reduced the hypoxia-mediated reporter gene activity in $\mathrm{B}-1$ cells, while the hypoxia response inducers desferrioxamine (DFO) and $\mathrm{CoCl}_{2}$ inhibited AhR-mediated CYP1A1 enzyme activity (93). These studies confirm that the HIF1-pathway activation inhibits the AhR pathway, but also indicate that AhR pathway activation results in a decreased HIF1 response. A plausible explanation for the differences observed could be a result of differences in cell lines used and different ways to induce a hypoxic response and a response of the AhR-pathway. Studies to better define this relationship would be helpful. 


\section{Chapter 1}

Possible mechanisms involved in the crosstalk

Although the studies presented above demonstrated that HIF reduces the AhR response, the exact mechanism is largely unknown, and clearly complex. The most logical mechanism would be competition for ARNT as has been shown by Gradin et al, whose data showed that HIF-1 $\alpha$ exhibited an affinity for ARNT in HepG2 cell extracts that was considerably higher than that of AhR (88). On the other hand, Pollenz et al. showed that the amount of ARNT sequestered during hypoxia represented only 12$15 \%$ of the total ARNT protein pool in mouse (Hepa-1), rat (H4IIE), and human (HepG2) hepatoma cell lines under hypoxic conditions $\left(1 \% \mathrm{O}_{2}\right)$. Furthermore, the same level of AhR/ARNT complexes could be detected in cells treated with TCDD during hypoxic and normoxic conditions (94). These results suggest that there also might be other mechanisms interfering with hypoxia and AHR-mediated signaling.

Another mechanism was proposed by Allen et al., who suggested that HIF-2 $\alpha$ played a role in the crosstalk. They found in wild-type mouse hepatocytes, being stimulated with hypoxia (1\% oxygen) and 3-methylcholanthrene (an AhR ligand), that hypoxic conditions reduced the CYP1A1 gene expression. This was also observed in mouse hepatocytes lacking HIF-1 $\alpha$, suggesting a HIF-1 $\alpha$ independent mechanism. (95). Moreover, Zhang et al. showed by gene silencing of HIF-2 $\alpha$ in primary human pulmonary microvascular endothelial cells exposed to hypoxia (1-2.5\% oxygen) that CYP1A1 mRNA expression is reduced by hypoxia via a HIF- $2 \alpha$-dependent mechanism. (96). Overall, there is strong evidence that there is crosstalk between the two pathways, the exact mechanism is however still largely unknown.

\section{Oxidative stress}

Although oxygen is an essential part of life, toxic oxygen species can be generated in the cells. Oxidative stress is the imbalance between the production of ROS and their removal resulting in an overall increase in cellular levels of ROS. These ROS are constantly generated in the mitochondria as respiration byproducts $(0.1-2 \%$ of consumed $\mathrm{O}_{2}$ depending on the tissue type), and are therefore a major source of oxidative damage (97). ROS can also be produced by macrophages and neutrophils at sites of inflammation and infection (98) or induced by exogenous sources such as environmental agents and radiation, (99). Table 1.1 gives an overview of sources of different types of oxidative species.

\section{Inflammation-induced oxidative stress}

Inflammation is a normal response of tissues to defend itself from invading pathogens, chemicals and physical agents. Inflammation starts when pro-inflammatory cytokines and chemokines at a site of injury or infection releases chemical signals. As a response, inflammatory cells including neutrophils are attracted, and upon activation produce oxidant generating enzymes, such as NAPDPH oxidase, superoxide dismutase and myeloperoxidase (MPO) resulting in the production of ROS to attack invading infectious agents. 
Inflammation has been linked to cancer for many decades and it is has been recognized as a major factor in cancer development (100) and has been suggested to be an important hallmark of cancer. Many mechanisms have been described to explain the cancer development due to inflammation, such as increasing proliferation and survival of malignant cells, promoting angiogenesis and metastasis, subverting adaptive immune responses, and altering responses to hormones and chemotherapeutic agents (101).

These alterations in molecular pathways also have a clinical effect as observed in epidemiological studies showing that chronic inflammation predisposes individuals to various types of cancer. For example, people suffering from chronic obstructive pulmonary disease (COPD) have a 2.2 fold higher risk of developing lung cancer (102) and have a 1.4 fold higher overall cancer risk (103), which could be a result of increased oxidative stress or reduced DNA repair (104). Non-alcoholic steatotic hepatitis (NASH) has been associated with an increased risk of developing hepatocellular carcinoma (105).

Table 1.1: Reactive oxygen generation in the cell. Adapted from Klaunig et al. (106).

\begin{tabular}{|c|c|c|}
\hline Cellular oxidants & Source & Oxidative species \\
\hline Endogenous & $\begin{array}{l}\text { Mitochondria } \\
\text { Cytochrome P450 } \\
\text { Inflammatory cells } \\
\text { Peroxisomes }\end{array}$ & $\begin{array}{l}\mathrm{O}_{2}^{-\bullet}, \mathrm{H}_{2} \mathrm{O}_{2}, \stackrel{\circ}{\circ} \mathrm{OH} \\
\mathrm{O}_{2}^{-\bullet}, \mathrm{H}_{2} \mathrm{O}_{2} \\
\mathrm{O}_{2}^{-\bullet}, \mathrm{H}_{2} \mathrm{O}_{2}, \mathrm{OCl}^{-} \\
\mathrm{H}_{2} \mathrm{O}_{2}\end{array}$ \\
\hline Exogenous & $\begin{array}{l}\text { Redox cycling compounds } \\
\text { Metals (Fenton reaction) } \\
\text { Radiation }\end{array}$ & $\begin{array}{l}\mathrm{O}_{2}^{-\bullet} \\
\cdot{ }^{\circ} \\
\cdot \mathrm{OH}\end{array}$ \\
\hline
\end{tabular}

\section{Oxidative stress and reduced repair capacity}

Oxidative stress can induce various forms of DNA damage and ultimately result in increased mutagenesis and carcinogenesis (107). Moreover, previous studies within our group have also indicated a role for oxidative stress in the reduction of NER. In vitro studies demonstrated that MPO-derived hypochlorous acid ( $\mathrm{HOCl}$ ) mediates NER capacity inhibition in A549 lung cancer cells by activated neutrophils (108). MPO is an important enzyme abundantly present in neutrophils and involved in the generation of $\mathrm{H}_{2} \mathrm{O}_{2}$ to $\mathrm{HOCl}$ (109). $\mathrm{HOCl}$ contributes to host tissue damage at sites of inflammation by causing side-chain modification, backbone fragmentation, and cross-linking of proteins (110) and by damaging DNA by oxidizing pyrimidine bases and chlorination of cytosine (111).

Although $50 \%$ reduction was observed in a mouse model, the mechanisms may differ from the in vitro system as it appeared to be independent of MPO, but was rather due to ROS following the influx of neutrophils (5). This finding was confirmed by the fact that oxidative stress reduced NER capacity in colon tissue of newborn piglets (112). 


\section{Aim and outline of the thesis}

$\mathrm{BaP}$ is an environmental agent capable of inducing DNA damage after metabolic activation. The balance between the induction of BaP-induced DNA damage and its repair determines the carcinogenicity of BaP. Endogenous factors can influence this balance. Understanding these endogenous factors influencing the carcinogenicity of chemical compounds is of great importance in the discovery of preventive measures or treatments. Therefore, the aim of this thesis was to investigate oxygen-related factors (hypoxia and oxidative stress) and their influence on the formation of BaP-induced DNA damage and its repair by NER.

The influence of hypoxia and HIF $\alpha$ stabilization have been studied extensively and there is some level of cross-talk between the hypoxia pathways and the AhR-pathway; however, none of the previously published studies demonstrated that the cross-talk had any biological significance, as, for instance, increased genetic instability. Therefore, in chapter $\mathbf{2}$, the involvement of HIF $\alpha$ stabilization on the genetic instability caused by carcinogens was determined. A549 cells were co-incubated with the HIF $\alpha$ stabilizing agent $\mathrm{CoCl}_{2}$ and $\mathrm{BaP}$. Not only was the level of crosstalk between the two pathways determined, but also its effect on genetic instability by measuring strand breaks, adduct formation and importantly mutation frequencies.

This crosstalk was further investigated in chapter 3, where changes in the metabolic pattern of BaP due to HIF $\alpha$ induction were determined. Therefore, A549 cells were cultured under different oxygen concentrations and the expressions of genes involved in carcinogen metabolism, together with metabolite and adduct formation were measured. The next step in investigating this mechanism was to determine whether this effect is present in the naturally occurring VHL deficient renal cell carcinoma (RCC) cells. The most frequent observed genetic alteration in RCC is the somatic mutation of the VHL tumor suppressor gene, resulting in a continuous activation of the HIF-1 pathway. To this end, in chapter 4, it was determined how VHL might impact the oncogenic capacity of BaP by determining the difference in metabolic profiles and NER between two renal cell lines with either a functional or a dysfunctional VHL gene.

As changes in oxygen levels results in alterations in oxidative stress (113), we sought to determine if this oxidative stress could be a second factor influencing carcinogen metabolism. Catalase is involved in reducing the oxidative stress levels in the cell by catalyzing the conversion of $\mathrm{H}_{2} \mathrm{O}_{2}$ into water and oxygen. In chapter 5, the effect of a polymorphism in the promoter region of catalase on CYP1B1 gene expression and BPDE-DNA adducts induction in lymphocytes was investigated.

Oxidative stress has also been linked to reduction in NER in A549 cells and in mice lung. In this thesis we investigated if this same effect could be observed in human liver samples. Therefore, in chapter $\mathbf{6}$, steatotic livers with or without NASH were tested for their NER capacity and the influence of oxidative stress on NER was determined.

Finally, in chapter $\mathbf{7}$ the main findings of this thesis are summarized, discussed and suggestions for further research and for possible future usage of the obtained knowledge are given. 


\section{Reference list}

1 Jemal, A., Bray, F., Center, M.M., Ferlay, J., Ward, E., and Forman, D. (2011) Global cancer statistics. CA Cancer J Clin, 61, 69-90.

2 Lichtenstein, P., Holm, N.V., Verkasalo, P.K., Iliadou, A., Kaprio, J., Koskenvuo, M., Pukkala, E., Skytthe, A., and Hemminki, K. (2000) Environmental and heritable factors in the causation of cancer--analyses of cohorts of twins from Sweden, Denmark, and Finland. $N$ Engl J Med, 343, 78-85.

3 Luch, A. (2005) Nature and nurture - lessons from chemical carcinogenesis. Nat Rev Cancer, 5, 113-125.

4 Chan, W.K., Yao, G., Gu, Y.Z., and Bradfield, C.A. (1999) Cross-talk between the aryl hydrocarbon receptor and hypoxia inducible factor signaling pathways. Demonstration of competition and compensation. J Biol Chem, 274, 12115-12123.

5 Gungor, N., Haegens, A., Knaapen, A.M., Godschalk, R.W., Chiu, R.K., Wouters, E.F., and van Schooten, F.J. (2010) Lung inflammation is associated with reduced pulmonary nucleotide excision repair in vivo. Mutagenesis, 25, 77-82.

6 Hanahan, D., and Weinberg, R.A. (2000) The hallmarks of cancer. Cell, 100, 57-70.

7 Hanahan, D., and Weinberg, R.A. (2011) Hallmarks of cancer: the next generation. Cell, 144, 646-674.

8 Warmerdam, D.O., and Kanaar, R. (2010) Dealing with DNA damage: relationships between checkpoint and repair pathways. Mutat Res, 704, 2-11.

9 Zhou, B.B., and Elledge, S.J. (2000) The DNA damage response: putting checkpoints in perspective. Nature, 408, 433-439.

10 Williams, G.M. (2001) Mechanisms of chemical carcinogenesis and application to human cancer risk assessment. Toxicology, 166, 3-10.

11 Hernandez, L.G., van Steeg, H., Luijten, M., and van Benthem, J. (2009) Mechanisms of non-genotoxic carcinogens and importance of a weight of evidence approach. Mutat Res, 682, 94-109.

12 Sinha, R., Kulldorff, M., Gunter, M.J., Strickland, P., and Rothman, N. (2005) Dietary benzo[a]pyrene intake and risk of colorectal adenoma. Cancer Epidemiol Biomarkers Prev, 14, 2030-2034.

13 Swauger, J.E., Steichen, T.J., Murphy, P.A., and Kinsler, S. (2002) An analysis of the mainstream smoke chemistry of samples of the U.S. cigarette market acquired between 1995 and 2000. Regul Toxicol Pharmacol, 35, 142-156.

14 Fromme, H., Lahrz, T., Piloty, M., Gebhardt, H., Oddoy, A., and Ruden, H. (2004) Polycyclic aromatic hydrocarbons inside and outside of apartments in an urban area. Sci Total Environ, 326, 143-149.

15 Rehwagen, M., Muller, A., Massolo, L., Herbarth, O., and Ronco, A. (2005) Polycyclic aromatic hydrocarbons associated with particles in ambient air from urban and industrial areas. Sci Total Environ, 348, 199-210.

16 Froehner, S., Maceno, M., Machado, K.S., and Grube, M. (2011) Health risk assessment of inhabitants exposed to PAHs particulate matter in air. J Environ Sci Health A Tox Hazard Subst Environ Eng, 46, 817-823.

17 Petrulis, J.R., and Perdew, G.H. (2002) The role of chaperone proteins in the aryl hydrocarbon receptor core complex. Chem Biol Interact, 141, 25-40.

18 Reyes, H., Reisz-Porszasz, S., and Hankinson, O. (1992) Identification of the Ah receptor nuclear translocator protein (Arnt) as a component of the DNA binding form of the Ah receptor. Science, 256, 1193-1195. 
19 Staal, Y.C., van Herwijnen, M.H., van Schooten, F.J., and van Delft, J.H. (2006) Modulation of gene expression and DNA adduct formation in HepG2 cells by polycyclic aromatic hydrocarbons with different carcinogenic potencies. Carcinogenesis, 27, 646-655.

20 Hockley, S.L., Arlt, V.M., Brewer, D., Giddings, I., and Phillips, D.H. (2006) Time- and concentration-dependent changes in gene expression induced by benzo(a)pyrene in two human cell lines, MCF-7 and HepG2. BMC Genomics, 7, 260.

21 Sparfel, L., Pinel-Marie, M.L., Boize, M., Koscielny, S., Desmots, S., Pery, A., and Fardel, O. (2010) Transcriptional signature of human macrophages exposed to the environmental contaminant benzo(a)pyrene. Toxicol Sci, 114, 247-259.

22 Nebert, D.W. (1989) The Ah locus: genetic differences in toxicity, cancer, mutation, and birth defects. Crit Rev Toxicol, 20, 153-174.

23 Spink, D.C., Katz, B.H., Hussain, M.M., Spink, B.C., Wu, S.J., Liu, N., Pause, R., and Kaminsky, L.S. (2002) Induction of CYP1A1 and CYP1B1 in T-47D human breast cancer cells by benzo[a]pyrene is diminished by arsenite. Drug Metab Dispos, 30, 262-269.

24 Gelboin, H.V. (1980) Benzo[alpha]pyrene metabolism, activation and carcinogenesis: role and regulation of mixed-function oxidases and related enzymes. Physiol Rev, 60, 11071166.

25 Baird, W.M., Hooven, L.A., and Mahadevan, B. (2005) Carcinogenic polycyclic aromatic hydrocarbon-DNA adducts and mechanism of action. Environ Mol Mutagen, 45, 106-114.

26 Jin, C.J., Miners, J.O., Burchell, B., and Mackenzie, P.I. (1993) The glucuronidation of hydroxylated metabolites of benzo[a]pyrene and 2-acetylaminofluorene by cDNAexpressed human UDP-glucuronosyltransferases. Carcinogenesis, 14, 2637-2639.

27 Hoffmann, U., and Kroemer, H.K. (2004) The ABC transporters MDR1 and MRP2: multiple functions in disposition of xenobiotics and drug resistance. Drug Metab Rev, 36, 669-701.

28 Yeh, G.C., Lopaczynska, J., Poore, C.M., and Phang, J.M. (1992) A new functional role for Pglycoprotein: efflux pump for benzo(alpha)pyrene in human breast cancer MCF-7 cells. Cancer Res, 52, 6692-6695.

29 Ebert, B., Seidel, A., and Lampen, A. (2005) Identification of BCRP as transporter of benzo[a]pyrene conjugates metabolically formed in Caco-2 cells and its induction by Ahreceptor agonists. Carcinogenesis, 26, 1754-1763.

30 Srivastava, S.K., Watkins, S.C., Schuetz, E., and Singh, S.V. (2002) Role of glutathione conjugate efflux in cellular protection against benzo[a]pyrene-7,8-diol-9,10-epoxideinduced DNA damage. Mol Carcinog, 33, 156-162.

31 Penning, T.M., Burczynski, M.E., Hung, C.F., McCoull, K.D., Palackal, N.T., and Tsuruda, L.S. (1999) Dihydrodiol dehydrogenases and polycyclic aromatic hydrocarbon activation: generation of reactive and redox active o-quinones. Chem Res Toxicol, 12, 1-18.

32 Zhang, Y., Wu, X., Guo, D., Rechkoblit, O., Geacintov, N.E., and Wang, Z. (2002) Two-step error-prone bypass of the (+)- and (-)-trans-anti-BPDE-N2-dG adducts by human DNA polymerases eta and kappa. Mutat Res, 510, 23-35.

33 Pfeifer, G.P., Denissenko, M.F., Olivier, M., Tretyakova, N., Hecht, S.S., and Hainaut, P. (2002) Tobacco smoke carcinogens, DNA damage and p53 mutations in smokingassociated cancers. Oncogene, 21, 7435-7451.

34 Sticha, K.R., Staretz, M.E., Wang, M., Liang, H., Kenney, P.M., and Hecht, S.S. (2000) Effects of benzyl isothiocyanate and phenethyl isothiocyanate on benzo[a]pyrene metabolism and DNA adduct formation in the A/J mouse. Carcinogenesis, 21, 1711-1719.

35 Zhou, S.F., Liu, J.P., and Chowbay, B. (2009) Polymorphism of human cytochrome P450 enzymes and its clinical impact. Drug Metab Rev, 41, 89-295.

36 Phillips, D.H. (2005) DNA adducts as markers of exposure and risk. Mutat Res, 577, 284292. 
37 Rojas, M., Marie, B., Vignaud, J.M., Martinet, N., Siat, J., Grosdidier, G., Cascorbi, I., and Alexandrov, K. (2004) High DNA damage by benzo[a]pyrene 7,8-diol-9,10-epoxide in bronchial epithelial cells from patients with lung cancer: comparison with lung parenchyma. Cancer Lett, 207, 157-163.

38 Rojas, M., Cascorbi, I., Alexandrov, K., Kriek, E., Auburtin, G., Mayer, L., Kopp-Schneider, A., Roots, I., and Bartsch, H. (2000) Modulation of benzo[a]pyrene diolepoxide-DNA adduct levels in human white blood cells by CYP1A1, GSTM1 and GSTT1 polymorphism. Carcinogenesis, 21, 35-41.

39 Lodovici, M., Luceri, C., Guglielmi, F., Bacci, C., Akpan, V., Fonnesu, M.L., Boddi, V., and Dolara, P. (2004) Benzo(a)pyrene diolepoxide (BPDE)-DNA adduct levels in leukocytes of smokers in relation to polymorphism of CYP1A1, GSTM1, GSTP1, GSTT1, and mEH. Cancer Epidemiol Biomarkers Prev, 13, 1342-1348.

40 Besaratinia, A., Kleinjans, J.C., and Van Schooten, F.J. (2002) Biomonitoring of tobacco smoke carcinogenicity by dosimetry of DNA adducts and genotyping and phenotyping of biotransformational enzymes: a review on polycyclic aromatic hydrocarbons. Biomarkers, 7, 209-229.

41 Wang, J.J., Zheng, Y., Sun, L., Wang, L., Yu, P.B., Li, H.L., Tian, X.P., Dong, J.H., Zhang, L., Xu, J., Shi, W., and Ma, T.Y. (2011) CYP1A1 lle462Val polymorphism and susceptibility to lung cancer: a meta-analysis based on 32 studies. Eur J Cancer Prev, 20, 445-452.

42 Zheng, Y., Wang, J.J., Sun, L., and Li, H.L. (2011) Association between CYP1A1 polymorphism and colorectal cancer risk: a meta-analysis. Mol Biol Rep.

43 Zhan, P., Wang, Q., Qian, Q., Wei, S.Z., and Yu, L.K. (2011) CYP1A1 Mspl and exon7 gene polymorphisms and lung cancer risk: an updated meta-analysis and review. J Exp Clin Cancer Res, 30, 99.

44 Cosma, G., Crofts, F., Taioli, E., Toniolo, P., and Garte, S. (1993) Relationship between genotype and function of the human CYP1A1 gene. J Toxicol Environ Health, 40, 309-316.

45 Zhang, Z.Y., Fasco, M.J., Huang, L., Guengerich, F.P., and Kaminsky, L.S. (1996) Characterization of purified human recombinant cytochrome P4501A1-Ile462 and -Val462: assessment of a role for the rare allele in carcinogenesis. Cancer Res, 56, 3926-3933.

46 Chen, B., Qiu, L.X., Li, Y., Xu, W., Wang, X.L., Zhao, W.H., and Wu, J.Q. (2010) The CYP1B1 Leu432Val polymorphism contributes to lung cancer risk: evidence from 6501 subjects. Lung Cancer, 70, 247-252.

47 Shimada, T., Watanabe, J., Kawajiri, K., Sutter, T.R., Guengerich, F.P., Gillam, E.M., and Inoue, K. (1999) Catalytic properties of polymorphic human cytochrome P450 1B1 variants. Carcinogenesis, 20, 1607-1613.

48 Carlsten, C., Sagoo, G.S., Frodsham, A.J., Burke, W., and Higgins, J.P. (2008) Glutathione Stransferase M1 (GSTM1) polymorphisms and lung cancer: a literature-based systematic HuGE review and meta-analysis. Am J Epidemiol, 167, 759-774.

49 Ye, Z., Song, H., Higgins, J.P., Pharoah, P., and Danesh, J. (2006) Five glutathione stransferase gene variants in 23,452 cases of lung cancer and 30,397 controls: metaanalysis of 130 studies. PLoS Med, 3, e91.

50 Hakem, R. (2008) DNA-damage repair; the good, the bad, and the ugly. Embo J, 27, 589605.

51 Gillet, L.C., and Scharer, O.D. (2006) Molecular mechanisms of mammalian global genome nucleotide excision repair. Chem Rev, 106, 253-276.

52 Cleaver, J.E., Lam, E.T., and Revet, I. (2009) Disorders of nucleotide excision repair: the genetic and molecular basis of heterogeneity. Nat Rev Genet, 10, 756-768.

53 Cheng, L., Spitz, M.R., Hong, W.K., and Wei, Q. (2000) Reduced expression levels of nucleotide excision repair genes in lung cancer: a case-control analysis. Carcinogenesis, 21, 1527-1530. 
54 Langie, S.A., Knaapen, A.M., Ramaekers, C.H., Theys, J., Brun, J., Godschalk, R.W., van Schooten, F.J., Lambin, P., Gray, D.A., Wouters, B.G., and Chiu, R.K. (2007) Formation of lysine 63-linked poly-ubiquitin chains protects human lung cells against benzo[a]pyrenediol-epoxide-induced mutagenicity. DNA Repair (Amst), 6, 852-862.

55 Chiu, R.K., Brun, J., Ramaekers, C., Theys, J., Weng, L., Lambin, P., Gray, D.A., and Wouters, B.G. (2006) Lysine 63-polyubiquitination guards against translesion synthesis-induced mutations. PLoS Genet, 2, e116.

56 Ulrich, H.D. (2004) How to activate a damage-tolerant polymerase: consequences of PCNA modifications by ubiquitin and SUMO. Cell Cycle, 3, 15-18.

57 Shuck, S.C., Short, E.A., and Turchi, J.J. (2008) Eukaryotic nucleotide excision repair: from understanding mechanisms to influencing biology. Cell Res, 18, 64-72.

58 Hansen, W.K., and Kelley, M.R. (2000) Review of mammalian DNA repair and translational implications. J Pharmacol Exp Ther, 295, 1-9.

59 Ruan, K., Song, G., and Ouyang, G. (2009) Role of hypoxia in the hallmarks of human cancer. J Cell Biochem, 107, 1053-1062.

60 Tredan, O., Galmarini, C.M., Patel, K., and Tannock, I.F. (2007) Drug resistance and the solid tumor microenvironment. J Nat/ Cancer Inst, 99, 1441-1454.

61 Vaupel, P., Thews, O., and Hoeckel, M. (2001) Treatment resistance of solid tumors: role of hypoxia and anemia. Med Oncol, 18, 243-259.

62 Minchinton, A.I., and Tannock, I.F. (2006) Drug penetration in solid tumours. Nat Rev Cancer, 6, 583-592.

63 Jaakkola, P., Mole, D.R., Tian, Y.M., Wilson, M.I., Gielbert, J., Gaskell, S.J., Kriegsheim, A., Hebestreit, H.F., Mukherji, M., Schofield, C.J., Maxwell, P.H., Pugh, C.W., and Ratcliffe, P.J. (2001) Targeting of HIF-alpha to the von Hippel-Lindau ubiquitylation complex by O2regulated prolyl hydroxylation. Science, 292, 468-472.

64 Cockman, M.E., Masson, N., Mole, D.R., Jaakkola, P., Chang, G.W., Clifford, S.C., Maher, E.R., Pugh, C.W., Ratcliffe, P.J., and Maxwell, P.H. (2000) Hypoxia inducible factor-alpha binding and ubiquitylation by the von Hippel-Lindau tumor suppressor protein. J Biol Chem, 275, 25733-25741.

65 Kallio, P.J., Wilson, W.J., O'Brien, S., Makino, Y., and Poellinger, L. (1999) Regulation of the hypoxia-inducible transcription factor 1alpha by the ubiquitin-proteasome pathway. J Biol Chem, 274, 6519-6525.

66 Wang, G.L., Jiang, B.H., Rue, E.A., and Semenza, G.L. (1995) Hypoxia-inducible factor 1 is a basic-helix-loop-helix-PAS heterodimer regulated by cellular $\mathrm{O} 2$ tension. Proc Natl Acad Sci U S A, 92, 5510-5514.

67 Kallio, P.J., Pongratz, I., Gradin, K., McGuire, J., and Poellinger, L. (1997) Activation of hypoxia-inducible factor 1alpha: posttranscriptional regulation and conformational change by recruitment of the Arnt transcription factor. Proc Natl Acad Sci U S A, 94, 5667-5672.

68 Semenza, G.L., Jiang, B.H., Leung, S.W., Passantino, R., Concordet, J.P., Maire, P., and Giallongo, A. (1996) Hypoxia response elements in the aldolase A, enolase 1, and lactate dehydrogenase $A$ gene promoters contain essential binding sites for hypoxia-inducible factor 1. J Biol Chem, 271, 32529-32537.

69 Harris, A.L. (2002) Hypoxia--a key regulatory factor in tumour growth. Nat Rev Cancer, 2, 38-47.

70 Baldewijns, M.M., van Vlodrop, I.J., Vermeulen, P.B., Soetekouw, P.M., van Engeland, M., and de Bruine, A.P. (2010) VHL and HIF signalling in renal cell carcinogenesis. J Pathol, 221, 125-138.

71 Semenza, G.L. (2002) HIF-1 and tumor progression: pathophysiology and therapeutics. Trends Mol Med, 8, S62-67. 
72 Epstein, A.C., Gleadle, J.M., McNeill, L.A., Hewitson, K.S., O'Rourke, J., Mole, D.R., Mukherji, M., Metzen, E., Wilson, M.I., Dhanda, A., Tian, Y.M., Masson, N., Hamilton, D.L., Jaakkola, P., Barstead, R., Hodgkin, J., Maxwell, P.H., Pugh, C.W., Schofield, C.J., and Ratcliffe, P.J. (2001) C. elegans EGL-9 and mammalian homologs define a family of dioxygenases that regulate HIF by prolyl hydroxylation. Cell, 107, 43-54.

73 Yuan, Y., Hilliard, G., Ferguson, T., and Millhorn, D.E. (2003) Cobalt inhibits the interaction between hypoxia-inducible factor-alpha and von Hippel-Lindau protein by direct binding to hypoxia-inducible factor-alpha. J Biol Chem, 278, 15911-15916.

74 Cash, T.P., Pan, Y., and Simon, M.C. (2007) Reactive oxygen species and cellular oxygen sensing. Free Radic Biol Med, 43, 1219-1225.

75 Bardos, J.I., and Ashcroft, M. (2004) Hypoxia-inducible factor-1 and oncogenic signalling. Bioessays, 26, 262-269.

76 Semenza, G.L. (2003) Targeting HIF-1 for cancer therapy. Nat Rev Cancer, 3, 721-732.

77 Kim, W.Y., and Kaelin, W.G. (2004) Role of VHL gene mutation in human cancer. J Clin Oncol, 22, 4991-5004.

78 Semenza, G.L. (2007) Evaluation of HIF-1 inhibitors as anticancer agents. Drug Discov Today, 12, 853-859.

79 Poon, E., Harris, A.L., and Ashcroft, M. (2009) Targeting the hypoxia-inducible factor (HIF) pathway in cancer. Expert Rev Mol Med, 11, e26.

80 Wilson, W.R., and Hay, M.P. (2011) Targeting hypoxia in cancer therapy. Nat Rev Cancer, 11, 393-410.

81 Wouters, B.G., Weppler, S.A., Koritzinsky, M., Landuyt, W., Nuyts, S., Theys, J., Chiu, R.K., and Lambin, P. (2002) Hypoxia as a target for combined modality treatments. Eur J Cancer, 38, 240-257.

82 Mengesha, A., Dubois, L., Chiu, R.K., Paesmans, K., Wouters, B.G., Lambin, P., and Theys, J. (2007) Potential and limitations of bacterial-mediated cancer therapy. Front Biosci, 12, 3880-3891.

83 Chan, N., and Bristow, R.G. (2010) "Contextual" synthetic lethality and/or loss of heterozygosity: tumor hypoxia and modification of DNA repair. Clin Cancer Res, 16, 45534560.

84 Yuan, J., Narayanan, L., Rockwell, S., and Glazer, P.M. (2000) Diminished DNA repair and elevated mutagenesis in mammalian cells exposed to hypoxia and low pH. Cancer Res, 60, 4372-4376.

85 Dregoesc, D., and Rainbow, A.J. (2009) Differential effects of hypoxia and acidosis on p53 expression, repair of UVC-damaged DNA and viability after UVC in normal and tumorderived human cells. DNA Repair (Amst), 8, 370-382.

86 Rezvani, H.R., Mahfouf, W., Ali, N., Chemin, C., Ged, C., Kim, A.L., de Verneuil, H., Taieb, A., Bickers, D.R., and Mazurier, F. (2010) Hypoxia-inducible factor-1alpha regulates the expression of nucleotide excision repair proteins in keratinocytes. Nucleic Acids Res, 38, 797-809.

87 Crosby, M.E., Kulshreshtha, R., Ivan, M., and Glazer, P.M. (2009) MicroRNA regulation of DNA repair gene expression in hypoxic stress. Cancer Res, 69, 1221-1229.

88 Gradin, K., McGuire, J., Wenger, R.H., Kvietikova, I., fhitelaw, M.L., Toftgard, R., Tora, L., Gassmann, M., and Poellinger, L. (1996) Functional interference between hypoxia and dioxin signal transduction pathways: competition for recruitment of the Arnt transcription factor. Mol Cell Biol, 16, 5221-5231.

89 Gassmann, M., Kvietikova, I., Rolfs, A., and Wenger, R.H. (1997) Oxygen- and dioxinregulated gene expression in mouse hepatoma cells. Kidney Int, 51, 567-574. 
90 Kim, J.E., and Sheen, Y.Y. (2000) Inhibition of 2,3,7,8-tetrachlorodibenzo-p-dioxin (TCDD)stimulated Cyp1a1 promoter activity by hypoxic agents. Biochem Pharmacol, 59, 15491556.

91 Takacova, M., Holotnakova, T., Vondracek, J., Machala, M., Pencikova, K., Gradin, K., Poellinger, L., Pastorek, J., Pastorekova, S., and Kopacek, J. (2009) Role of aryl hydrocarbon receptor in modulation of the expression of the hypoxia marker carbonic anhydrase IX. Biochem J, 419, 419-425.

92 Chan, W.K., Yao, G., Gu, Y.Z., and Bradfield, C.A. (1999) Cross-talk between the aryl hydrocarbon receptor and hypoxia inducible factor signaling pathways. Demonstration of competition and compensation. J Biol Chem, 274, 12115-12123.

93 Nie, M., Blankenship, A.L., and Giesy, J.P. (2001) Interactions between aryl hydrocarbon receptor (AhR) and hypoxia signaling pathways. Environ Toxicol Pharmacol, 10, 17-27.

94 Pollenz, R.S., Davarinos, N.A., and Shearer, T.P. (1999) Analysis of aryl hydrocarbon receptor-mediated signaling during physiological hypoxia reveals lack of competition for the aryl hydrocarbon nuclear translocator transcription factor. Mol Pharmacol, 56, 11271137.

95 Allen, J.W., Johnson, R.S., and Bhatia, S.N. (2005) Hypoxic inhibition of 3methylcholanthrene-induced CYP1A1 expression is independent of HIF-1alpha. Toxicol Lett, 155, 151-159.

96 Zhang, N., and Walker, M.K. (2007) Crosstalk between the aryl hydrocarbon receptor and hypoxia on the constitutive expression of cytochrome P4501A1 mRNA. Cardiovasc Toxicol, 7, 282-290.

97 Tahara, E.B., Navarete, F.D., and Kowaltowski, A.J. (2009) Tissue-, substrate-, and sitespecific characteristics of mitochondrial reactive oxygen species generation. Free Radic Biol Med, 46, 1283-1297.

98 Hussain, S.P., Hofseth, L.J., and Harris, C.C. (2003) Radical causes of cancer. Nat Rev Cancer, 3, 276-285.

99 Klaunig, J.E., Wang, Z., Pu, X., and Zhou, S. (2011) Oxidative stress and oxidative damage in chemical carcinogenesis. Toxicol Appl Pharmacol, 254, 86-99.

100 Coussens, L.M., and Werb, Z. (2002) Inflammation and cancer. Nature, 420, 860-867.

101 Mantovani, A., Allavena, P., Sica, A., and Balkwill, F. (2008) Cancer-related inflammation. Nature, 454, 436-444.

102 Brenner, D.R., McLaughlin, J.R., and Hung, R.J. (2011) Previous lung diseases and lung cancer risk: a systematic review and meta-analysis. PLoS One, 6, e17479.

103 van Gestel, Y.R., Hoeks, S.E., Sin, D.D., Huzeir, V., Stam, H., Mertens, F.W., van Domburg, R.T., Bax, J.J., and Poldermans, D. (2009) COPD and cancer mortality: the influence of statins. Thorax, 64, 963-967.

104 Adcock, I.M., Caramori, G., and Barnes, P.J. (2011) Chronic obstructive pulmonary disease and lung cancer: new molecular insights. Respiration, 81, 265-284.

105 Ascha, M.S., Hanouneh, I.A., Lopez, R., Tamimi, T.A., Feldstein, A.F., and Zein, N.N. (2010) The incidence and risk factors of hepatocellular carcinoma in patients with nonalcoholic steatohepatitis. Hepatology, 51, 1972-1978.

106 Klaunig, J.E., and Kamendulis, L.M. (2004) The role of oxidative stress in carcinogenesis. Annu Rev Pharmacol Toxicol, 44, 239-267.

107 Knaapen, A.M., Gungor, N., Schins, R.P., Borm, P.J., and Van Schooten, F.J. (2006) Neutrophils and respiratory tract DNA damage and mutagenesis: a review. Mutagenesis, 21, 225-236.

108 Gungor, N., Godschalk, R.W., Pachen, D.M., Van Schooten, F.J., and Knaapen, A.M. (2007) Activated neutrophils inhibit nucleotide excision repair in human pulmonary epithelial cells: role of myeloperoxidase. Faseb J, 21, 2359-2367. 
109 Klebanoff, S.J. (2005) Myeloperoxidase: friend and foe. J Leukoc Biol, 77, 598-625.

110 Pattison, D.I., and Davies, M.J. (2001) Absolute rate constants for the reaction of hypochlorous acid with protein side chains and peptide bonds. Chem Res Toxicol, 14, 1453-1464.

111 Spencer, J.P., Whiteman, M., Jenner, A., and Halliwell, B. (2000) Nitrite-induced deamination and hypochlorite-induced oxidation of DNA in intact human respiratory tract epithelial cells. Free Radic Biol Med, 28, 1039-1050.

112 Langie, S.A., Kowalczyk, P., Tudek, B., Zabielski, R., Dziaman, T., Olinski, R., van Schooten, F.J., and Godschalk, R.W. (2010) The effect of oxidative stress on nucleotide-excision repair in colon tissue of newborn piglets. Mutat Res, 695, 75-80.

113 Chandel, N.S., and Budinger, G.R. (2007) The cellular basis for diverse responses to oxygen. Free Radic Biol Med, 42, 165-174. 



\section{Chapter 2}

\section{Diminished carcinogen detoxification is a novel mechanism for hypoxia inducible factor 1-mediated genetic instability}

J Biol Chem. 2010 May 7;285(19):14558-64

Marten A. Schults

Leen Timmermans

Roger W. Godschalk

Jan Theys

Bradly G. Wouters

Frederik J. van Schooten

Roland K. Chiu 


\begin{abstract}
The HIF1-pathway is induced in many tumors and associated with poorer outcome. The hypoxia responsive transcription factor HIF-1 $\alpha$ dimerizes with the aryl hydrocarbon receptor nuclear translocator, which is also an important binding partner for the aryl hydrocarbon receptor (AhR). The AhR is an important mediator in the metabolic activation and detoxification of carcinogens, such as the environmental pollutant benzo[a]pyrene (BaP). We hypothesized that HIF-1 $\alpha$ activation attenuates the BaP induced AhR mediated gene expression, which may lead to increased genetic instability and malignant progression. Human lung carcinoma cells (A549) were simultaneously stimulated with $\mathrm{CoCl}_{2}$ which leads to HIF-1 $\alpha$ stabilization and varying concentrations of BaP. Both quantitative PCR and immunoblotting analysis indicated that the induction of the hypoxic response pathway significantly reduced the levels of AhR downstream targets CYP1A1 and CYP1B1 and AhR protein binding to ARNT. We further demonstrated that the BaP-induced HPRT-mutation frequency and $\mathrm{YH} 2 \mathrm{AX}$ foci were markedly amplified when the HIF1-pathway was induced. BaP-DNA adducts were only marginally increased and transient strand breaks were diminished by HIF-1 induction, indicating changes in DNA repair. These data indicate that concurrent exposure of tumor cells to hypoxia and exogenous genotoxins can enhance genetic instability.
\end{abstract}




\section{Introduction}

Hypoxia is a characteristic of a number of pathologies including cancer (1), inflammation (2), and kidney disease (3). It promotes genetic instability, as exposure of cultured cells to hypoxia results in an elevated mutation frequency $(4,5)$. Several mechanisms have been proposed for this observation including downregulation of DNA repair (6) and induction of DNA damage by reactive oxygen species produced during reoxygenation (7). In many tumors, the hypoxia responsive transcription factor HIF-1 $\alpha$ (hypoxia inducible factor $1 \alpha$ ) is overexpressed (8) and is associated, together with its downstream targets with poorer outcome (9). We propose a novel alternative mechanism whereby overexpression of the HIF1-pathway alters the mutagenicity of exogenous carcinogens, which lead to a mutagenic phenotype.

HIF- $1 \alpha$ is regarded as the primary molecular switch to alter gene expression in response to reduced oxygen tension. Under normoxia, HIF-1 $\alpha$ is hydroxylated by an oxygen-dependent prolyl hydroxylase (HIF-PH). This modification targets it for ubiquitination and subsequent degradation (10). In contrast, under hypoxic conditions, HIF-1 $\alpha$ becomes stabilized and is translocated into the nucleus, where it forms HIF-1, a heterodimer with HIF-1 $\beta$ also known as aryl hydrocarbon receptor nuclear translocator (ARNT). ARNT is constitutively expressed irrespective of oxygen tension (11). Subsequently, HIF-1 binds to the (A/G)CGTG consensus sequence in the hypoxic responsive elements of the promoter/enhancer regions in the DNA (12), where it drives the expression of a wide array of hypoxia-inducible genes, including vascular endothelial growth factor (13), glucose transporter 1 (14) and carbonic anhydrase IX (CA-IX) (15). These genes are crucial in mediating the cellular responses to hypoxia.

Interestingly, in addition to HIF-1 $\alpha$, ARNT also forms a dimer with the aryl hydrocarbon receptor (AhR). AhR is a receptor for environmental pollutants such as dioxins (e.g 2,3,7,8-tetrachlorodibenzo-p-dioxin, TCDD) and polycyclic aromatic hydrocarbons (PAH; e.g benzo[a]pyrene, BaP). PAHs are widely distributed environmental contaminants produced as byproducts of combustion processes such as in coke ovens, cigarette smoking and charcoal grilling of food. On ligand binding, AhR translocates into the nucleus, dimerizes with ARNT, and activates gene expression by binding to the TNGCGTG consensus sequence in the xenobiotic response elements of target genes (16). This leads to the upregulation of a multitude of genes including the cytochrome P450 isoforms CYP1A1 and CYP1B1. These enzymes metabolize their PAH substrates to more soluble and excretable products, but at the same time may activate certain metabolites into highly reactive forms (17). BaP is a classic example, and is enzymatically activated to BaP-7,8-dihydrodiol-9,10-epoxide (BPDE) by cytochrome P450s. BPDE can covalently bind to DNA forming highly mutagenic DNA adducts (18).

Since HIF-1 $\beta / A R N T$ is a component of the AhR as well as the HIF1-signalling pathway, it has been suggested that simultaneous activation of the two pathways can result in competition for ARNT thereby reducing the activity of both the HIF-1 and AhR mediated response (19). This implies that in hypoxic regions, the availability of HIF$1 \beta /$ ARNT for the metabolism of carcinogens is attenuated. Cross-talk between both these two pathways has previously been demonstrated, but studies on the exposure of various hepatoma cell lines to hypoxia and AhR ligands (mostly TCDD) revealed 
inconsistent interactive results. While Chan et al and Nie et al demonstrated mutual inhibition between the HIF-1 and AhR-pathways $(20,21)$, Gradin et al, Gassmann et al, and Pollenz et al showed that HIF1-pathway activation inhibits the AhR-pathway, but not vice versa $(19,22,23)$. All these studies showed some level of crosstalk between the two pathways; however none demonstrated that the crosstalk had any biologic significance, as for instance increased genetic instability. The above mentioned studies used TCDD as an activator of AhR and although TCDD is the strongest activator of AhR, it is not metabolized by the CYPs induced by the AhR pathway. Importantly, in the present study, we used BaP as it induces downstream CYP expression that results in self-metabolism. Thus, we are studying an interaction that is physiological and relevant to carcinogenesis.

The aim of the present study was to determine the involvement of HIF-1 induction on detoxification of carcinogens. Firstly, we determined the level of HIF-1 and AhRpathway crosstalk by qPCR, immunoprecipitation and immunoblot. Secondly, to investigate the genetic instability, we used $\mathrm{yH} 2 \mathrm{AX}$-staining and a mutation sensitive cell line to assess the influence of HIF-1 induction on BaP-induced mutation frequencies (24). Finally, we measured BPDE-DNA adducts levels and transient strand breaks to further investigate the relationship between the crosstalk and the changed genetic instability.

\section{Materials and methods}

\section{Cell culture and treatment}

A549 cells (human epithelial lung carcinoma cells), obtained from the American Tissue Culture Collection (ATCC, Rockville, MD, USA), were cultured in DMEM (Sigma, St. Louis, MO, USA) supplemented with $10 \%$ heat inactivated fetal calf serum (FCS, Invitrogen, Breda, The Netherlands) and $1 \%$ penicillin/streptomycin (Sigma) and maintained at $37^{\circ} \mathrm{C}$ in a $5 \% \mathrm{CO}_{2}$ atmosphere. $1 \times 10^{6}$ cells were treated with or without the HIF1 $\alpha$ stabilizing agent cobalt chloride $\left(300 \mu \mathrm{M}\right.$; Sigma). After 1 hour at $37^{\circ} \mathrm{C}, \mathrm{BaP}$ (Sigma), in DMSO, was added to the medium to final concentrations of $0-10 \mu \mathrm{M}$. Concentrations of DMSO did not exceed $0.5 \%$. After a further 18 hours, the cells were harvested. For the determination of the effect on adduct formation and mutation frequency we used previously established A549 cell lines stably expressing ubiquitin Lys63 mutants (K63R-Ub) (24).

\section{Real-Time Quantitative PCR}

After 18 hours of incubation medium was removed. Cells were washed twice with PBS and Trizol (Invitrogen) was added. Total RNA was isolated according to the manufacturer's instructions. The quantity and quality of each RNA sample were measured spectrophotometrically using Nanodrop 1000 (Thermo Scientific, Waltham, MA, USA). cDNA synthesis was performed using the iScript cDNA Synthesis kit (Biorad, Veenendaal, The Netherlands) starting with $1 \mu \mathrm{g}$ of RNA. cDNA was diluted $25 \mathrm{x}$ in RNase free water. Real-time PCR was performed using the MyiQ Single Color RT-PCR detection system (Biorad) using SYBR Green Supermix (Biorad), $5 \mu l$ diluted cDNA and 
$0.3 \mu \mathrm{M}$ primers (Table 2.1) in a total volume of $25 \mu \mathrm{l}$. Samples were amplified under the following conditions: $95^{\circ} \mathrm{C}$ for 3 minutes, followed by 40 cycles of $95^{\circ} \mathrm{C}$ for 15 second and $60^{\circ} \mathrm{C}$ for 45 seconds. PCR was checked for a-specific products by performing a melting curve analysis $\left(65^{\circ} \mathrm{C}-95^{\circ} \mathrm{C}\right)$. Data were analyzed using the MyiQ Software system (Biorad) and were expressed as relative gene expression (fold increase) using the $2^{-\Delta \Delta C t}$ method. Two stably expressed genes, $\beta$-actin and GAPDH, were included as reference.

Table 2.1: Primer sequences for real time RT-PCR

\begin{tabular}{lll}
\hline Gene & Forward primer $\left(5^{\prime}-3^{\prime}\right)$ & Reverse primer $\left(5^{\prime}\right.$-3') \\
\hline -actin & CCTGGCACCCAGCACAAT & GCCGATCCACACGGAGTACT \\
GAPDH & GCACCACCAACTGCTTAGCA & TGGCAGTGATGGCATGGA \\
CA-IX & CATCCTAGCCCTGGTTTTTGG & GCTCACACCCCCTTTGGTT \\
CYP1A1 & TCCTGGAGACCTTCCGACACT & CTTTCAAACTTGTGTCTCTTGTTGTG \\
CYP1B1 & AGTGCAGGCAGAATTGGATCA & GCGCATGGCTTCATAAAGGA \\
\hline
\end{tabular}

Western blot assay

Following treatment with $\mathrm{CoCl}_{2}$ and $\mathrm{BaP}$, cells were washed twice and proteins were extracted in RIPA buffer $(150 \mathrm{mM} \mathrm{NaCl}, 1 \% \mathrm{NP}-40,0.5 \%$ Na-deoxycholate, $0.1 \%$ SDS, $50 \mathrm{mM}$ Tris $\mathrm{pH} 7.5$ ) for 30 minutes on ice. Samples were sonicated and protein concentrations were determined by a Lowry assay (Bio-Rad) with BSA as standard. Proteins were separated on a 10\% SDS-polyacrylamide gel (150V, 2 hours) and transferred (100V, 1 hour) to a nitrocellulose membrane (GE Healthcare, Little Chalfont, UK). Membranes were blocked for one hour with 5\% BSA and subsequently incubated overnight at $4^{\circ} \mathrm{C}$ with a 1:2000 dilution of mouse monoclonal CA-IX antibody (Novus Biologicals, Littleton, USA), a 1:1000 dilution of rabbit polyclonal Chk1 Phospho-Ser $^{317}$, (Cell Signaling, Danvers, MA, USA) or a 1:1000 dilution of mouse monoclonal Chk1 (Abcam, Cambridge, UK). After washing, blots were incubated for 1 hour with either a 1:5000 dilution of goat anti-rabbit HRP conjugated IgG (Cell Signaling) or goat anti-mouse HRP conjugated IgG (Santa Cruz Biotechnology, Santa Cruz, CA, USA). Proteins were visualized by an Enhanced Chemiluminescence (GE Healthcare). Mouse monoclonal $\beta$-actin (Sigma) was used as loading control.

\section{Immunoprecepitation}

After $\mathrm{CoCl}_{2}$ and $\mathrm{BaP}$ treatment as described above, cells were washed twice and proteins were extracted in lysisbuffer $(150 \mathrm{mM} \mathrm{NaCl}, 1 \% \mathrm{NP}-40,50 \mathrm{mM}$ Tris $\mathrm{pH} 7.5)$ for 30 minutes on ice. Samples were sonicated, soluble fractions were recovered and proteins were quantified using the Lowry protein assay, and $250 \mu \mathrm{g}$ protein was incubated with a 1:50 dilution of rabbit HIF1ß/ARNT (C15A11) antibody (Cell Signalling) overnight at $4^{\circ} \mathrm{C}$. The following day, lysates were incubated for 48 hours at $4^{\circ} \mathrm{C}$ with $100 \mu \mathrm{l}$ of Gamma-Bound Sepharose Beads (GE Healthcare). Beads were washed 5 times in lysis buffer, and proteins were eluted by boiling in Laemmli's SDS sample buffer for 5 minutes at $95^{\circ} \mathrm{C}$. Western blot was performed as described above using mouse HIF-1 $\alpha$ monoclonal antibody (1:1000; BD Biosciences, San Jose, CA) or mouse AhR monoclonal antibody 3B12 (1:500; Abnova, Heidelberg, Germany). 


\section{HPRT-mutation analysis}

Cells were cultured in hypoxanthine, aminopterin, and thymidine (HAT) supplemented culture medium for one week to eliminate background mutations. Cells were then seeded at $1 \times 10^{6}$ cells per $10 \mathrm{~cm}$ dish and exposed to $\mathrm{CoCl}_{2}$ and $\mathrm{BaP}$ as described previously. Subsequently, cells were passaged for one week to allow for phenotypic expression of the acquired mutations. HPRT mutant cells were selected in medium supplemented with 30 $\mu \mathrm{M}$ 6-thioguanine (6-TG). After 14-21 days, cells were fixed and stained with $2 \%$ bromophenol blue in $70 \%$ ethanol. After staining, the colonies were counted and corrected for plating efficiency.

\section{$\mathrm{\gamma H} 2 \mathrm{AX}$-staining}

Cells were seeded on glass cover slides before treatment with $\mathrm{CoCl}_{2}$ and $\mathrm{BaP}$. After treatment, cells were fixated with $4 \%$ formaldehyde at RT for 10 minutes, washed in PBS and permeabilized with $0.2 \%$ Triton $X-100$ for 5 minutes at $4^{\circ} \mathrm{C}$, washed twice for 5 minutes with PBS and blocked in PBS with 1\% BSA and 0.5\% Tween-20 for 1 hour at $37^{\circ} \mathrm{C}$. The coverslips were incubated with a $1: 1000$ dilution of anti- $\gamma-\mathrm{H} 2 \mathrm{AX}$ antibody Clone JBW 301 (Upstate, Billerica, MA) for 2 hours at $37^{\circ} \mathrm{C}$, washed twice in PBS for 5 minutes, and incubated with a 1:1000 dilution Alexa Fluor 488 goat anti-mouse (Invitrogen) for 1 hour at $37^{\circ} \mathrm{C}$. Cells were washed twice in PBS for 5 minutes and dehydrated in 70, 90 and 100\% ethanol, 3 minutes each. Cells were stained with 4,6diamidino-2-phenylindole and mounted with Vectashield mounting medium (Vector Laboratories, Peterborough, UK). Digital fluorescence images were taken and damage was assessed. Positive cells were defined as greater than 3 foci per cell.

\section{${ }^{32}$ P-postlabeling of BPDE-DNA adducts}

After removal of the aqueous phase during RNA isolation using Trizol, the remaining phases were used for DNA isolation according to the manufacturer's protocol. DNA adduct levels were determined according to the nuclease P1 enrichment technique originally described by Reddy and Randerath (25) with the modifications described by Godschalk et al (26). In all experiments, three BPDE-DNA standards with known BPDEDNA adduct levels (one adduct per $10^{6}, 10^{7}$, and $10^{8}$ normal nucleotides) were analyzed in parallel for quantification purposes. Adduct spots on the chromatograms were quantified using Phosphor-Imaging technology (Fujifilm FLA-3000, Rotterdam, The Netherlands).

\section{Comet assay}

Following $\mathrm{CoCl}_{2}$ and $\mathrm{BaP}$ treatment, cell suspensions were diluted 1:4 in 0.5\% low melting point agarose and added to microscope slides pre-coated with a layer of $1.5 \%$ normal melting-point agarose and put at $4^{\circ} \mathrm{C}$ for 45 minutes. Cells were lysed $(0.25 \mathrm{M}$ $\mathrm{NaOH}, 0.1 \mathrm{M}$ EDTA, $0.01 \mathrm{M}$ Tris, $2.5 \mathrm{M} \mathrm{NaCl}, 1 \%$ Triton X-100 and 10\% DMSO, adjusted to $\mathrm{pH} 10)$ for 1 hour at $4{ }^{\circ} \mathrm{C}$, washed with PBS, placed in electrophoresis buffer ( $1 \mathrm{mM}$ EDTA, 300mM NaOH, $\mathrm{pH}$ 13) for 40 minutes for denaturation, and subsequently separated by electrophoresis for 30 minutes at $25 \mathrm{~V}$ and $300 \mathrm{~mA}$. The slides were 
washed twice with PBS for 10 minutes and stained with ethidium bromide $(10 \mu \mathrm{g} / \mathrm{ml})$ and visualized using a Zeiss Axioskop fluorescence microscope. 50 randomly selected nuclei were analyzed per slide using the Comet assay III software program (Perceptive Instruments, Havervill, UK).

\section{Statistical Analysis}

Results are expressed as the mean \pm standard error of the mean, and experiments were repeated up to five times. GraphPad Prism 4 was used for statistical analysis. To examine differences between cells incubated with or without $\mathrm{CoCl}_{2}$ a two-way analysis of variance test (ANOVA) with Bonferroni post-hoc multiple comparison correction was used. To assess differences between different BaP concentrations a one-way ANOVA was used. Differences were considered to be statistically significant when $p<0.05$.

\section{Results}

$\mathrm{BaP}$ down regulates in a dose-dependent manner the $\mathrm{CoCl}_{2}$-mediated induction of $\mathrm{CA}$ IX.

The effect of BaP on the HIF1-pathway was tested by determining changes in mRNA and protein levels of CA-IX. A549 cells were exposed to $300 \mu \mathrm{M} \mathrm{CoCl}$, to stabilize HIF$1 \alpha$, and to various concentrations of $\mathrm{BaP}$ (Figure 2.1). After exposure to $\mathrm{CoCl}_{2}, \mathrm{a} \approx 17$ fold increase in CA-IX mRNA levels was observed compared to cells without $\mathrm{CoCl}_{2}$. After addition of $\mathrm{BaP}$, a dose dependent decrease was detected that reached $36 \%$ at $10 \mu \mathrm{M} \mathrm{BaP}(\mathrm{p}<0.05)$. In addition, CA-IX was also statistically significantly down regulated when incubated only with $\mathrm{BaP}(\mathrm{p}<0.05)$.

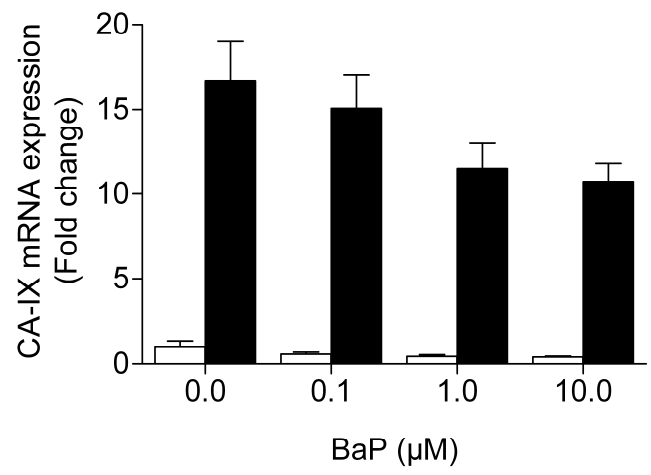

Figure 2.1: BaP attenuates the induction of the HIF-1 target CA-IX. A549 cells were incubated without ( $\square$ ) or with (घ) $300 \mu \mathrm{M}$ $\mathrm{CoCl}_{2}$ and with $0-10 \mu \mathrm{M}$ BaP. Data are presented as fold increase compared to no $\mathrm{CoCl}_{2}$ and no BaP.

The same conditions were used to test the effect of BaP on the protein levels of CA-IX. $A \approx 31$ fold increase in CA-IX protein levels was observed when cells were exposed to $\mathrm{CoCl}_{2}$ compared to cells without $\mathrm{CoCl}_{2}$ exposure (Figure 2.2). This increase was in agreement with the mRNA levels and was dose-dependently down regulated by addition of BaP. A $53 \%$ reduction was already observed after incubation with $1 \mu \mathrm{M} \mathrm{BaP}$ $(p<0.05)$. After treatment with $10 \mu \mathrm{M} \mathrm{BaP}$, reduction in CA-IX protein levels was further increased to $\approx 66 \%(p<0.05)$. In contrast to the mRNA analysis, the influence of $\mathrm{BaP}$ alone on the CA-IX protein levels was absent. 
Figure 2.2: BaP downregulates in a dosedependent manner the $\mathrm{CoCl}_{2}$-mediated induction of CA-IX. A549 cells were incubated without ( $\square$ ) or with (घ) $300 \mu \mathrm{M}$ $\mathrm{CoCl}_{2}$ and with $0-10 \mu \mathrm{M}$ BaP. Data are presented as fold increase compared to no $\mathrm{CoCl}_{2}$ and no BaP corrected for actin. The figure presented is a representative western blot. $\left({ }^{*} p<0.05\right)$.
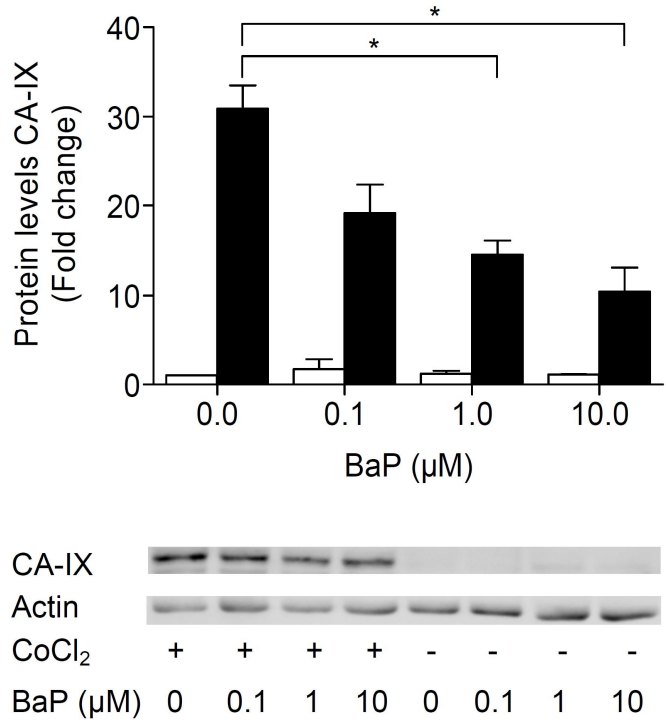

HIF-1 induction reduces BaP induced CYP1A1 and CYP1B1 mRNA expression.

To determine the influence of the induction of the HIF1-pathway on the AhR-pathway, the mRNA levels of CYP1A1 and CYP1B1 was investigated in $\mathrm{CoCl}_{2}$ treated cells. BaP, as expected, caused a dose-dependent increase in both CYP1A1 (Figure 2.3A) and CYP1B1 (Figure 2.3B) mRNA levels. This dose-dependent increase in CYP1A1 mRNA levels was down regulated by incubation with $\mathrm{CoCl}_{2}$. Without $\mathrm{CoCl}_{2}$, cells showed $\mathrm{a} \approx 24$ to $\approx 30$ fold increase when incubated with $1 \mu \mathrm{M}$ and $10 \mu \mathrm{M}$ BaP, respectively, but by simultaneous incubation with $\mathrm{CoCl}_{2}$, this induction of mRNA levels was approximately $60 \%$ lower. CYP1B1 mRNA levels showed the same pattern, although the increase by $\mathrm{BaP}$ was less pronounced; cells incubated with $\mathrm{BaP}$ alone showed $\mathrm{a} \approx 8$ and $\approx 9$ fold increase when incubated with $1 \mu \mathrm{M}$ or $10 \mu \mathrm{M}$ BaP, respectively. When simultaneously
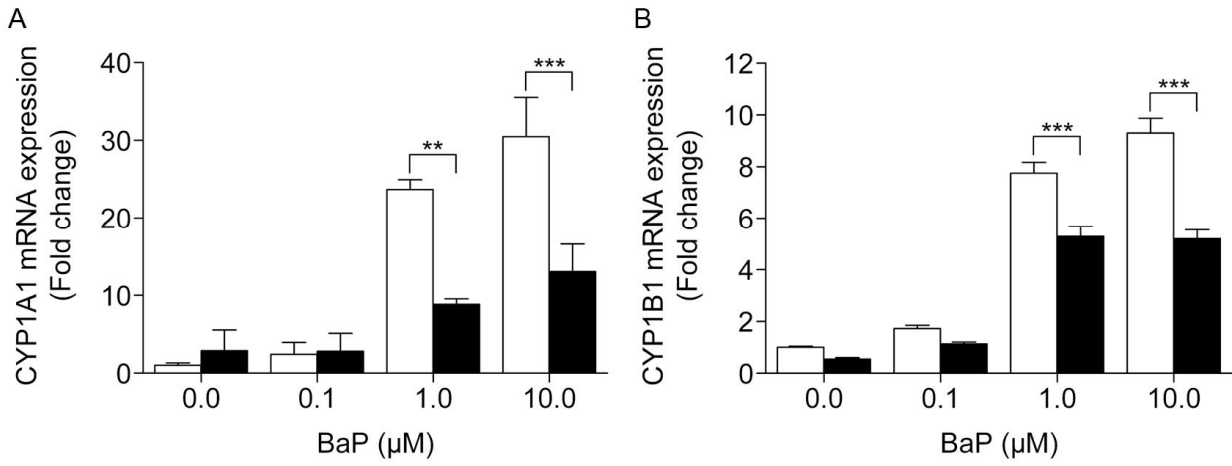

Figure 2.3: BaP induced CYP1A1 and CYP1B1 mRNA expression are reduced by HIF-1 induction. A549 cells were incubated without ( $\square$ ) or with ( $\left(-300 \mu \mathrm{M} \mathrm{CoCl}_{2}\right.$ and with $0-10 \mu \mathrm{M} \mathrm{BaP}$ and $\mathrm{mRNA}$ expression of (A) CYP1A1 and (B) CYP1B1 was measured. Data are presented as fold increase compared to no $\mathrm{CoCl}_{2}$ and no BaP. (**p<0.01, $\left.{ }^{* * *} \mathrm{p}<0.001\right)$ 


$\begin{array}{lcccccc}\mathrm{CoCl}_{2} & - & - & - & + & + & + \\ \mathrm{BaP}(\mu \mathrm{M}) & 0 & 0.1 & 1 & 0 & 0.1 & 1 \\ \mathrm{HIF-1 \alpha} & & & & & & \\ \begin{array}{l}\text { Fold } \\ \text { change }\end{array} & 1 & 1.2 & 1.3 & 6.6 & 5.0 & 3.5 \\ \begin{array}{l}\text { AhR } \\ \begin{array}{l}\text { Fold } \\ \text { change }\end{array}\end{array} & 1 & 1.3 & 0.7 & 0.6 & 0.3 & 0.4\end{array}$

Figure 2.4: Competition for ARNT results in a reduction in HIF-1 $\alpha$ and AhR protein bound to ARNT. A549 cells were incubated without or with $300 \mu \mathrm{M} \mathrm{CoCl}{ }_{2}$ and with $0-1 \mu \mathrm{M} \mathrm{BaP}$. The representative Western blots show the amount of HIF-1 $\alpha$ and AhR bound to ARNT. Data are presented as fold increase compared to no $\mathrm{CoCl}_{2}$ and no $\mathrm{BaP}$ corrected for amount of protein loaded.

incubated with $\mathrm{CoCl}_{2}$ this induction only reached $68 \%$ and $56 \%$ of the levels found without $\mathrm{CoCl}_{2}$ incubation, respectively.

Competition for ARNT results in a reduction in HIF-1 $\alpha$ and AhR protein bound to ARNT.

To directly assess the influence of pathway convergence on protein complex interaction, HIF- $1 \alpha$ and AhR bound ARNT was determined by immunoprecipitation. HIF- $1 \alpha$ bound to ARNT increased $\approx 7$-fold after exposure to $\mathrm{CoCl}_{2}$ (Figure 2.4). After addition of $\mathrm{BaP}$, a dose dependent decrease was detected in the $\mathrm{CoCl}_{2}$ treated cells of $\approx 24 \%$ and $\approx 48 \%$, at $0.1 \mu \mathrm{M}$ and $1 \mu \mathrm{M} \mathrm{BaP}$, respectively. AhR bound to ARNT was $40-75 \%$ lower when the HIF1-pathway was induced compared to the cells without the addition of $\mathrm{CoCl}_{2}$ (Figure 2.4).

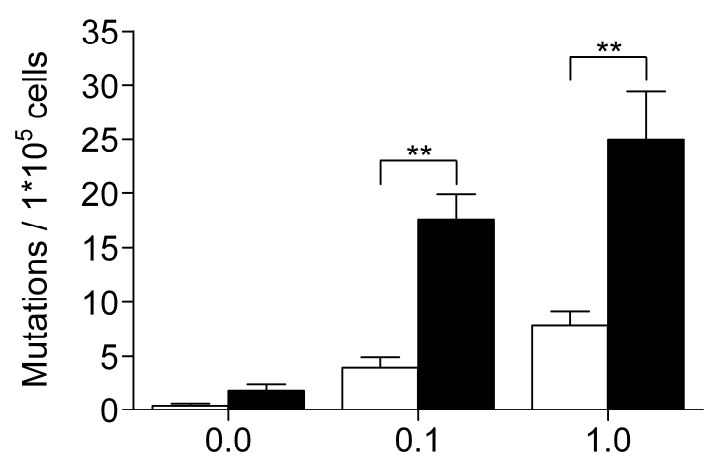

$\operatorname{BaP}(\mu \mathrm{M})$
Figure 2.5: HIF-1 induction increases BaP induced mutation frequency. A549 cells expressing the ubiquitin K63R mutant were incubated without (口) or with (घ) $300 \mu \mathrm{MCoCl}_{2}$ and with $0-1 \mu \mathrm{M}$ BaP. Data are presented as mutations per $10^{5}$ cells. $\left({ }^{* *} p<0.01\right)$

HIF-1 induction increases BaP induced mutation frequency.

To further determine whether this HIF1 mediated attenuation of the AhR-pathway results in changes to the mutagenic phenotype. A549 cells stably expressing K63R-Ub were exposed to $\mathrm{CoCl}_{2}$ and various concentrations of BaP and mutations in the HPRT gene were assessed. This cell line has a diminished capacity to perform error-free bypass of DNA lesions, greatly enhancing the carcinogen associated mutagenicity of $\mathrm{BaP}$ without changing its metabolic activation (27). Cells incubated with $\mathrm{CoCl}_{2}$ alone already showed a slight although not yet significant increase in mutation frequency compared to the control cells $(\approx 6$ fold) (Figure 2.5$)$. In addition, the mutation 
frequency was significantly induced with $\approx 10$ and $\approx 21$ times when cells were incubated with $0.1 \mu \mathrm{M}$ and $1 \mu \mathrm{M} \mathrm{BaP}$, respectively, without $\mathrm{CoCl}_{2}$. Interestingly, after the combined incubation with $\mathrm{CoCl}_{2}$ and 0.1 and $1 \mu \mathrm{M} \mathrm{BaP}$, mutation frequencies were further increased to $\approx 46$ and $\approx 66$ times, respectively as compared to unexposed cells.

HIF-1 induction increases the BaP induced $\mathrm{yH} 2 \mathrm{AX}$ foci.

To further confirm the increased genomic instability we assessed $\gamma \mathrm{H} 2 \mathrm{AX}$ foci formation following treatment with $\mathrm{CoCl}_{2}$ and $\mathrm{BaP}$. Addition of $\mathrm{BaP}$ increased the amount of damaged cells to $\approx 46 \%$ (from $\approx 24 \%$ in untreated and $\mathrm{CoCl}_{2}$ alone treated cells) (Table 2.2). With the addition of $\mathrm{CoCl}_{2}$ to the BaP treated cells, the number of damaged cells further increased to $\approx 59 \%$ and $\approx 53 \%$, at $0.1 \mu \mathrm{M}$ and $1 \mu \mathrm{M}$ BaP respectively.

Table 2.2: HIF-1 induction increases the BaP induced $\mathrm{pH} 2 \mathrm{AX}$ foci. A549 cells were incubated without or with $300 \mu \mathrm{M} \mathrm{CoCl} 2$ and with $0-1 \mu \mathrm{M} \mathrm{BaP}$. Data is presented as percentage cells with more than 3 foci per cells. Exposure to BaP significantly increased the number of cells with $>3$

\begin{tabular}{|c|c|c|c|}
\hline $\mathrm{BaP}(\mu \mathrm{M})$ & $-\mathrm{CoCl}_{2}$ & $+\mathrm{CoCl}_{2}$ & $\gamma \mathrm{H} 2 \mathrm{AX}$ foci $(p<0.001$, exposed to $\mathrm{BaP}$ vs. \\
\hline 0 & $24.0 \pm 8.1$ & $24.7 \pm 6.9$ & eased by \\
\hline 0.1 & $46.5 \pm 5.1$ & $58.7 \pm 3.1$ & no $\mathrm{CoCl}_{2}$ in the combined group of 0.1 and $1 \mu \mathrm{M}$ \\
\hline 1 & $46.4 \pm 3.9$ & $52.5 \pm 5.4$ & $\mathrm{BaP})$. \\
\hline
\end{tabular}

HIF-1 induction increases Chk1 phosphorylation.

To determine if the observed increase in $\mathrm{YH} 2 \mathrm{AX}$ foci was associated with replication fork blockage, Chk1 phosphorylation was measured by immunoblotting. Interestingly, $\mathrm{CoCl}_{2}$ alone was sufficient to induce a 1.6 fold increase in phosphorylation of Chk1 (Figure 2.6) while BaP alone induced $a \approx 1.5$ fold increase compared to no treatment. This $\mathrm{BaP}$ effect was further augmented with the addition of $\mathrm{CoCl}_{2}$ to a combined maximum effect of 2.4 fold increase at $0.1 \mu \mathrm{M} \mathrm{BaP}$.

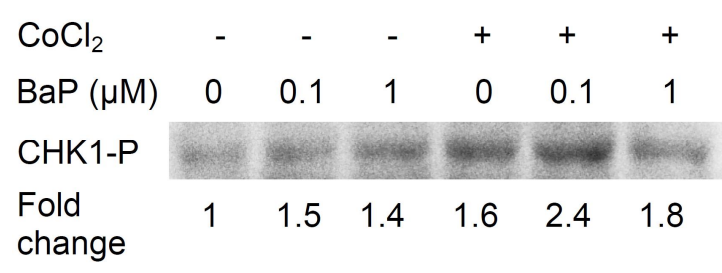

and no BaP corrected for total amount of CHK1.
Figure 2.6: HIF-1 induction increases Chk1 phosphorylation. A549 cells were incubated without or with $300 \mu \mathrm{M} \mathrm{CoCl}{ }_{2}$ and with $0-1 \mu \mathrm{M}$ BaP. The representative Western blots show the amount of phosphorylated CHK1 at Ser317. Data are presented as fold increase compared to no $\mathrm{CoCl}_{2}$

\section{HIF-1 induction may alter BaP induced adduct formation.}

Since the expression of metabolic enzymes for BaP were altered by HIF induction, one possible explanation for the increased mutant frequency by the combined exposure to $\mathrm{BaP}$ and $\mathrm{CoCl}_{2}$ would be an increased formation of reactive derivatives and subsequent formation of pro-mutagenic BPDE-DNA adducts. Therefore, BPDE-DNA adducts were measured in cells incubated with both $\mathrm{CoCl}_{2}$ and $0.1 \mu \mathrm{M}$ or $1 \mu \mathrm{M}$ BaP. DNA adducts 
showed a trend to be higher (20-50\%) under HIF-1 induction as compared to BaP alone (Figure 2.7).

HIF-1 induction decreases the DNA repair associated strand breaks.

One known mechanism that could further explain the increased mutagenicity of combined $\mathrm{BaP}$ and $\mathrm{CoCl}_{2}$ would be inhibition of DNA repair processes. DNA repair induces transient strand breaks that can be detected by the comet assay. Indeed, as expected the amount of strand breaks was dose dependently increased by addition of $\mathrm{BaP}$ and importantly, induction of the HIF1-pathway reduced the comet size by $12-25 \%$ (Figure 2.8).

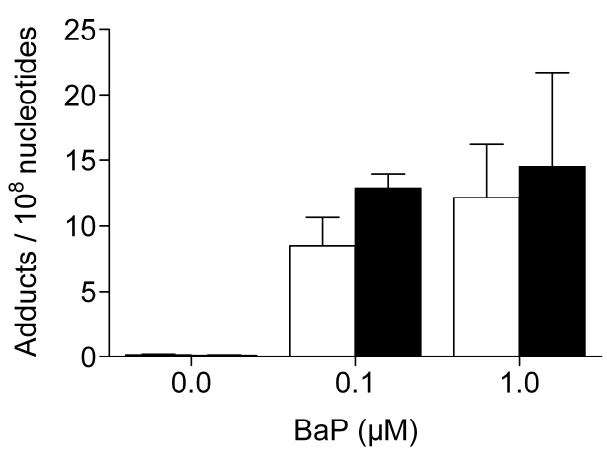

Figure 2.7: HIF-1 induction marginally augments BaP induced adduct formation. A549-K63R cells were incubated without ( $\square$ ) or with (-) $300 \mu \mathrm{M} \mathrm{CoCl}$ and with $0-1 \mu \mathrm{M}$ BaP. Data are presented adducts per $10^{8}$ nucleotides.

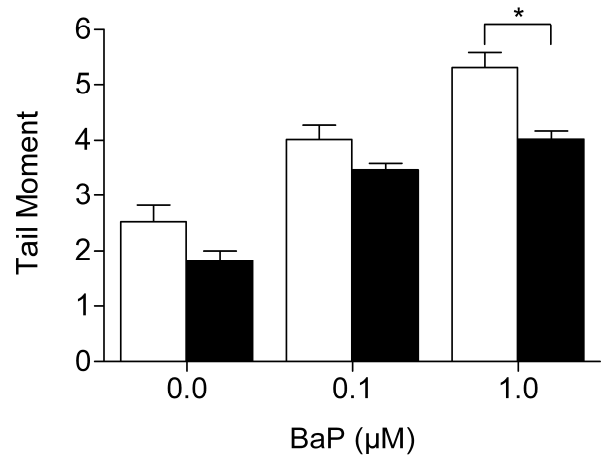

Figure 2.8: HIF-1 induction decreases the amount of strand breaks. A549 cells were incubated without ( $\square$ ) or with (घ) $300 \mu \mathrm{M}$ $\mathrm{CoCl}_{2}$ and with $0-1 \mu \mathrm{M} \mathrm{BaP}$ and strand breaks were measured. Data are presented as tail moment. $\left({ }^{*} p<0.05\right)$

\section{Discussion}

Hypoxia has been reported in several studies to increase mutation frequencies $(4,5)$. Understanding the cause for this mutation induction is important in determining the role of hypoxia in genetic instability. We propose a novel mechanism in which the interaction between induction of the HIF1-pathway and the AhR receptor leads to an increase in chemical induced mutations, which is of major relevance for the pre-clinical stages of carcinogenesis; humans are continuously exposed to carcinogens and hypoxia may already occur in the early phases of disease development. In this report we provide evidence that the combined stimulation of the AhR by BaP and the HIF1pathway leads to an increase in HPRT mutations and thus disrupts genetic stability.

To determine whether AhR stimulation could result in an alteration of HIF1-mediated signaling cells were simultaneously incubated with BaP to induce the AhR-pathway and with $\mathrm{CoCl}_{2}$ to induce the HIF1-pathway. Cells under hypoxic conditions have to undergo metabolic adaptations to survive and the expression of many genes changes as a result. We used CA-IX as an exemplary downstream gene to test the influence of $\mathrm{BaP}$ on the HIF1-pathway, because CA-IX is strongly up regulated by hypoxia (15) and it is a 
prognostic factor for many cancers (28). Our results showed that BaP exposure inhibited both the basal levels as the induction of CA-IX by $\mathrm{CoCl}_{2}$ (Figure 2.1). Although the mechanisms responsible for expression of basal levels of CA-IX regulation have not been studied, this could suggest that CA-IX is partly induced by HIF1 independent mechanisms. A recently published study of Takacova et al. (29) showed that next to mRNA levels, the protein levels decreased similarly after exposure to TCDD. To confirm that this effect also occurs with $\mathrm{BaP}$, we measured the CA-IX protein levels and indeed, a combined exposure to $\mathrm{CoCl}_{2}$ and $\mathrm{BaP}$ leads to a statistically significant dosedependent decrease in protein concentrations. This dose-dependent decrease in protein levels was even stronger compared to the mRNA levels (Figure 2.2). In contrast with the mRNA results, BaP alone did not reduce CA-IX protein levels. These results confirm the hypothesis that induction of the AhR pathway leads to downstream effects in the HIF1-pathway.

To determine whether HIF1-induction may influence the metabolism of $\mathrm{BaP}$, we studied the effect of HIF1 activation on CYP1A1 and CYP1B1 gene expression induced by BaP. Consistent with previous reports, we found a decrease in BaP-induced CYP1A1 mRNA levels (Figure 2.3A) due to $\mathrm{CoCl}_{2}(20,30)$. This $\mathrm{CoCl}_{2}$ reduced AhR-mediated induction was also observed for CYP1B1 expression, although to a lesser extent (Fig. $3 \mathrm{~B})$, which was also observed in a previous study (30). We also confirm that CYP1B1 levels were already reduced by $\mathrm{CoCl}_{2}$ even without the addition of $\mathrm{BaP}$, while CYP1A1 was only reduced when simultaneously incubated with $\mathrm{BaP}(20,30)$. This could be explained by the lower baseline expression of CYP1A1 than CYP1B1. However, the effect of $\mathrm{CoCl}_{2}$ on CYP1A1 expression was stronger compared to its effect on CYP1B1, which is biologically relevant because CYP1A1 has a greater capacity for BaP metabolism than CYP1B1 (31). These results indicate that induction of the HIF1pathway leads to downstream effects in the AhR-pathway.

To investigate if this mutual interaction is a result of the competition for ARNT, we determined the amount of HIF- $1 \alpha$ and AhR protein bound to ARNT and whether this is influenced by costimulation with $\mathrm{CoCl}_{2}$ and $\mathrm{BaP}$. The present results showed that ARNT bound HIF-1 $\alpha$ decreases in a dose dependent manner with increasing $\mathrm{BaP}$ concentrations (Figure 2.4). Furthermore, AhR bound to ARNT was also reduced upon HIF1 induction. This confirms our mRNA transcription results suggesting that fewer complexes are available to bind to xenobiotic and hypoxic response elements on the DNA, which leads to decreased mRNA and protein levels of CYP1A1, CYP1B1 and CA-IX. Our data is in agreement with Chan et al and Nie et al, who both observed that AhR inhibited HIF1 $\alpha$-ARNT interaction with the DNA and that HIF-1 $\alpha$ lowers the amount of AhR-ARNT complexes bound to the DNA $(20,21)$. Taken together, our results demonstrate a mutual interaction between the AhR-pathway and the HIF1-pathway.

We further investigated whether this interaction leads to an increase in HPRT mutation frequency by using a previously developed highly sensitive A549 mutant cell line (24). We earlier described that the mutants and A549 cells behave in an identical manner with regards to cell growth, clonogenic survival, and BPDE-DNA adduct formation $(18,24)$. The present results showed that the amount of BaP-induced mutant cells was significantly higher when the HIF1-pathway was accordingly induced. A more than additive effect is observed since the amount of mutations caused by both $\mathrm{CoCl}_{2}$ and 
$\mathrm{BaP}$ is more than the sum of $\mathrm{CoCl}_{2}$ and $\mathrm{BaP}$ alone. These results imply that when both pathways are triggered at the same time the mutagenic effects of chemical carcinogens may be potentiated resulting in enhanced genetic instability. Additionally the well-established DNA damage marker $\mathrm{\gamma H} 2 \mathrm{AX}$ was used to further investigate genetic instability (Table 2.2). HIF1 induction itself does not induce more damaged cells. Treatment with BaP on the other hand enhances the amount of damaged cells, which was further increased by the concomitant induction of the HIF1-pathway. As this induction of $\mathrm{\gamma H} 2 \mathrm{AX}$ staining may be associated with replication fork blockage (32), we examined Chk1 phosphorylation. Upon stalling of the replication machinery, ataxia telangiectasia and Rad3 related protein (ATR) is recruited to these sites where it phosphorylates Chk1 at Ser317 and Ser345 (33). We determined that the BaP induced phosphorylation of Chk1 was further increased by HIF1 induction (Figure 2.6). Taken together, these experiments additionally confirmed the hypothesis that inducing both pathways leads to a greater genomic instability.

Since we observed an effect of HIF1 induction on the expression of BaP metabolizing enzymes, the increased mutation frequency may be explained by an accumulation of pro-mutagenic DNA adducts (Figure 2.7). Interestingly, there was only a small rise in adduct levels due to incubation with $\mathrm{CoCl}_{2}$. As the bulk of adducts are removed by the NER pathway, this may mask the significance of remaining lesions entering S-phase. This is further supported by the observed increase in $\mathrm{YH} 2 \mathrm{AX}$ foci and increased phosphorylation of Chk1, suggesting adduct associated blockages of replication forks. Alternatively, other mechanisms related to BaP mutagenicity may be involved. For example, it has been reported that the most relevant repair mechanism for BPDE-DNA adducts, nucleotide excision repair (NER) is inhibited by hypoxia (34). Therefore, although the initial adduct levels do not differ substantially it may be that under HIF1 induction crucial DNA lesions may be less well removed, leading to higher mutation rates upon proliferation. Still, the relation between BaP adducts and mutagenesis is complex and multiple factors both structural and biological, are able to influence the mutagenicity of BaP-related DNA adducts (35).

To further elucidate the mechanism behind the increased mutation frequency, we quantitated DNA strand breaks using the comet assay. BaP does not induce strand breaks directly, because damage is induced after metabolism to BPDE and the formation of adducts. During the repair of these adducts, transient single strand breaks are generated (36). Our data showed that the amount of strand breaks is lower when the HIF1-pathway is induced compared to control conditions. It is interesting to note that even without treatment with $\mathrm{BaP}$, the number of breaks is lower under conditions where HIF1 is induced compared to normal conditions. The data are highly suggestive that the decrease we observe in breaks due to the induction of HIF1 is not explained by a decrease in DNA damage but is rather a decrease in repair incisions. This indicates and confirms that hypoxia reduces NER capacity (34), which is relevant for removal of bulky polymerase blocking lesions.

We showed that alteration of the HIF1-pathway by $\mathrm{CoCl}_{2}$ results in a mutagenic phenotype. It is interesting to note that a secondary mode of HIF induction has been attributed to either oncogene activation $(37,38)$ or by loss of function mutations in tumor suppressor genes $(39,40)$. This may suggests an important role in malignant 
progression as oncogenes or tumor suppressor genes alteration may lead to subsequent genetic instability via HIF1 modulation of carcinogen detoxification.

Interestingly, our results suggest an overall detrimental effect on survival and one may question the evolutionary benefits of this complex pathway interaction. This further underscores the poorly understood physiological role of AhR as even its natural ligand is still unknown. In this study, we demonstrate that there is a two-way interaction between the HIF1-pathway and the AhR-pathway. We provide evidence that $\mathrm{CoCl}_{2}$ results in an increase of $\mathrm{BaP}$ induced mutation frequency. These data support the idea that modulation of carcinogen metabolism may be an important mechanism for the observed HIF1 mediated genetic instability suggesting a potential role in cancer development. 


\section{Reference list}

1 Harris, A.L. (2002) Hypoxia--a key regulatory factor in tumour growth. Nat Rev Cancer, 2, 38-47.

2 Taylor, C.T. (2008) Interdependent roles for hypoxia inducible factor and nuclear factorkappaB in hypoxic inflammation. J Physiol, 586, 4055-4059.

3 Nangaku, M., and Eckardt, K.U. (2007) Hypoxia and the HIF system in kidney disease. J Mol Med, 85, 1325-1330.

4 Reynolds, T.Y., Rockwell, S., and Glazer, P.M. (1996) Genetic instability induced by the tumor microenvironment. Cancer Res, 56, 5754-5757.

5 Papp-Szabo, E., Josephy, P.D., and Coomber, B.L. (2005) Microenvironmental influences on mutagenesis in mammary epithelial cells. Int J Cancer, 116, 679-685.

6 Chan, N., Koritzinsky, M., Zhao, H., Bindra, R., Glazer, P.M., Powell, S., Belmaaza, A., Wouters, B., and Bristow, R.G. (2008) Chronic hypoxia decreases synthesis of homologous recombination proteins to offset chemoresistance and radioresistance. Cancer Res, 68, 605-614.

7 Hammond, E.M., Denko, N.C., Dorie, M.J., Abraham, R.T., and Giaccia, A.J. (2002) Hypoxia links ATR and p53 through replication arrest. Mol Cell Biol, 22, 1834-1843.

8 Zhong, H., De Marzo, A.M., Laughner, E., Lim, M., Hilton, D.A., Zagzag, D., Buechler, P., Isaacs, W.B., Semenza, G.L., and Simons, J.W. (1999) Overexpression of hypoxia-inducible factor 1alpha in common human cancers and their metastases. Cancer Res, 59, 5830-5835.

9 Vaupel, P., and Mayer, A. (2007) Hypoxia in cancer: significance and impact on clinical outcome. Cancer Metastasis Rev, 26, 225-239.

10 Maxwell, P.H., Wiesener, M.S., Chang, G.W., Clifford, S.C., Vaux, E.C., Cockman, M.E., Wykoff, C.C., Pugh, C.W., Maher, E.R., and Ratcliffe, P.J. (1999) The tumour suppressor protein VHL targets hypoxia-inducible factors for oxygen-dependent proteolysis. Nature, 399, 271-275.

11 Kallio, P.J., Pongratz, I., Gradin, K., McGuire, J., and Poellinger, L. (1997) Activation of hypoxia-inducible factor 1alpha: posttranscriptional regulation and conformational change by recruitment of the Arnt transcription factor. Proc Natl Acad Sci U S A, 94, 5667-5672.

12 Semenza, G.L., Jiang, B.H., Leung, S.W., Passantino, R., Concordet, J.P., Maire, P., and Giallongo, A. (1996) Hypoxia response elements in the aldolase A, enolase 1, and lactate dehydrogenase $A$ gene promoters contain essential binding sites for hypoxia-inducible factor 1. J Biol Chem, 271, 32529-32537.

13 Goldberg, M.A., and Schneider, T.J. (1994) Similarities between the oxygen-sensing mechanisms regulating the expression of vascular endothelial growth factor and erythropoietin. J Biol Chem, 269, 4355-4359.

14 Wood, S.M., Wiesener, M.S., Yeates, K.M., Okada, N., Pugh, C.W., Maxwell, P.H., and Ratcliffe, P.J. (1998) Selection and analysis of a mutant cell line defective in the hypoxiainducible factor-1 alpha-subunit (HIF-1alpha). Characterization of hif-1alpha-dependent and -independent hypoxia-inducible gene expression. J Biol Chem, 273, 8360-8368.

15 Wykoff, C.C., Beasley, N.J., Watson, P.H., Turner, K.J., Pastorek, J., Sibtain, A., Wilson, G.D., Turley, H., Talks, K.L., Maxwell, P.H., Pugh, C.W., Ratcliffe, P.J., and Harris, A.L. (2000) Hypoxia-inducible expression of tumor-associated carbonic anhydrases. Cancer Res, 60, 7075-7083.

16 Reyes, H., Reisz-Porszasz, S., and Hankinson, O. (1992) Identification of the Ah receptor nuclear translocator protein (Arnt) as a component of the DNA binding form of the Ah receptor. Science, 256, 1193-1195.

17 Shimada, T., Sugie, A., Shindo, M., Nakajima, T., Azuma, E., Hashimoto, M., and Inoue, K. (2003) Tissue-specific induction of cytochromes P450 1A1 and 1B1 by polycyclic aromatic 
hydrocarbons and polychlorinated biphenyls in engineered C57BL/6J mice of arylhydrocarbon receptor gene. Toxicol Appl Pharmacol, 187, 1-10.

18 Langie, S.A., Knaapen, A.M., Ramaekers, C.H., Theys, J., Brun, J., Godschalk, R.W., van Schooten, F.J., Lambin, P., Gray, D.A., Wouters, B.G., and Chiu, R.K. (2007) Formation of lysine 63-linked poly-ubiquitin chains protects human lung cells against benzo[a]pyrenediol-epoxide-induced mutagenicity. DNA Repair (Amst), 6, 852-862.

19 Gradin, K., McGuire, J., Wenger, R.H., Kvietikova, I., fhitelaw, M.L., Toftgard, R., Tora, L., Gassmann, M., and Poellinger, L. (1996) Functional interference between hypoxia and dioxin signal transduction pathways: competition for recruitment of the Arnt transcription factor. Mol Cell Biol, 16, 5221-5231.

20 Chan, W.K., Yao, G., Gu, Y.Z., and Bradfield, C.A. (1999) Cross-talk between the aryl hydrocarbon receptor and hypoxia inducible factor signaling pathways. Demonstration of competition and compensation. J Biol Chem, 274, 12115-12123.

21 Nie, M., Blankenship, A.L., and Giesy, J.P. (2001) Interactions between aryl hydrocarbon receptor (AhR) and hypoxia signaling pathways. Environ Toxicol Pharmacol, 10, 17-27.

22 Gassmann, M., Kvietikova, I., Rolfs, A., and Wenger, R.H. (1997) Oxygen- and dioxinregulated gene expression in mouse hepatoma cells. Kidney Int, 51, 567-574.

23 Pollenz, R.S., Davarinos, N.A., and Shearer, T.P. (1999) Analysis of aryl hydrocarbon receptor-mediated signaling during physiological hypoxia reveals lack of competition for the aryl hydrocarbon nuclear translocator transcription factor. Mol Pharmacol, 56, 11271137.

24 Chiu, R.K., Brun, J., Ramaekers, C., Theys, J., Weng, L., Lambin, P., Gray, D.A., and Wouters, B.G. (2006) Lysine 63-polyubiquitination guards against translesion synthesis-induced mutations. PLoS Genet, 2, e116.

25 Reddy, M.V., and Randerath, K. (1986) Nuclease P1-mediated enhancement of sensitivity of 32P-postlabeling test for structurally diverse DNA adducts. Carcinogenesis, 7, 15431551.

26 Godschalk, R.W., Maas, L.M., Van Zandwijk, N., van 't Veer, L.J., Breedijk, A., Borm, P.J., Verhaert, J., Kleinjans, J.C., and van Schooten, F.J. (1998) Differences in aromatic-DNA adduct levels between alveolar macrophages and subpopulations of white blood cells from smokers. Carcinogenesis, 19, 819-825.

27 Tsirigotis, M., Zhang, M., Chiu, R.K., Wouters, B.G., and Gray, D.A. (2001) Sensitivity of mammalian cells expressing mutant ubiquitin to protein-damaging agents. $J$ Biol Chem, 276, 46073-46078.

28 Potter, C.P., and Harris, A.L. (2003) Diagnostic, prognostic and therapeutic implications of carbonic anhydrases in cancer. Br J Cancer, 89, 2-7.

29 Takacova, M., Holotnakova, T., Vondracek, J., Machala, M., Pencikova, K., Gradin, K., Poellinger, L., Pastorek, J., Pastorekova, S., and Kopacek, J. (2009) Role of aryl hydrocarbon receptor in modulation of the expression of the hypoxia marker carbonic anhydrase IX. Biochem J.

30 Lee, K.A., Burgoon, L.D., Lamb, L., Dere, E., Zacharewski, T.R., Hogenesch, J.B., and LaPres, J.J. (2006) Identification and characterization of genes susceptible to transcriptional crosstalk between the hypoxia and dioxin signaling cascades. Chem Res Toxicol, 19, 1284-1293.

31 Kim, J.H., Stansbury, K.H., Walker, N.J., Trush, M.A., Strickland, P.T., and Sutter, T.R. (1998) Metabolism of benzo[a]pyrene and benzo[a]pyrene-7,8-diol by human cytochrome P450 1B1. Carcinogenesis, 19, 1847-1853.

32 Furuta, T., Takemura, H., Liao, Z.Y., Aune, G.J., Redon, C., Sedelnikova, O.A., Pilch, D.R., Rogakou, E.P., Celeste, A., Chen, H.T., Nussenzweig, A., Aladjem, M.I., Bonner, W.M., and Pommier, Y. (2003) Phosphorylation of histone H2AX and activation of Mre11, Rad50, and 
Nbs1 in response to replication-dependent DNA double-strand breaks induced by mammalian DNA topoisomerase I cleavage complexes. J Biol Chem, 278, 20303-20312.

33 Zhao, H., and Piwnica-Worms, H. (2001) ATR-mediated checkpoint pathways regulate phosphorylation and activation of human Chk1. Mol Cell Biol, 21, 4129-4139.

34 Yuan, J., Narayanan, L., Rockwell, S., and Glazer, P.M. (2000) Diminished DNA repair and elevated mutagenesis in mammalian cells exposed to hypoxia and low pH. Cancer Res, 60, 4372-4376.

35 Seo, K.Y., Jelinsky, S.A., and Loechler, E.L. (2000) Factors that influence the mutagenic patterns of DNA adducts from chemical carcinogens. Mutat Res, 463, 215-246.

36 Costa, R.M., Chigancas, V., Galhardo Rda, S., Carvalho, H., and Menck, C.F. (2003) The eukaryotic nucleotide excision repair pathway. Biochimie, 85, 1083-1099.

37 Chen, C., Pore, N., Behrooz, A., Ismail-Beigi, F., and Maity, A. (2001) Regulation of glut1 mRNA by hypoxia-inducible factor-1. Interaction between $\mathrm{H}$-ras and hypoxia. J Biol Chem, 276, 9519-9525.

38 Jiang, B.H., Agani, F., Passaniti, A., and Semenza, G.L. (1997) V-SRC induces expression of hypoxia-inducible factor 1 (HIF-1) and transcription of genes encoding vascular endothelial growth factor and enolase 1: involvement of HIF-1 in tumor progression. Cancer Res, 57, 5328-5335.

39 Zundel, W., Schindler, C., Haas-Kogan, D., Koong, A., Kaper, F., Chen, E., Gottschalk, A.R., Ryan, H.E., Johnson, R.S., Jefferson, A.B., Stokoe, D., and Giaccia, A.J. (2000) Loss of PTEN facilitates HIF-1-mediated gene expression. Genes Dev, 14, 391-396.

40 Ravi, R., Mookerjee, B., Bhujwalla, Z.M., Sutter, C.H., Artemov, D., Zeng, Q., Dillehay, L.E., Madan, A., Semenza, G.L., and Bedi, A. (2000) Regulation of tumor angiogenesis by p53induced degradation of hypoxia-inducible factor 1alpha. Genes Dev, 14, 34-44. 



\section{Chapter 3}

\section{Hypoxia diminishes the detoxification of the environmental mutagen benzo[a]pyrene}

Submitted

Marten A. Schults

Kathleen Sanen

Roger W. Godschalk

Jan Theys

Frederik J. van Schooten

Roland K. Chiu 


\begin{abstract}
Hypoxia promotes genetic instability and is therefore an important factor in carcinogenesis. We have previously shown that activation of the hypoxia responsive transcription factor HIF $\alpha$ can enhance the mutagenic phenotype induced by the environmental mutagen benzo[a]pyrene (BaP). To further elucidate the mechanism behind the ability of hypoxia to increase mutagenicity of carcinogens, we examined the activation and detoxification of BaP under hypoxic conditions. To this end, the human lung carcinoma cell line A549 was treated with BaP under $20 \%$ or $0.2 \%$ oxygen for 18 hours and alterations in BaP metabolism were assayed. First, BaP-induced expression of key metabolic enzymes was analyzed; expression levels of the activating CYP1A1 and CYP1B1 were increased, while the detoxifying enzymes UGT1A6 and UGT2B7 were significantly reduced by hypoxia. To evaluate whether these changes had an effect on metabolism, levels of BaP and several of its metabolites were determined. Cells under hypoxia have a reduced capacity to metabolize BaP leaving more of the parent molecule intact. Additionally, BaP-7,8-dihydrodiol, the pre-cursor metabolite of the reactive metabolite BaP-7,8-dihydroxy-9,10-epoxide (BPDE), was formed in higher concentrations. Finally, under hypoxia, DNA adducts accumulated over a period of 168 hours, whereas adducts were efficiently removed in $20 \%$ oxygen conditions. The delayed detoxification kinetics resulted in a 1.6 fold increase in DNA adducts. These data indicate that the metabolism under hypoxic conditions has shifted towards increased activation of $\mathrm{BaP}$ instead of detoxification and support the idea that modulation of carcinogen metabolism is an important additional mechanism for the observed HIF1 mediated genetic instability.
\end{abstract}




\section{Introduction}

Although hypoxia plays an important role in normal development and physiology, disruption of oxygen homeostasis is an important characteristic of a number of pathologies including cancer (1) and chronic inflammation (2). Therefore, understanding the mechanisms by which cells respond to hypoxia can be of etiological as well as therapeutic interest. We recently demonstrated that hypoxia inducible factor $\alpha(\mathrm{HIF} \alpha)$ stabilization augmented benzo[a]pyrene (BaP) induced DNA adduct levels and subsequent mutation frequencies. These data indicated that concurrent exposure of hypoxia and exogenous genotoxins could enhance genetic instability (3). For example, in pathologies in which oxygen intake is decreased such as chronic obstructive pulmonary disease (COPD), changed carcinogen metabolism could explain the increased cancer risk observed in these patients (4).

$\mathrm{HIF} \alpha$ is regarded as the primary molecular switch to alter gene expression in response to reduced oxygen tension. Hydroxyl groups are attached to HIF $\alpha$, via an oxygendependent prolyl hydroxylase (5). The hydroxylated HIF $\alpha$ is then targeted for ubiquitylation (6) and subsequent proteasomal degradation (7). Under hypoxic conditions, HIF $\alpha$ becomes stabilized and translocated into the nucleus, where it forms a heterodimer with the aryl hydrocarbon receptor nuclear translocator (ARNT) (8). Subsequently, the HIF-1 heterodimer binds to hypoxic responsive elements (9) and induces the expression of a wide array of genes able to augment oxygen delivery or provide alternative pathways for energy production and cell metabolism (10).

As hypoxia is a common characteristic of many tumors and because HIF $\alpha$ can also be induced by aberrant oncogenic activation or loss of tumor suppressor function, HIF $\alpha$ is often found overexpressed in many cancers $(11,12)$. HIF $\alpha$ overexpression and its downstream effectors are associated with increased tumor invasion and metastasis, resistance to chemo-, radio- and immunotherapy, and increased mortality $(8,11,13)$. In addition, exposure of cultured cells to hypoxia results in an elevated mutation frequency $(14,15)$. Several mechanisms have been proposed for this observation including downregulation of DNA repair (16), induction of reactive oxygen species mediated DNA generated during reoxygenation (17), and competition for ARNT (3).

In addition to forming heterodimers with HIF $\alpha$, ARNT also dimerizes with the aryl hydrocarbon receptor (AhR). AhR is a receptor for environmental pollutants such as polycyclic aromatic hydrocarbons (PAH), which are widely distributed environmental contaminants produced as byproducts of combustion processes as in vehicle exhaust and cigarette smoking. BaP is a classic example of PAH and is readily absorbed by inhalation, ingestion and through the skin. Given the lipophilic behavior of BaP, it can easily diffuse into cells, where it can bind AhR. Upon binding, AhR translocates together with its ligand into the nucleus, dimerizes with ARNT, and binds to xenobiotic response elements of target genes (18). This results in the transcription of genes that encode for enzymes involved in xenobiotic detoxification, including the cytochrome P450 (CYPs) isoforms CYP1A1 and CYP1B1 $(19,20)$.

The detoxification of $\mathrm{BaP}$ is a multistep process involving a number of critical enzymes. The first stage requires an epoxidation reaction by the mono-oxygenases CYP1A1 and CYP1B1 (phase I) that requires NADPH and molecular oxygen. One of the resulting 
metabolites (e.g. BaP-7,8-epoxide) can be converted to a dihydrodiol (e.g. BaP-7,8dihydrodiol) by epoxide hydrolase. BaP-7,8-dihydrodiols can be further metabolized by CYP1A1 or CYP1B1 to diol epoxides (e.g. BaP-7,8-diol-9,10-epoxide (BPDE)) or conjugated by uridine diphosphate glucuronosyl transferase (UGT) (phase II) (20). BPDE is the active mutagenic compound as it can covalently bind to DNA to form promutagenic adducts (19).

We recently demonstrated that under normal oxygen conditions chemical stabilization of $\mathrm{HIF} \alpha$ augmented BaP induced adduct levels. Furthermore, we observed a marked increase in adduct levels under hypoxic exposure (3). Interestingly, as the metabolism of $\mathrm{BaP}$ is oxygen dependent, exposure of cells to low oxygen concentrations was expected to generate less bioactive BaP metabolites, which in turn would lead to reduced BPDE-DNA adduct levels. To further elucidate the mechanism behind the ability of hypoxia to increase mutagenicity of carcinogens, alterations in metabolism and adduct kinetics were determined. In this current report, we show that hypoxia alters the pro-mutagenic capacity of $\mathrm{BaP}$ by increasing the formation of $\mathrm{BaP}-7,8$ dihydrodiol (BaP-7,8-diOH), the precursor of BPDE and prolonging the exposure to the parent $\mathrm{BaP}$ compound, which results in an increased BPDE-DNA-adducts.

\section{Materials and Methods}

\section{Cell culture and treatment}

A549 cells (human epithelial lung carcinoma cells), obtained from the American Tissue Culture Collection (ATCC, Rockville, MD, USA), were cultured in DMEM (Sigma, St. Louis, MO, USA) supplemented with $10 \%$ heat inactivated fetal calf serum (FCS, Invitrogen, Breda, The Netherlands) and $1 \%$ penicillin/streptomycin (Sigma) and maintained at $37^{\circ} \mathrm{C}$ in a $5 \% \mathrm{CO}_{2}$ atmosphere. Cells were seeded one day before treatment and maintained at $37^{\circ} \mathrm{C}$ in a $5 \% \mathrm{CO}_{2}$ atmosphere and different oxygen concentrations $\left(20 \%\right.$ or $\left.0.2 \% \mathrm{O}_{2}\right)$. All cells were treated with 0 or $0.1 \mu \mathrm{M} \mathrm{BaP}$ (Sigma) dissolved in DMSO (final DMSO concentrations did not exceed 0.5\%). After treatment, medium was removed and cells were harvested using trypsin. All samples were stored at $-20^{\circ} \mathrm{C}$.

\section{Real-Time Quantitative PCR}

Cells were washed twice with PBS followed by Qiazol (Qiagen, Hilden, Germany) addition. Total RNA was isolated according to the manufacturer's instructions. The RNA samples were quantified spectrophotometrically using a Nanodrop 1000 (Thermo Scientific, Waltham, MA, USA). cDNA synthesis was performed using the iScript cDNA Synthesis kit (Biorad, Veenendaal, The Netherlands) starting with $1 \mu \mathrm{g}$ of RNA. cDNA was diluted $25 x$ in RNase free water. Real-time PCR was performed using the MyiQ Single Color RT-PCR detection system (Biorad) using SYBR Sensimix Sybr Green

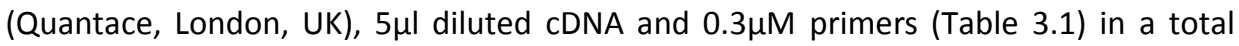
volume of $25 \mu \mathrm{l}$. Samples were amplified under the following conditions: $95^{\circ} \mathrm{C}$ for 3 minutes, followed by 40 cycles of $95^{\circ} \mathrm{C}$ for 15 second and $60^{\circ} \mathrm{C}$ for 45 seconds. PCR was checked for aspecific products by performing a melting curve analysis $\left(65^{\circ} \mathrm{C}-95^{\circ} \mathrm{C}\right)$. 
Data were analyzed using the MyiQ Software system (Biorad) and were expressed as relative gene expression (fold increase) using the $2^{-\Delta \Delta C t}$ method. The stably expressed gene cyclophilin A was included as reference.

Table 3.1: Primer sequences for real time RT-PCR

\begin{tabular}{lll}
\hline Gene & Forward primer $\left(5^{\prime}-3^{\prime}\right)$ & Reverse primer $\left(5^{\prime}{ }^{\prime} 3^{\prime}\right)$ \\
\hline Cyclophilin A & TTCCTGCTTTCACAGAATTATTCC & GCCACCAGTGCCATTATGG \\
CYP1A1 & GAGGCCAGAAGAAACTCCGT & CCCAGCTCAGCTCAGTACCT \\
CYP1B1 & AGTGCAGGCAGAATTGGATCA & GCGCATGGCTTCATAAAGGA \\
UGT1A6 & GGAACCCGACCATCGAATC & TCGGGTGACCAAGCAGATC \\
UGT2B7 & TCCCATCAAATCTCCACAGA & GGTGTTTTCTCTGGGGTCAA \\
\hline
\end{tabular}

\section{DNA isolation}

Cells were harvested and resuspended in $400 \mu \mathrm{ISET} / \mathrm{SDS}(100 \mathrm{mM} \mathrm{NaCl}, 20 \mathrm{mM}$ EDTA, $50 \mathrm{mM}$ Tris, $0.5 \% \mathrm{SDS})$ and incubated at $37^{\circ} \mathrm{C}$ for 2 hours. $50 \mu \mathrm{l}$ of DNAse-free RNAsesolution (RNAse $A(0.1 \mathrm{mg} / \mathrm{ml})$ and RNAse T1 $(1000 \mathrm{U} / \mathrm{mL})$ in SET, incubated at $80^{\circ} \mathrm{C}$ for 5 minutes) was added and samples were incubated at $37^{\circ} \mathrm{C}$ for 1 hour followed by addition of $50 \mu \mathrm{l}$ DNAse-free proteinase $\mathrm{K}\left(10 \mathrm{mg} / \mathrm{ml}\right.$ in SET-SDS, pre-incubated at $37^{\circ} \mathrm{C}$ for 30 minutes) and samples were incubated overnight at $37^{\circ} \mathrm{C}$. After addition of $500 \mu \mathrm{l}$ phenol/chloroform/isoamyl alcohol (25:24:1), samples were rotated for 5 minutes and centrifuged for 5 minutes at $14000 \mathrm{rpm}$. To the upper aqueous phase, $500 \mu \mathrm{l}$ chloroform/Isoamyl alcohol (24:1) was added and samples were rotated for 5 minutes, centrifuged for 5 minutes (14000 rpm) and 1/30 volume NaAc (3M, pH 5.2) was added to the upper phase. Samples were mixed for a few seconds and two volumes ethanol $100 \%\left(4^{\circ} \mathrm{C}\right)$ were added, samples were mixed and incubated at $-20^{\circ} \mathrm{C}$ for 30 minutes. Samples were centrifuged for 5 minutes and DNA pellets were washed with ethanol $70 \%$. DNA pellets were dried and resuspended in Mili-Q $\mathrm{H}_{2} \mathrm{O}$. The quantity of the DNA was measured using the Nanodrop 1000.

\section{${ }^{32}$ P-postlabeling of BPDE-DNA adducts}

DNA adduct levels were determined according to the nuclease P1 enrichment technique originally described by Reddy and Randerath (21) with the modifications described by Godschalk et al (22). In all experiments, three BPDE-DNA standards with known BPDE-DNA adduct levels (one adduct per $10^{6}, 10^{7}$, and $10^{8}$ normal nucleotides) were analyzed in parallel for quantification purposes. Adducts spots in DNA from BaP treated A549 cells that chromatographed at the same position as the BPDE-DNA adducts standards were considered to be derived from BPDE, and were quantified using Phosphor-Imaging technology (Fujifilm FLA-3000, Rotterdam, The Netherlands).

HPLC

In order to determine BaP-metabolite composition, $4 \mathrm{ml}$ medium or cell lysate was extracted with $1 \mathrm{ml}$ ethyl acetate after addition of $1 \mathrm{ml} 3 \mathrm{M} \mathrm{NaCl}$. Samples were vortexed for 10 minutes, centrifuged for 5 minutes at 1000rpm and after briefly vortexing, centrifuged again for 10 minutes at $1500 \mathrm{rpm}$. The ethyl acetate fraction was collected and the extraction step was repeated twice. The second time and third time, 
only ethyl acetate was added and the third time, also two droplets of ethanol were added to the samples for better separation. The ethyl acetate fractions were combined, evaporated to dryness under $\mathrm{N}_{2}$, and residues were resuspended in $0.5 \mathrm{ml}$ methanol. For chromatographic separation, a $50 \mu \mathrm{l}$ volume of the sample was injected onto a Hypersil $5 \mu \mathrm{m}$ ODS HPLC column (250x3mm i.d.) (Supelco 54933, Bellefonte, PA, USA) at a flow rate of $0.5 \mathrm{ml} / \mathrm{min}$. Mobile phase $A$ and $B$ were $100 \%$ methanol (Biosolve Chemicals, Valkenswaard, The Netherlands) and $40 \%$ methanol in water, respectively. The time program for the multi-step gradient was: 0-5min: isocratically 40/60 (A/B, $v / v), 5-30 \mathrm{~min}$ : gradient from 40/60 (A/B, v/v) to $90 / 10(A / B, v / v), 30-35 \mathrm{~min}$ : isocratically $90 / 10(A / B, v / v), 35-37 m i n$ : gradient from 90/10 (A/B, v/v) to 40/60 (A/B, $\mathrm{v} / \mathrm{v}), 37-40 \mathrm{~min}: 40 / 60(A / B, v / v)$. The total run time was 40 minutes. For quantitation purposes, a standard mix consisting of 50ng/ml BaP-9,10-diol, 50ng/ml BaP-7,8-diol, and 50ng/ml 3-hydroxy-BaP (Midwest Research Institute, Kansas City, Missouri, USA) was used. Samples were analyzed on a Gynkotek P580A HPLC system (Separations Analytical Instruments, Hendrik Ido Ambacht, The Netherlands) with a Spark SP830 autosampler (Spark Holland, Emmen, The Netherlands) and a Perkin Elmer LS-30 programmable fluorescence detector (Perkin Elmer, Foster City, CA, USA). Excitation/emission wavelengths were 257/ $>350 \mathrm{~nm}$. For quantification, the area of each metabolite peak on the chromatogram was determined.

\section{Statistical analysis}

Results are expressed as the mean \pm standard error of the mean. GraphPad Prism 4 was used for statistical analysis. To examine differences between cells incubated with or without BaP a two-way analysis of variance test (ANOVA) with Bonferroni post-hoc multiple comparison correction was used. To assess differences between various oxygen concentrations a t-test was used. Area under the curve was computed using the trapezoidal method. Differences were considered to be statistically significant when $\mathrm{p}<0.05$.

\section{Results}

BaP-mediated induction of phase I enzymes CYP1A1 and CYP1B1 is increased under hypoxia.

To determine whether oxygen levels affect the induction of CYP1A1 (Figure 3.1A) and CYP1B1 (Figure 3.1B) and the subsequent metabolic activation of $\mathrm{BaP}$, gene expressions were determined in A549 cells treated with or without $0.1 \mu \mathrm{M} \mathrm{BaP}$ for 18 hours. Both CYP isoforms showed higher mRNA levels under hypoxic conditions. BaP induced CYP1A1 levels were $\approx 1.3$ fold higher in cells cultured under $0.2 \%$ oxygen compared to cells cultured in $20 \%$ oxygen ( $p<0.05$ ). CYP1B1 gene expression under hypoxic conditions was induced by $\approx 1.6$ fold $(p<0.001)$ and $\approx 2.1$ fold $(p<0.001)$ compared to $20 \%$ oxygen, in the absence and presence of $\mathrm{BaP}$ respectively. This induction of phase I enzyme expression suggests an increased metabolic activation of BaP. 

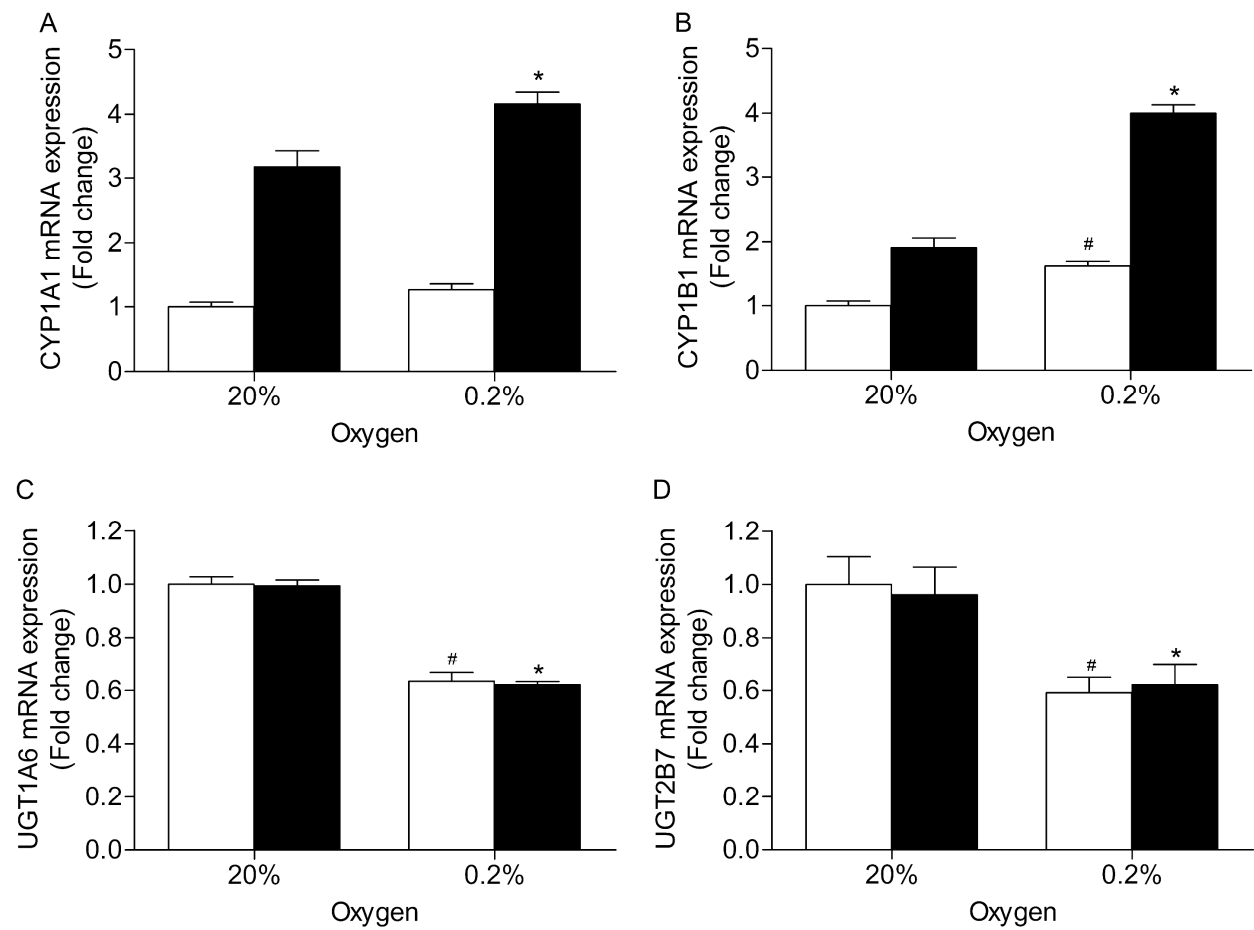

Figure 3.1: Changes in oxygen tension alters the expression of the phase I metabolic enzymes Cyp1a1/1b1 and the phase II enzymes Ugt1a6, and Ugt2b7. A549 cells were treated with DMSO $(\square)$ or $0.1 \mu \mathrm{M} \mathrm{BaP}(\square)$ and incubated in an atmosphere containing $20 \%$ or $0.2 \%$ oxygen. CYP1A1 (A), CYP1B1 (B), UGT1A6 (C), and UGT2B7 (D) mRNA levels were measured. Data are presented as fold increase compared to $20 \%$ oxygen levels and DMSO. \# and * indicate statistical significant differences compared to $20 \%$ oxygen and DMSO and BaP treatment, respectively.

Hypoxia decreased phase II enzymes UGT1A6 and UGT2B7 gene expression.

To investigate whether enzymes involved in the detoxification of $\mathrm{BaP}$ are altered under hypoxic conditions, gene expression was measured for the UDP glucuronosyltransferases, UGT1A6 and UGT2B7, two enzymes responsible for the conjugation of $\mathrm{BaP}$ metabolites and subsequent excretion of BaP. Both enzymes showed lower mRNA levels under hypoxic conditions. UGT1A6 gene expression was $\approx 37 \%(p<0.001)$ lower for cells in $0.2 \%$ oxygen, independent of BaP treatment (Figure 3.1). When cells were under hypoxic conditions, a statistical significant $\approx 41 \%(p<0.01)$ and $\approx 35 \%(p<0.05)$ decreased level of UGT2B7, for DMSO and BaP treated cells respectively, was observed compared to $20 \%$ oxygen (Figure 3.1 ). This induction in gene expression of $\mathrm{BaP}$ activating enzymes and reduction of detoxifying gene expression under hypoxic conditions suggests that metabolism is directed towards an increased activation of BaP. 


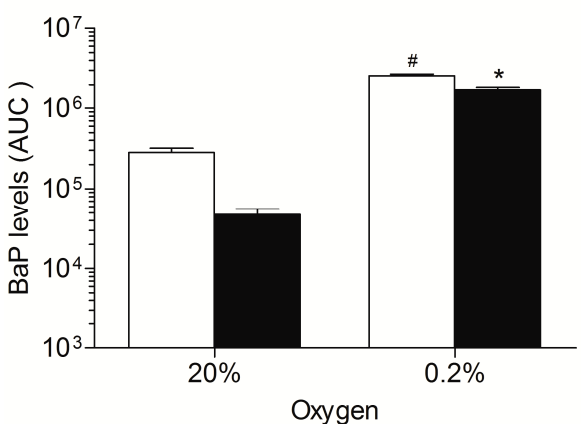

Figure 3.2: Hypoxia diminishes BaP metabolism. A549 cells were treated with $0.1 \mu \mathrm{M} \mathrm{BaP}$ and incubated in an atmosphere containing $20 \%$ or $0.2 \%$ oxygen. BaP levels were measured after 18 hours, extracellularly ( $\square$ ) and intracellularly ( $\mathbf{\square})$. Data are presented as area under the curve. \# and * indicate statistical significant differences compared to $20 \%$ oxygen extracellularly and intracellularly, respectively.

The parent BaP compound remains unmetabolized in cells treated $18 \mathrm{~h}$ under hypoxia.

To determine if increased CYP mRNA levels results in increased BaP metabolism, remaining unmetabolized $\mathrm{BaP}$ was measured extracellular and intracellular after 18 hours of incubation. Importantly, extracellular BaP levels in hypoxic cells were 9 fold higher $(p<0.001)$ compared to cells incubated under $20 \%$ oxygen, while intracellular the difference was 36 times $(p<0.001)$ (Figure 3.2 ). The hypoxia induced increase in $\mathrm{BaP}$ parent compound suggests that, although an increased CYP expression is observed, lack of oxygen prevents the metabolism of BaP under hypoxic conditions, while in the normoxic cells BaP is conjugated.

Table 3.2: Higher BaP-7,8-diOH levels in cells exposed to BaP under hypoxic conditions. A549 cells were treated with $0.1 \mu \mathrm{M} \mathrm{BaP}$ and incubated in an atmosphere containing $20 \%$ or $0.2 \%$ oxygen for 18 hours and the extracellular and intracellular BaP metabolites; BaP-9,10-diOH, BaP$7,8-\mathrm{diOH}$, and $\mathrm{BaP}-3-\mathrm{OH}$ were measured and normalized for the amount present at $20 \%$ oxygen. Data are presented as mean \pm standard error * indicates statistical significant difference.

\begin{tabular}{llll}
\hline & $\begin{array}{l}\text { Oxygen } \\
(\%)\end{array}$ & $\begin{array}{l}\text { Extracellular } \\
\text { (Fold change) }\end{array}$ & $\begin{array}{l}\text { Intracellular } \\
\text { (Fold change) }\end{array}$ \\
\hline BaP-9,10-diOH & 20 & $1.00 \pm 0.11$ & $1.00 \pm 0.13$ \\
& 0.2 & $0.47 \pm 0.06^{*}$ & $0.91 \pm 0.10$ \\
\hline BaP-7,8-diOH & 20 & $1.00 \pm 0.13$ & $1.00 \pm 0.19$ \\
& 0.2 & $3.66 \pm 0.05^{*}$ & $8.07 \pm 0.14^{*}$ \\
\hline $\mathrm{BaP}-3-\mathrm{OH}$ & 20 & $1.00 \pm 0.12$ & $1.00 \pm 0.09$ \\
& 0.2 & $0.68 \pm 0.03^{*}$ & $1.24 \pm 0.12$ \\
\hline
\end{tabular}

The active metabolite $\mathrm{BaP}-7,8-\mathrm{diOH}$ is enriched in cells treated with hypoxia for $18 \mathrm{~h}$.

To determine whether hypoxia directs the metabolism of $\mathrm{BaP}$ towards unfavorable activation, three important BaP metabolites, BaP-9,10-dihydrodiol (BaP-9,10-diOH), BaP-7,8-dihydrodiol (BaP-7,8-diOH) and 3-hydroxy-BaP (BaP-3-OH), were measured extracellular and intracellular (Table 3.2). Extracellular $\mathrm{BaP}-9,10-\mathrm{diOH}$ and $\mathrm{BaP}-3-\mathrm{OH}$ metabolite levels were significantly lower in hypoxic cells compared to the $20 \%$ oxygen condition, $\approx 53 \%,(p<0.01)$ and $\approx 32 \%(p<0.05)$ respectively. In hypoxic cells the amount of both extracellular and intracellular levels of $\mathrm{BaP}-7,8-$ diOH were increased $\approx 3.6$ $(p<0.001)$ and $\approx 8.1(p<0.001)$ fold respectively, compared to cells cultured under $20 \%$ oxygen. So despite reduced BaP metabolism, more $\mathrm{BaP}-7,8-\mathrm{diOH}$ is observed under 
hypoxic conditions suggesting an increased opportunity for the formation of BPDEDNA adducts.
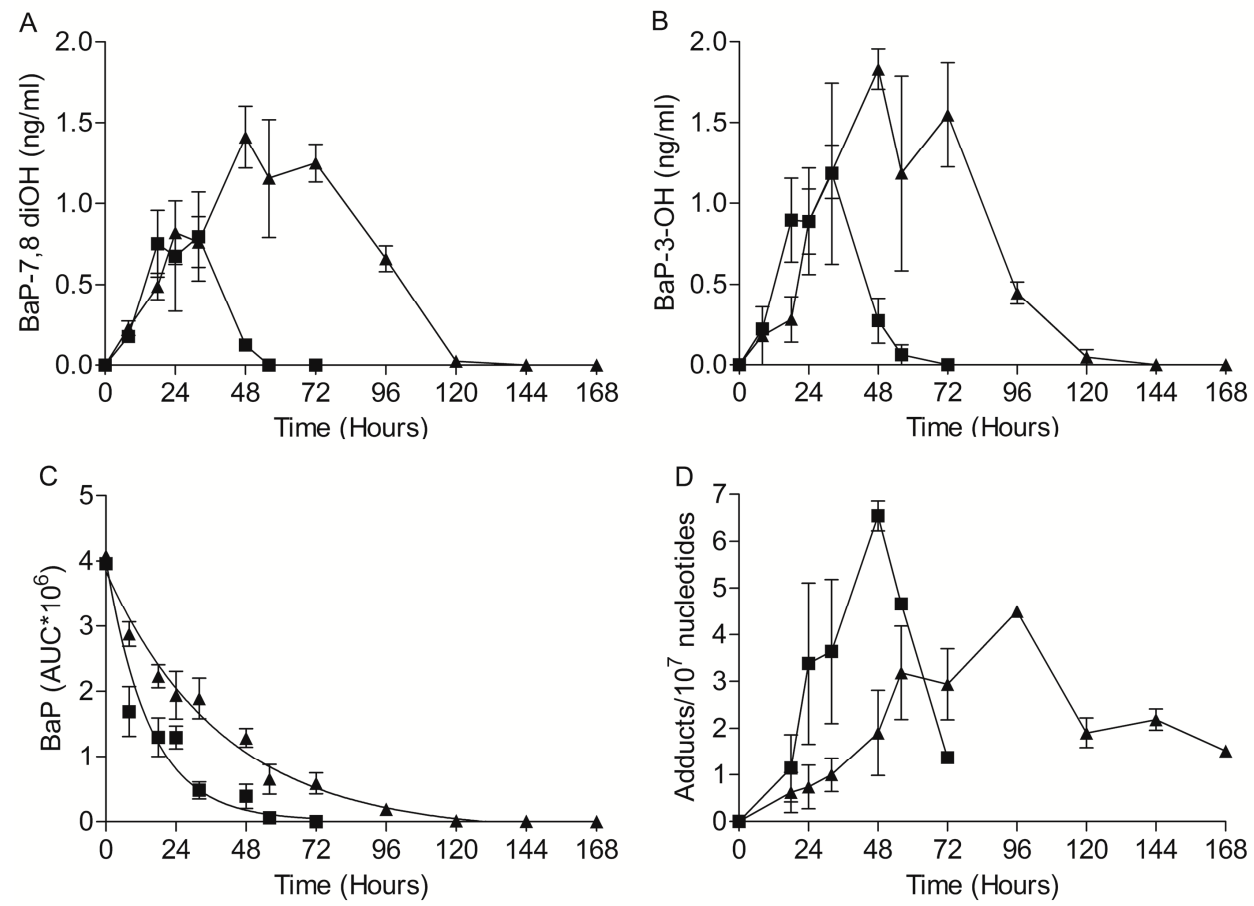

Figure 3.3: Hypoxia diminishes BaP metabolism, but increases metabolite and adduct formation. A549 cells were treated with $0.1 \mu \mathrm{M} \mathrm{BaP}$ and incubated in an atmosphere containing $20 \%(\mathbf{\square})$, or $0.2 \%$ oxygen $(\mathbf{\Delta})$. BaP metabolite levels of BaP-7,8-diOH (A) and BaP-3OH (B), BaP levels (C) and BPDE-DNA adduct levels (D) were measured.

Hypoxia prolongs exposure to BaP by altering metabolism kinetics.

A well-documented and logical factor critical for carcinogenesis is the duration of $\mathrm{BaP}$ exposure (23). To determine if indeed under hypoxic conditions the exposure to $\mathrm{BaP}$ and its metabolites was increased, a time kinetic experiment was performed to compare the regular culturing oxygen concentration with hypoxic conditions for a prolonged exposure period. Up to 32 hours, similar levels of both BaP-7,8-diOH (Figure 3.3A) and $\mathrm{BaP}-3-\mathrm{OH}$ (Figure 3.3B) were observed under oxygen conditions, although the metabolic rate was reduced in the cells under hypoxic conditions as there was less BaP metabolized (Figure 3.3C). The metabolites in the medium of cells cultured under $20 \%$ oxygen could be detected up to 56 hours after BaP addition, while in the hypoxic cells the amount of metabolites increased further to $a \approx 1.8$ fold and $\approx 1.5$ fold higher level compared to $20 \%$ oxygen for $\mathrm{BaP}-7,8-\mathrm{diOH}$ and $\mathrm{BaP}-3-\mathrm{OH}$ respectively. Under hypoxic conditions, the metabolites remained present for a significantly longer time and could be detected up to 144 hours after BaP addition. 
Hypoxia induced increase in BaP exposure time leads to more DNA adducts.

To determine whether the hypoxia induced changes in $\mathrm{BaP}$ metabolism results in more adducts, BPDE-DNA adducts were measured in the time kinetic experiment. The adduct levels in cells cultured under $20 \%$ oxygen were for the first 56 hours higher than under hypoxic conditions (Figure 3.3D). At 48 hours, the amount of adducts was $\approx 6.5$ adducts per $10^{7}$ nucleotides, after which the adduct levels decreased, while in the hypoxic cells the amount of adducts increased to $a \approx 4.5$ adducts per $10^{7}$ nucleotides 96 hours after $\mathrm{BaP}$ addition. To determine the total amount of adducts formed during the whole incubation period, the area under the curve was measured. Importantly, under hypoxic conditions, the amount of adducts formed was $\approx 1.6$ times higher compared to cells under cultured under $20 \%$ oxygen. These data indicate that under hypoxic conditions the BaP metabolism has shifted towards increased activation of BaP.

\section{Discussion}

The link between hypoxia and pathologies such as cancer may be the result of the previously reported increased mutation frequencies $(14,15)$. Understanding the mechanisms involved in mutation induction is important in determining the role of hypoxia in genetic instability. Previously, we have shown a novel mechanism in which the interaction between induction of the HIF1 pathway and the AhR-pathway led to an increase in BaP-induced mutations (3). In this current study we further elucidated the mechanism behind the ability of hypoxia to increase mutagenicity of carcinogens. We provide evidence that hypoxia changes carcinogen metabolism towards a more activating metabolic pattern and alters kinetics of BaP-metabolism resulting in an increase in $\mathrm{BaP}$ and $\mathrm{BaP}-7,8-\mathrm{diOH}$ exposure and subsequent increase in BPDE-DNA adduct formation.

The induction of CYP1A1 is believed to be an activating event leading to enhanced levels of reactive metabolites and subsequent carcinogenesis. For example, a positive correlation was found between CYP1A1 activity and pulmonary PAH-associated DNA adduct formation (24) while high CYP1A1 inducibility in lymphocytes has been related to a high lung cancer risk $(25,26)$. Conversely, CYP1A1 knockout mice were more susceptible to form adducts indicating the dual role of CYPs in activating and deactivating carcinogens (27). In this study, we showed that BaP induced CYP1A1 and CYP1B1 gene expression were augmented under hypoxia compared to cells cultured under 20\% oxygen (Figure 3.1). This induced expression suggests an increased conversion of $\mathrm{BaP}$ and a subsequent enhanced elimination by conjugation, which however depends on phase II enzymes. Therefore, we assessed the expression of UGTs as these enzymes have a profound effect in both detoxification and promotion of $\mathrm{BaP}$ excretion and in particular, UGT2B7 exhibited strong activity towards BaP-7,8-diOH (28). The UGT gene expressions in this study showed lower levels under hypoxic conditions independent of the addition of BaP. The increased phase I enzymes and decreased phase II enzyme gene expression under hypoxia suggests a possible diversion of the metabolism towards the formation of BPDE. Decreased UGTs reduces the amount of BaP-7,8-diOH conjugation while at the same time the increase in CYPs may result in an increased metabolism of BaP-7,8-diOH towards BPDE. 
To investigate the effect of $\mathrm{BaP}$ metabolic gene expression alteration, $\mathrm{BaP}$ metabolites were measured both extracellular and intracellular (Table 3.2). Under hypoxic conditions, very little BaP was metabolized within 18 hours of incubation. Unmetabolized BaP levels in cells incubated under 20\% oxygen were 9 fold and 36 fold lower compared to hypoxic cells, extracellular and intracellular, respectively. This suggests that the metabolism of $\mathrm{BaP}$ is not only reduced but also its removal from the cell is decreased under hypoxic conditions. Extracellular levels of $\mathrm{BaP}-3-\mathrm{OH}$, a non mutagenic metabolite of $\mathrm{BaP}$ and $\mathrm{BaP}-9,10-\mathrm{diOH}$, a precursor of $\mathrm{BaP}-9,10-$ diol-7,8epoxide, which is much less carcinogenic compared to BPDE, were lower at $0.2 \%$ oxygen compared to $20 \%$ oxygen. On the other hand, levels of the BPDE precursor $\mathrm{BaP}-7,8-\mathrm{diOH}$ were much higher under hypoxic conditions. Interestingly, higher intracellular levels of $\mathrm{BaP}-7,8-\mathrm{diOH}$ were present under hypoxic conditions compared to extracellular levels, which may suggest a reduced removal of this metabolite from the cell. Very little is known about the transport of BaP unconjugated metabolites and thus may be an avenue of further studies. Overall, the levels of the metabolites are much higher under hypoxic conditions while the metabolism of $\mathrm{BaP}$ itself is decreased. Incubation times of up to 168 hours were used to determine the differences in the formation of BPDE-DNA-adducts over a prolonged exposure period in cells cultured at regular culturing conditions and at hypoxic conditions (Figure 3.3). The BaP metabolism was reduced under hypoxic conditions, which however did not result in a decreased formation of metabolites. In fact, this reduced metabolism resulted in a prolonged formation of $\mathrm{BaP}-7,8-\mathrm{diOH}$, and $\mathrm{BaP}-3-\mathrm{OH}$ metabolites and in the end, more ethyl acetate extractable metabolites were formed in the cell during the metabolism of BaP. Importantly, the alteration in metabolism resulted in a 1.6 times more DNA adducts being formed under hypoxic conditions compared to cells cultured in $20 \%$ oxygen. This correlates well with the study by Ross et al. in which a relation between the total amount of adducts present in time and tumor induction in mouse lung was observed and concluded that area under the curve is a better predictor of cancer risk than peak adducts levels (23). This suggests that in BaP exposure studies, the timing of kinetics must be carefully considered. Our data indicate that the observed CYP induced gene expression under hypoxic conditions does not increase $\mathrm{BaP}$ metabolism, but rather the metabolism of BaP-7,8-diOH to BPDE. This in combination with a reduced detoxification of BaP-7,8-diOH results in an increased formation of BPDE-DNA adducts. The prolonged presence of adducts under hypoxic conditions could result in a greater genetic instability. That our in vitro findings can be translated to the in vivo situation is exemplified by results obtained in skin exposed Ahr (-/-) mice that showed a lower metabolic clearance of $\mathrm{BaP}$ resulting in increased formation of $\mathrm{BaP}-7,8-\mathrm{diOH}$ metabolites, and higher levels of unmetabolised $\mathrm{BaP}$ and DNA adduct levels in tissues, especially lung. So, in intact animals hypoxic interference of the Ahr signaling pathway is very well anticipated to lead to similar effects upon exposure to BaP (29).

Taken together, these results suggest that cells exposed to low oxygen concentrations generate more bioactive intracellular BaP metabolites. Importantly, we demonstrate that the time in which cells were exposed to BaP was elongated under hypoxic conditions. This ultimately led to prolonged time to form BPDE-DNA adducts in the cells, which is associated with increased tumorigenesis. Interestingly, this suggests that 
Chapter 3

pathologies that limit the oxygen tension such as COPD or local hypoxia due to for example inflammation or poor angiogenesis can result in a disturbed oxygen balance and a subsequent dysregulation of the carcinogen detoxification and increased cancer risk. 


\section{Reference list}

1 Harris, A.L. (2002) Hypoxia--a key regulatory factor in tumour growth. Nat Rev Cancer, 2, 38-47.

2 Taylor, C.T. (2008) Interdependent roles for hypoxia inducible factor and nuclear factorkappaB in hypoxic inflammation. J Physiol, 586, 4055-4059.

3 Schults, M.A., Timmermans, L., Godschalk, R.W., Theys, J., Wouters, B.G., van Schooten, F.J., and Chiu, R.K. (2010) Diminished carcinogen detoxification is a novel mechanism for hypoxia-inducible factor 1-mediated genetic instability. J Biol Chem, 285, 14558-14564.

4 van Gestel, Y.R., Hoeks, S.E., Sin, D.D., Huzeir, V., Stam, H., Mertens, F.W., van Domburg, R.T., Bax, J.J., and Poldermans, D. (2009) COPD and cancer mortality: the influence of statins. Thorax, 64, 963-967.

5 Jaakkola, P., Mole, D.R., Tian, Y.M., Wilson, M.I., Gielbert, J., Gaskell, S.J., Kriegsheim, A., Hebestreit, H.F., Mukherji, M., Schofield, C.J., Maxwell, P.H., Pugh, C.W., and Ratcliffe, P.J. (2001) Targeting of HIF-alpha to the von Hippel-Lindau ubiquitylation complex by O2regulated prolyl hydroxylation. Science, 292, 468-472.

6 Cockman, M.E., Masson, N., Mole, D.R., Jaakkola, P., Chang, G.W., Clifford, S.C., Maher, E.R., Pugh, C.W., Ratcliffe, P.J., and Maxwell, P.H. (2000) Hypoxia inducible factor-alpha binding and ubiquitylation by the von Hippel-Lindau tumor suppressor protein. $J$ Biol Chem, 275, 25733-25741.

7 Kallio, P.J., Wilson, W.J., O'Brien, S., Makino, Y., and Poellinger, L. (1999) Regulation of the hypoxia-inducible transcription factor 1alpha by the ubiquitin-proteasome pathway. J Biol Chem, 274, 6519-6525.

8 Wang, G.L., Jiang, B.H., Rue, E.A., and Semenza, G.L. (1995) Hypoxia-inducible factor 1 is a basic-helix-loop-helix-PAS heterodimer regulated by cellular $\mathrm{O} 2$ tension. Proc Natl Acad Sci U S A, 92, 5510-5514.

9 Semenza, G.L., Jiang, B.H., Leung, S.W., Passantino, R., Concordet, J.P., Maire, P., and Giallongo, A. (1996) Hypoxia response elements in the aldolase A, enolase 1, and lactate dehydrogenase $A$ gene promoters contain essential binding sites for hypoxia-inducible factor 1. J Biol Chem, 271, 32529-32537.

10 Semenza, G.L. (2000) Expression of hypoxia-inducible factor 1: mechanisms and consequences. Biochem Pharmacol, 59, 47-53.

11 Zhong, H., De Marzo, A.M., Laughner, E., Lim, M., Hilton, D.A., Zagzag, D., Buechler, P., Isaacs, W.B., Semenza, G.L., and Simons, J.W. (1999) Overexpression of hypoxia-inducible factor 1alpha in common human cancers and their metastases. Cancer Res, 59, 5830-5835.

12 Semenza, G.L. (2000) HIF-1: using two hands to flip the angiogenic switch. Cancer Metastasis Rev, 19, 59-65.

13 Semenza, G.L. (2001) Hypoxia-inducible factor 1: oxygen homeostasis and disease pathophysiology. Trends Mol Med, 7, 345-350.

14 Reynolds, T.Y., Rockwell, S., and Glazer, P.M. (1996) Genetic instability induced by the tumor microenvironment. Cancer Res, 56, 5754-5757.

15 Papp-Szabo, E., Josephy, P.D., and Coomber, B.L. (2005) Microenvironmental influences on mutagenesis in mammary epithelial cells. Int J Cancer, 116, 679-685.

16 Chan, N., Koritzinsky, M., Zhao, H., Bindra, R., Glazer, P.M., Powell, S., Belmaaza, A., Wouters, B., and Bristow, R.G. (2008) Chronic hypoxia decreases synthesis of homologous recombination proteins to offset chemoresistance and radioresistance. Cancer Res, 68, 605-614.

17 Hammond, E.M., Denko, N.C., Dorie, M.J., Abraham, R.T., and Giaccia, A.J. (2002) Hypoxia links ATR and p53 through replication arrest. Mol Cell Biol, 22, 1834-1843. 
18 Reyes, H., Reisz-Porszasz, S., and Hankinson, O. (1992) Identification of the Ah receptor nuclear translocator protein (Arnt) as a component of the DNA binding form of the Ah receptor. Science, 256, 1193-1195.

19 Gelboin, H.V. (1980) Benzo[alpha]pyrene metabolism, activation and carcinogenesis: role and regulation of mixed-function oxidases and related enzymes. Physiol Rev, 60, 11071166.

20 Baird, W.M., Hooven, L.A., and Mahadevan, B. (2005) Carcinogenic polycyclic aromatic hydrocarbon-DNA adducts and mechanism of action. Environ Mol Mutagen, 45, 106-114.

21 Reddy, M.V., and Randerath, K. (1986) Nuclease P1-mediated enhancement of sensitivity of 32P-postlabeling test for structurally diverse DNA adducts. Carcinogenesis, 7, 15431551.

22 Godschalk, R.W., Maas, L.M., Van Zandwijk, N., van 't Veer, L.J., Breedijk, A., Borm, P.J., Verhaert, J., Kleinjans, J.C., and van Schooten, F.J. (1998) Differences in aromatic-DNA adduct levels between alveolar macrophages and subpopulations of white blood cells from smokers. Carcinogenesis, 19, 819-825.

23 Ross, J.A., Nelson, G.B., Wilson, K.H., Rabinowitz, J.R., Galati, A., Stoner, G.D., Nesnow, S., and Mass, M.J. (1995) Adenomas induced by polycyclic aromatic hydrocarbons in strain A/J mouse lung correlate with time-integrated DNA adduct levels. Cancer Res, 55, 10391044.

24 Bartsch, H., Castegnaro, M., Rojas, M., Camus, A.M., Alexandrov, K., and Lang, M. (1992) Expression of pulmonary cytochrome P4501A1 and carcinogen DNA adduct formation in high risk subjects for tobacco-related lung cancer. Toxicol Lett, 64-65 Spec No, 477-483.

25 Kouri, R.E., McKinney, C.E., Slomiany, D.J., Snodgrass, D.R., Wray, N.P., and McLemore, T.L. (1982) Positive correlation between high aryl hydrocarbon hydroxylase activity and primary lung cancer as analyzed in cryopreserved lymphocytes. Cancer Res, 42, 5030-5037.

26 Kiyohara, C., Nakanishi, Y., Inutsuka, S., Takayama, K., Hara, N., Motohiro, A., Tanaka, K., Kono, S., and Hirohata, T. (1998) The relationship between CYP1A1 aryl hydrocarbon hydroxylase activity and lung cancer in a Japanese population. Pharmacogenetics, 8, 315323.

27 Uno, S., Dalton, T.P., Shertzer, H.G., Genter, M.B., Warshawsky, D., Talaska, G., and Nebert, D.W. (2001) Benzo[a]pyrene-induced toxicity: paradoxical protection in Cyp1a1(-/) knockout mice having increased hepatic BaP-DNA adduct levels. Biochem Biophys Res Commun, 289, 1049-1056.

28 Jin, C.J., Miners, J.O., Burchell, B., and Mackenzie, P.I. (1993) The glucuronidation of hydroxylated metabolites of benzo[a]pyrene and 2-acetylaminofluorene by cDNAexpressed human UDP-glucuronosyltransferases. Carcinogenesis, 14, 2637-2639.

29 Sagredo, C., Mollerup, S., Cole, K.J., Phillips, D.H., Uppstad, H., and Ovrebo, S. (2009) Biotransformation of benzo[a]pyrene in Ahr knockout mice is dependent on time and route of exposure. Chem Res Toxicol, 22, 584-591. 




\section{Chapter 4}

\section{Loss of von Hippel-Lindau affects benzo[a]pyrene induced genotoxic responses and reduces its repair in renal-cell carcinoma in vitro}

Submitted

Marten A. Schults

Yvonne Oligschläger

Roger W. Godschalk

Frederik J. van Schooten

Roland K. Chiu 


\begin{abstract}
Mutations of the von Hippel-Lindau (VHL) tumor suppressor gene occur in the majority of sporadic renal-cell carcinomas (RCC). Loss of VHL function is associated with stabilization of hypoxia-inducible factor $\alpha$ (HIF $\alpha)$. We and others have shown that there is a two-way interaction between the aryl hydrocarbon receptor (AhR), which is an important mediator in the metabolic activation and detoxification of carcinogens, and the HIF1-pathway leading to an increased genetic instability when both pathways are simultaneously activated. The aim of this study was to investigate how environmental carcinogens, such as benzo[a]pyrene (BaP), which can be metabolically activated to BaP-7,8-diOH-9,10-epoxide (BPDE) play a role in the etiology of RCC. To this end, we exposed VHL deficient RCC4 cells, in which HIF $\alpha$ is stabilized regardless of oxygen tension, to $0.1 \mu \mathrm{M}$ BaP for 18 hours. In this study we demonstrated that the mutagenic BPDE-DNA adduct levels were increased in HIF $\alpha$ stabilized cells. Using qRT$P C R$, we demonstrated that absence of VHL significantly induced the mRNA levels of the AhR downstream target CYP1A1. Furthermore, HPLC analysis indicated that loss of $\mathrm{VHL}$ increased the concentration of BaP-7,8-dihydroxydiol, the pre-cursor metabolite of BPDE. Interestingly, the capacity to repair BPDE-DNA adducts in the HIF $\alpha$ stabilized RCC4 cells was markedly reduced. Taken together, these data indicate that loss of VHL affects BaP-mediated genotoxic responses in RCC and decreases repair capacity.
\end{abstract}




\section{Introduction}

Renal-cell carcinoma (RCC) is the most common type of kidney cancer in adults and accounts for $4 \%$ of all cancers (1). The most frequently observed genetic alteration in RCC is the somatic mutation of the von Hippel-Lindau (VHL) tumor suppressor gene $(2,3)$. The protein encoded by VHL is a crucial regulator of the oxygen sensing pathway, which involves the transcription factor hypoxia-inducible factor $(2,4)$. In the presence of oxygen, HIFa is hydroxylated by an oxygen-dependent prolyl hydroxylase (HIF-PH) (5). An E3 ubiquitin ligase complex containing the von Hippel-Lindau protein ( $\mathrm{pVHL}$ ) recognizes the hydroxylated $H I F \alpha$, and targets it for ubiquitination (6) and subsequently proteasomal degradation (7). Under hypoxic conditions, HIFa is not prolyl-hydroxylated and thus unrecognized by pVHL. Therefore, the stabilized HIF $\alpha$ can translocate to the nucleus where it forms a heterodimer with HIF-1 $\beta$, also referred to as aryl hydrocarbon receptor nuclear translocator (ARNT) (8). HIF1 then binds to the $(\mathrm{A} / \mathrm{G}) \mathrm{CGTG}$ consensus sequence in the hypoxic responsive elements of the promoter/enhancer regions in the DNA (9), where it drives the expression of a wide array of hypoxia-inducible genes to augment oxygen delivery or to provide alternative pathways for energy production and cell metabolism.

The functional loss of pVHL in some RCCs results in an aberrant stabilization of HIF $\alpha$ independent of the oxygen tension. The subsequent overexpression of proteins encoded by HIF $\alpha$ regulated target genes contributes to the creation of a microenvironment favorable for cell proliferation (2,10-12). In many tumors including RCC, the hypoxia-responsive transcription factor HIF $\alpha$ is overexpressed, (13) and is associated, together with its downstream targets, with poorer outcome (14). Patients diagnosed with such hypoxic tumors will often have a poor clinical prognosis due to the formation of metastases and the resistance to chemotherapeutics (15). Kallio and colleagues have proposed that this negative prognosis may occur due to low oxygen concentrations having the capacity to induce genetic instability, leading to increased rates of mutagenesis and angiogenesis, decreased rates of apoptosis and upregulation of genes involved in the metastatic cascade (16). Suppression of the DNA damage response pathways within the hypoxic tumors may also play a critical role (9).

In addition to forming a complex with HIF $\alpha$, HIF1 $\beta$ /ARNT also dimerizes with the aryl hydrocarbon receptor (AhR). AhR is known to interact with environmental pollutants such as dioxins and polycyclic aromatic hydrocarbons (PAH). PAHs are widely distributed contaminants produced as byproducts of combustion processes such as in vehicle exhaust, cigarette smoking and charcoal grilling of food. Benzo[a]pyrene (BaP) is a classic example of PAH and is readily absorbed by inhalation, ingestion, and through the skin. As BaP is lipophilic, it can easily diffuse into cells where it binds to AhR, translocates into the nucleus and subsequently heterodimerizes with HIF1ß/ARNT. This complex can then bind to the TNGCGTG consensus sequence in the xenobiotic response elements of target genes (17) where it acts as a transcription factor for a number of genes, which encode for enzymes involved in xenobiotic detoxification, including the cytochrome P450 (CYPs) isoforms CYP1A1 and CYP1B1 $(18,19)$. The detoxification process of $\mathrm{BaP}$ begins with an epoxidation reaction by the mono-oxygenases CYP1A1 and CYP1B1 (phase I). The resulting metabolites (e.g. BaP- 
7,8-epoxide and BaP-9,10-epoxide) can be converted nonenzymatically to phenols (e.g. 3-OH BaP) or enzymatically to dihydrodiols (e.g. BaP-7,8-diOH or BaP-9,10-diOH) by epoxide hydrolase. Phenols can subsequently be converted to water-soluble sulphate or glucuronide conjugates (phase II) and dihydrodiols can be further transformed by CYP1A1 or CYP1B1 to diol epoxides (e.g. BaP-7,8-diol-9,10-epoxide (BPDE)) or conjugated by uridine diphosphate glucuronosyl transferase (UGT) (19). An unfortunate consequence of the detoxification reaction is the production of the intermediate BPDE, which can covalently bind to DNA forming highly mutagenic DNA adducts, where it preferentially binds to the nucleotide guanine at the N2 position (BPDE-N2-dG lesion) (18). When unrepaired, these lesions may result in mutations, for example, BPDE induces $\mathrm{G}$ to $\mathrm{T}$ transversions in the $\mathrm{p} 53$ tumor suppressor gene and is as such evidenced to be involved in lung cancer development (20)

Previously, we have shown that exposure of cells to hypoxia markedly enhances the genetic instability caused by exogenous genotoxins and that HIF activation decreases nucleotide excision repair (NER) (21). Furthermore, we have demonstrated that the kinetics of $\mathrm{BaP}$ metabolism is altered under hypoxia resulting in a prolonged time of exposure and a higher amount of BPDE-DNA adducts being formed (Schults, M.A. et al, submitted for publication). From these initial studies in which we induced HIF $\alpha$ expression using chemicals or hypoxia, we observed an important link between the HIF1 mediated response pathway and the cellular response pathway that counteracts chemical carcinogens. In the present study, we hypothesize that in naturally occurring RCC cells that have a defect in HIF regulation, the observed genetic instability may be the result of a faulty response to environmental carcinogens such as BaP. In this current report, we show that loss of $\mathrm{VHL}$ affects BaP-mediated genotoxic responses by inducing CYP1A1 mRNA levels, which mediated a significant change in $\mathrm{BaP}-7,8-\mathrm{diOH}$, the pre-cursor metabolite of BPDE. Secondly, the capacity to repair DNA by NER is reduced in these cells, thereby preventing the repair of those BPDE-DNA adducts

\section{Materials and Methods}

\section{Cell culture and treatment}

RCC4 (VHL-/-) cells, a VHL-deficient cell line and RCC4-VHL (VHL+/+), RCC4 reconstituted with VHL, were cultured in Dulbecco's Modified Eagle Medium (DMEM; Sigma-Aldrich, UK) supplemented with $10 \%$ heat inactivated Fecal Calf Serum (FCS; Invitrogen Breda, The Netherlands) and $1 \%$ penicillin streptomycin (P/S; Gibco, Invitrogen, Paisley, UK) at $37^{\circ} \mathrm{C}$ in a $5 \% \mathrm{CO}_{2}$ and $20 \% \mathrm{O}_{2}$ atmosphere. Cells were seeded one day before treatment and maintained at $37^{\circ} \mathrm{C}$ in a $5 \% \mathrm{CO}_{2}$ atmosphere. All cells were treated with 0 or $0.1 \mu \mathrm{M} \mathrm{BaP}$ (Sigma) dissolved in DMSO (final concentrations did not exceed $0.5 \%$ ) for 18 hours. After treatment medium was removed and cells were harvested using trypsin. All samples were stored at $-20^{\circ} \mathrm{C}$.

\section{Quantitative Real-Time PCR}

Cells were washed twice with PBS and lyzed with Trizol (Invitrogen). Total RNA was isolated according to the manufacturer's instructions. The quantity of each RNA sample was spectrophotometrically assessed by a Nanodrop 1000 (Thermo Scientific, 
Waltham, MA, USA). cDNA synthesis was performed using the iScript cDNA Synthesis kit (Biorad, Veenendaal, The Netherlands) starting with $1 \mu \mathrm{g}$ of RNA. cDNA was diluted $25 x$ in RNase free water. Real-time PCR was performed using the MyiQ Single Color RTPCR detection system (Biorad) using Sensimix Sybr Green (Quantace, London, UK), $5 \mu l$ diluted cDNA and $0.3 \mu \mathrm{M}$ primers (Table 4.1 ) in a total volume of $25 \mu \mathrm{l}$. Samples were amplified under the following conditions: $95^{\circ} \mathrm{C}$ for 3 minutes, followed by 40 cycles of $95^{\circ} \mathrm{C}$ for 15 second and $60^{\circ} \mathrm{C}$ for 45 seconds. PCR was checked for a-specific products by performing a melting curve analysis $\left(65^{\circ} \mathrm{C}-95^{\circ} \mathrm{C}\right)$. Data were analyzed using the MyiQ Software system (Biorad) and were expressed as relative gene expression (fold increase) using the $2^{-\Delta \Delta C t}$ method. The stably expressed gene cyclophilin A was included as reference.

Table 4.1: Primer sequences for real time RT-PCR

\begin{tabular}{lll}
\hline Gene & Forward primer $\left(5^{\prime}-3^{\prime}\right)$ & Reverse primer $\left(5^{\prime}\right.$ - $\left.^{\prime}\right)$ \\
\hline Cyclophilin A & TTCCTGCTTTCACAGAATTATTCC & GCCACCAGTGCCATTATGG \\
CYP1A1 & TCCTGGAGACCTTCCGACACT & CTTTCAAACTTGTGTCTCTTGTTGTG \\
CYP1B1 & AGTGCAGGCAGAATTGGATCA & GCGCATGGCTTCATAAAGGA \\
XPA & CCGACAGGAAAACCGAGAAA & TTCCACACGCTGCTTCTTACTG \\
XPC & CCCAGCCCGCTTTACCA & TGCATTAACTGTAAATGTTCCAATGA \\
ERCC4 & CACCTCCCTCGCCGTGTA & CGCAAATATAACACCACCTTGTG \\
ERCC5 & GCATGAAATCTTGACTGATATGAAAGA & TAAGCAAGCCTTTGAGTTGGTACTG \\
ERCC1 & ACCCCTCGACGAGGATGAG & CAGTGGGAAGGCTCTGTGTAGA \\
GSTP1 & CTCAAAAGGCTTCAGTTGCC & ACCTCCGCTGCAAATACATC \\
EPHX1 & CTTCACGTGGATGAAGTGGA & CTGGCGGAATGATTTGACT \\
UGT1A6 & GGAACCCGACCATCGAATC & TCGGGTGACCAAGCAGATC \\
UGT2B7 & TCCCATCAAATCTCCACAGA & GGTGTTTTCTCTGGGGTCAA \\
\hline
\end{tabular}

\section{DNA isolation}

Cells were harvested and resuspended in $400 \mu \mathrm{L}$ SET/SDS $(100 \mathrm{mM} \mathrm{NaCl}, 20 \mathrm{mM}$ EDTA, $50 \mathrm{mM}$ Tris, $0.5 \%$ SDS) and incubated at $37^{\circ} \mathrm{C}$ for 2 hours. $50 \mu \mathrm{L}$ of DNAse-free RNAsesolution (RNAse A $(0.1 \mathrm{mg} / \mathrm{mL})$ and RNAse T1 $(1000 \mathrm{U} / \mathrm{mL})$ in SET, incubated at $80^{\circ} \mathrm{C}$ for 5 minutes) was added and samples were incubated at $37^{\circ} \mathrm{C}$ for 1 hour followed by adding $50 \mu \mathrm{L}$ DNAse-free proteinase $\mathrm{K}\left(10 \mathrm{mg} / \mathrm{mL}\right.$ in SET-SDS, heat-inactivated at $37^{\circ} \mathrm{C}$ for 30 minutes) and samples were incubated overnight at $37^{\circ} \mathrm{C}$. After addition of $500 \mu \mathrm{L}$ phenol/chloroform/Isoamylalcohol (25:24:1), samples were rotated for 5 minutes and centrifuged for 5 minutes at 14000rpm. To the upperphase, $500 \mu \mathrm{L}$ chloroform/Isoamylalcohol (24:1) was added and samples were 5 minutes rotated, centrifuged for 5 minutes (14000rpm) and 1/30 volume NaAc (3M, pH 5.2) was added to the upperphase. Samples were mixed for a few seconds and two volumes ethanol $100 \%\left(4^{\circ} \mathrm{C}\right)$ were added, samples were mixed and incubated at $-20^{\circ} \mathrm{C}$ for 30 minutes. Samples were centrifuged for 5 minutes and DNA pellets were washed with ethanol $70 \%$. DNA pellets were dried and resuspended in Mili-Q $\mathrm{H}_{2} \mathrm{O}$. The quantity and quality of DNA was measured using the Nanodrop 1000. 


\section{${ }^{32}$ P-postlabeling of BPDE-DNA adducts}

DNA adduct levels were determined according to the nuclease P1 enrichment technique originally described by Reddy and Randerath (22) with the modifications described by Godschalk et al. (23). In all experiments, three BPDE-DNA standards with known BPDE-DNA adduct levels (one adduct per $10^{6}, 10^{7}$, and $10^{8}$ normal nucleotides) were analyzed in parallel for quantification purposes. Adducts spots in DNA from BaP treated RCC4 cells that chromatographed at the same position as the BPDE-DNA adducts standards were considered to be derived from BPDE, and were quantified using Phosphor-Imaging technology (Fujifilm FLA-3000, Rotterdam, The Netherlands).

\section{HPLC}

In order to determine BaP-metabolite composition, $4 \mathrm{ml}$ medium was extracted with $1 \mathrm{ml}$ ethyl acetate after addition of $1 \mathrm{ml} 3 \mathrm{M} \mathrm{NaCl}$. Samples were vortexed for 10 minutes, centrifuged for 5 minutes at 1000rpm and after briefly vortexing, centrifuged again for 10 minutes at 1500 rpm. The ethyl acetate fraction was collected and the extraction step was repeated twice. The second time and third time, only ethyl acetate was added and the third time, also two droplets of ethanol were added to the samples for better separation. The ethyl acetate fractions were combined, evaporated to dryness under $\mathrm{N}_{2}$, and residues were resuspended in $0.5 \mathrm{ml}$ methanol. For chromatographic separation, a $50 \mu$ l volume of the sample was injected onto a Hypersil $5 \mu \mathrm{m}$ ODS HPLC column (250x3mm i.d.) (Supelco 54933, Bellefonte, PA, USA) at a flow rate of $0.5 \mathrm{ml} / \mathrm{min}$. Mobile phase $A$ and $B$ were $100 \%$ methanol (Biosolve Chemicals, Valkenswaard, The Netherlands) and $40 \%$ methanol in water, respectively. The time program for the multi-step gradient was: 0-5min: isocratically 40/60 (A/B, v/v), 530min: gradient from $40 / 60(A / B, v / v)$ to $90 / 10(A / B, v / v), 30-35 \mathrm{~min}$ : isocratically 90/10 (A/B, v/v), 35-37min: gradient from 90/10 (A/B, v/v) to 40/60 (A/B, v/v), 3740min: $40 / 60(A / B, v / v)$. The total run time was 40 minutes. For quantitation purposes, a standard mix consisting of 50ng/ml BaP-9,10-diOH, 50ng/ml BaP-7,8-diOH, and $50 \mathrm{ng} / \mathrm{ml} 3-\mathrm{OH}$ BaP (Midwest Research Institute, Kansas City, Missouri, USA) was used. Samples were analyzed on a Gynkotek P580A HPLC system (Separations Analytical Instruments, Hendrik Ido Ambacht, The Netherlands) with a Spark SP830 autosampler (Spark Holland, Emmen, The Netherlands) and a Perkin Elmer LS-30 programmable fluorescence detector (Perkin Elmer, Foster City, CA, USA). Excitation/emission wavelengths were $257 />350 \mathrm{~nm}$. For quantification, the area of each metabolite peak on the chromatogram was determined.

\section{Measurement of repair capacity}

To assess NER capacity in the liver samples, we applied a well characterized and validated modified comet assay (24). This assay measures the ability of NER-related enzymes that are present in cell extracts, to incise substrate DNA containing BPDE-DNA adducts. The substrate nucleoids were prepared from untreated A549 cells (human epithelial lung carcinoma cells) obtained from the American Tissue Culture Collection (ATCC, Rockville, MD, USA). The cells were cultured in DMEM supplemented with $10 \%$ heat-inactivated FCS and $1 \%$ penicillin/streptomycin and maintained at $37^{\circ} \mathrm{C}$ in a $5 \%$ 
$\mathrm{CO}_{2}$ atmosphere. A549 cells were embedded in LMP agarose on glass microscope slides and subsequently lyses overnight in cold $\left(4^{\circ} \mathrm{C}\right)$ lysis buffer $(2.5 \mathrm{M} \mathrm{NaCl}, 0.1 \mathrm{M}$ EDTA, $0.01 \mathrm{M}$ Tris, $0.25 \mathrm{M} \mathrm{NaOH}$ plus $1 \%$ Triton $\mathrm{X}-100$ and $10 \% \mathrm{DMSO}$ ). The resulting nucleoids were then either exposed to $1 \mu \mathrm{M}$ BPDE ( $\mathrm{NCl}$ Chemical Carcinogen Reference Standard Repository, Midwest Research Institute, Kansas City, MO, USA) in PBS or vehicle control (DMSO, $0.5 \%$ ) for 30 minutes at $4^{\circ} \mathrm{C}$. To prepare protein/enzyme extracts, RCC4 and RCC4-VHL cells were harvested and resuspended in buffer A $(45 \mathrm{mM}$ HEPES, $0.4 \mathrm{M} \mathrm{KCl}, 1 \mathrm{mM}$ EDTA, $0.1 \mathrm{mM}$ dithiothreitol, $10 \%$ glycerol, adjusted to $\mathrm{pH} 7.8$ using $\mathrm{KOH}$ ). Resulting aliquots were snap-frozen, thawed again and $30 \mu \mathrm{l}$ of $1 \%$ Triton $\mathrm{X}-100$ in buffer A per $100 \mu \mathrm{l}$ of extract was added. Protein concentrations were determined by the BioRAD DC protein assay using bovine serum albumin as a standard. Tissue extracts were diluted to a concentration of $1 \mathrm{mg} / \mathrm{ml}$. Next, 4 volumes of reaction buffer B (45mM HEPES, $0.25 \mathrm{mM}$ EDTA, $2 \%$ glycerol, $0.3 \mathrm{mg} / \mathrm{ml}$ BSA, adjusted to $\mathrm{pH} 7.8$ with $\mathrm{KOH}$ ) were added and $50 \mu \mathrm{l}$ of the mixture was added to the gel-embedded nucleoids and incubated for 20 minutes at $37^{\circ} \mathrm{C}$. Alkaline treatment ( 40 minutes) and electrophoresis (30 minutes) were conducted as described in the standard comet assay (25). Comets were visualized using a Zeiss Axioskop fluorescence microscope and quantified as tail moment. Samples were tested in two independent incubations within each single experiment. On every slide, 50 cells were analyzed randomly using the Comet assay III software program (Perspective Instruments, Haverhill, UK). The increased DNA strand breakage (tail moment) in the BPDE-modified nucleoids vs. the DMSO-treated nucleoids is indicative for the NER capacity of the cell extracts. The final repair capacity was calculated according to Langie et al.(24).

\section{Statistical analysis}

Results are expressed as the mean \pm standard error of the mean. GraphPad Prism 4 was used for statistical analysis. A two-way analysis of variance (ANOVA) with Bonferroni post-hoc multiple comparison correction was used to assess differences in mRNA levels. To analyze differences in metabolite levels, adduct levels, and repair capacity a t-test was used. Differences were considered to be statistically significant when $\mathrm{p}<0.05$.

\section{Results}

BPDE-DNA adduct levels are higher in cells deficient in VHL

To examine the influence of VHL deletion on BaP-mediated genotoxic responses, we quantified the amount of BPDE-DNA adducts in VHL deficient RCC4 cells and compared it with the genetically wild type RCC4-VHL cells, and normalized it to the total amount of DNA (Figure 4.1). Exposure to $0.1 \mu \mathrm{M} \mathrm{BaP}$ resulted in $a \approx 1.7$ fold higher induced formation of pro-mutagenic BPDE-DNA adduct levels in RCC4 cells, compared to RCC4VHL cells $(p<0.05)$. To our knowledge, this is the first demonstration of enhanced carcinogen activity in VHL deficient RCC cells. 


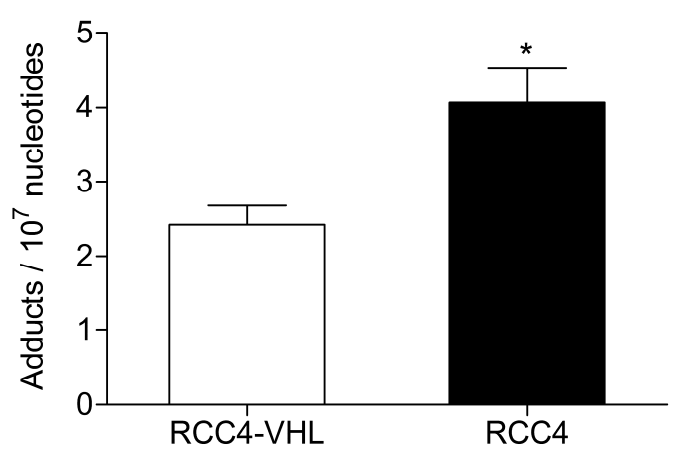

Figure 4.1: BPDE-DNA adduct levels are higher in cells deficient in VHL. RCC4-VHL and RCC4 cells were incubated with $0.1 \mu \mathrm{M}$ BaP. DNA was isolated after 18 hours and BPDE-DNA adduct levels were measured by ${ }^{32}$ P-postlabeling. Data $(n=4)$ are presented as mean adduct level per $10^{7}$ nucleotides \pm standard error $\left({ }^{*} p<0.05\right)$

Cells deficient in VHL have changes gene expression of metabolic enzymes

To determine whether metabolism may be the underlying cause of the increase in BPDE-DNA adducts in cells deficient in VHL, we assessed the mRNA expression of several key phase I and II metabolic enzymes (Figure 4.2). Of the phase I enzymes responsible for the activation of $\mathrm{BaP}, \mathrm{CYP} 1 \mathrm{~A} 1 \mathrm{mRNA}$ levels significantly differs between the two cell lines (Figure $4.2 \mathrm{~A}$ ). The CYP1A1 mRNA levels were $\approx 31$ times and $\approx 5.8$ times higher in the RCC4 cells compared to the RCC4-VHL cells $(p<0.01)$, for untreated and $\mathrm{BaP}$ treated cells, respectively. CYP1B1 gene expression was not statistically different between the two cell lines (Figure 4.2B). Gene expression of four phase II enzymes responsible for the conjugation of $\mathrm{BaP}$ metabolites was alsomeasured (Figure 4.3). The expression of the glutathione S-transferases GSTP1 was $\approx 24 \%$ lower in RCC4 cells compared to RCC4-VHL cells ( $p<0.05$, Figure 4.3A). Epoxide hydrolase 1 (Figure $4.3 \mathrm{~B}$ ) and the UDP glucuronosyltransferases UGT1A6 (Figure 4.3C) showed no difference between the two cell lines. Conversely, UGT2B7 was $\approx 1.5$ and $\approx 1.6$ times higher (DMSO and BaP treatment respectively) in RCC4 cells compared to the RCC4$\mathrm{VHL}$ cells (Figure 4.3D). This induction in gene expression of the BaP activating enzyme
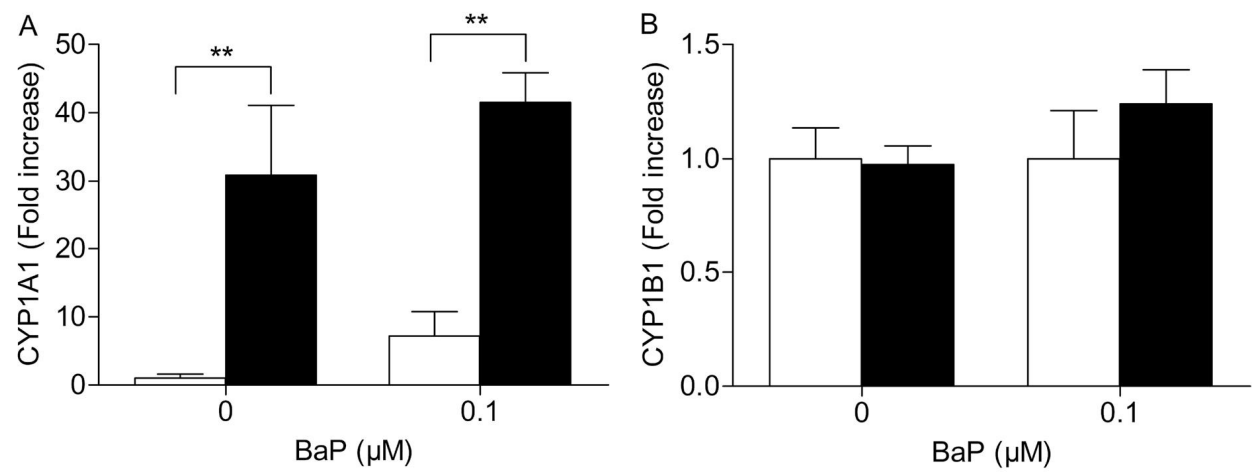

Figure 4.2: CYP1A1, but not CYP1B1 mRNA expression is markedly enhanced in VHL defective cells. RCC4-VHL ( $\square$ ) and RCC4 cells ( $\square$ ) were incubated with DMSO or $0.1 \mu \mathrm{M}$ BaP for 18 hours. RNA was isolated and mRNA levels were measured of A. CYP1A1 and B. CYP1B1. Data $(n=4)$ are presented as mean fold change \pm standard error $(* * p<0.01)$ 
CYP1A1 and the unchanged or small increased gene expression of the detoxifying genes in the absence of VHL suggests that metabolism is directed towards an increased activation of BaP
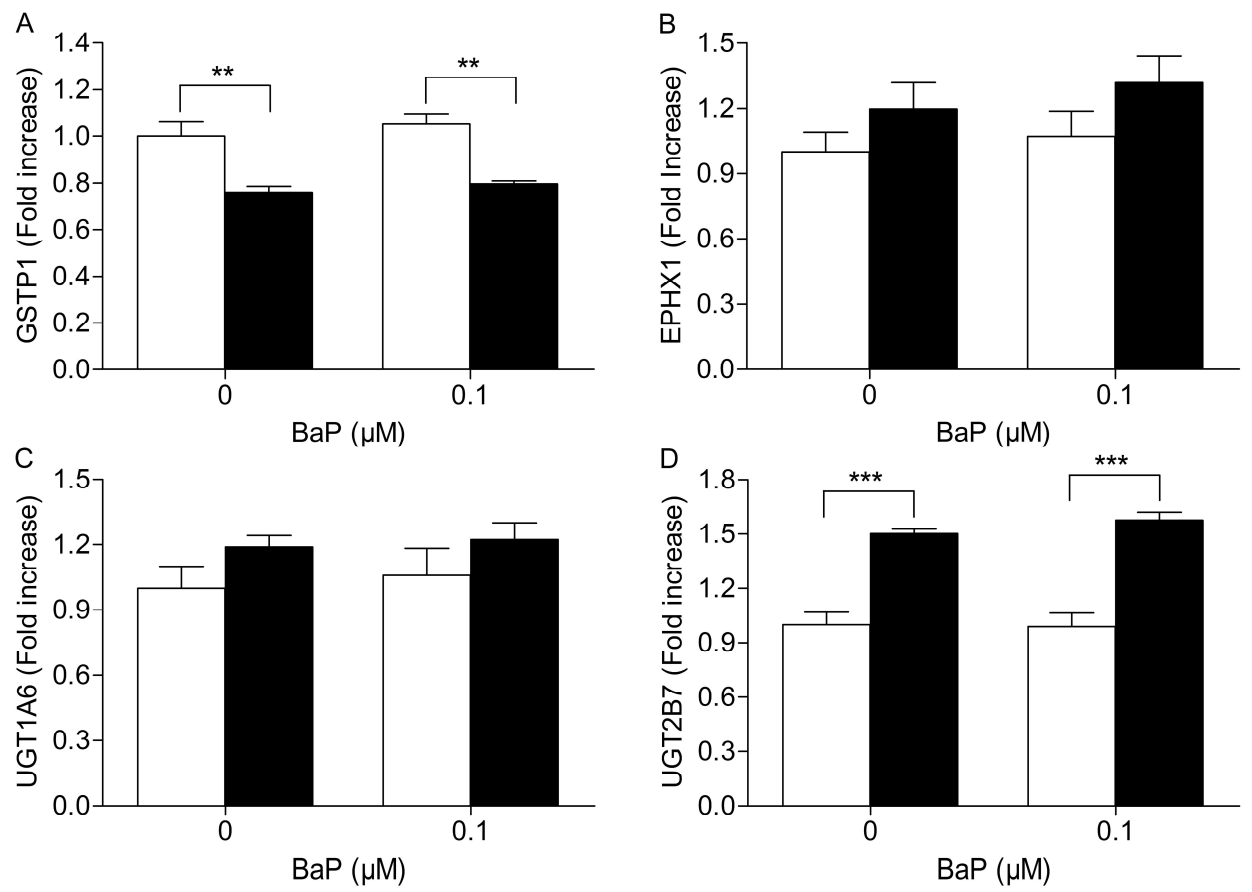

Figure 4.3: Loss of VHL increases UGT2B7, but decreases GSTP1 gene expression. RCC4-VHL ( $\square$ ) and RCC4 cells $(\mathbf{-})$ were incubated with DMSO or $0.1 \mu \mathrm{M} \mathrm{BaP}$ for 18 hours. RNA was isolated and mRNA levels were measured of A. GSTP1, B. EPHX1, C. UGT1A6, and D. UGT2B7. Data $(n=4)$ are presented as mean fold change \pm standard error $(* * p<0.01, * * * p<0.001)$

\section{Absence of VHL in cells directs BaP metabolism toward unfavorable activation}

To determine whether the observed differences in BaP metabolic enzymes between the two cell lines resulted in the expected detrimental changes in BaP metabolism, we assessed $\mathrm{BaP}$ and its metabolites $\mathrm{BaP}-9,10-\mathrm{diOH}, \mathrm{BaP}-7.8-\mathrm{diOH}$ and 3-OH BaP by HPLC analysis with fluorescence detection (Figure 4.4). RCC4 and RCC4-VHL were exposed for 18 hours to $0.1 \mu \mathrm{M} \mathrm{BaP}$ and the medium was collected. The rate of metabolism was determined from measuring the remaining amount of unmetabolized BaP. In the medium, a non-statistically significant $\approx 2$ fold higher level of BaP was measured in the RCC4 cells compared to the control RCC4-VHL cells (Figure 4.4A). For all three metabolites assessed, statistically significant higher levels of metabolites were found in the medium of the RCC4 cells compared to the RCC4-VHL cells. A $\approx 1.7$ and $\approx 2.7$ fold induction of $\mathrm{BaP}-9,10-\mathrm{diOH}$ and $3-\mathrm{OH} \mathrm{BaP}$, respectively, was observed in RCC4 cells compared to RCC4-VHL cells (Figure 4.4B and C). Furthermore, compared to RCC4-VHL cells, BaP-7,8-diOH levels, the BPDE precursor, were $\approx 2.9$ times higher in RCC4 cells (Figure 4.4D), suggesting an increased opportunity for the formation of BPDE-DNA adducts. 

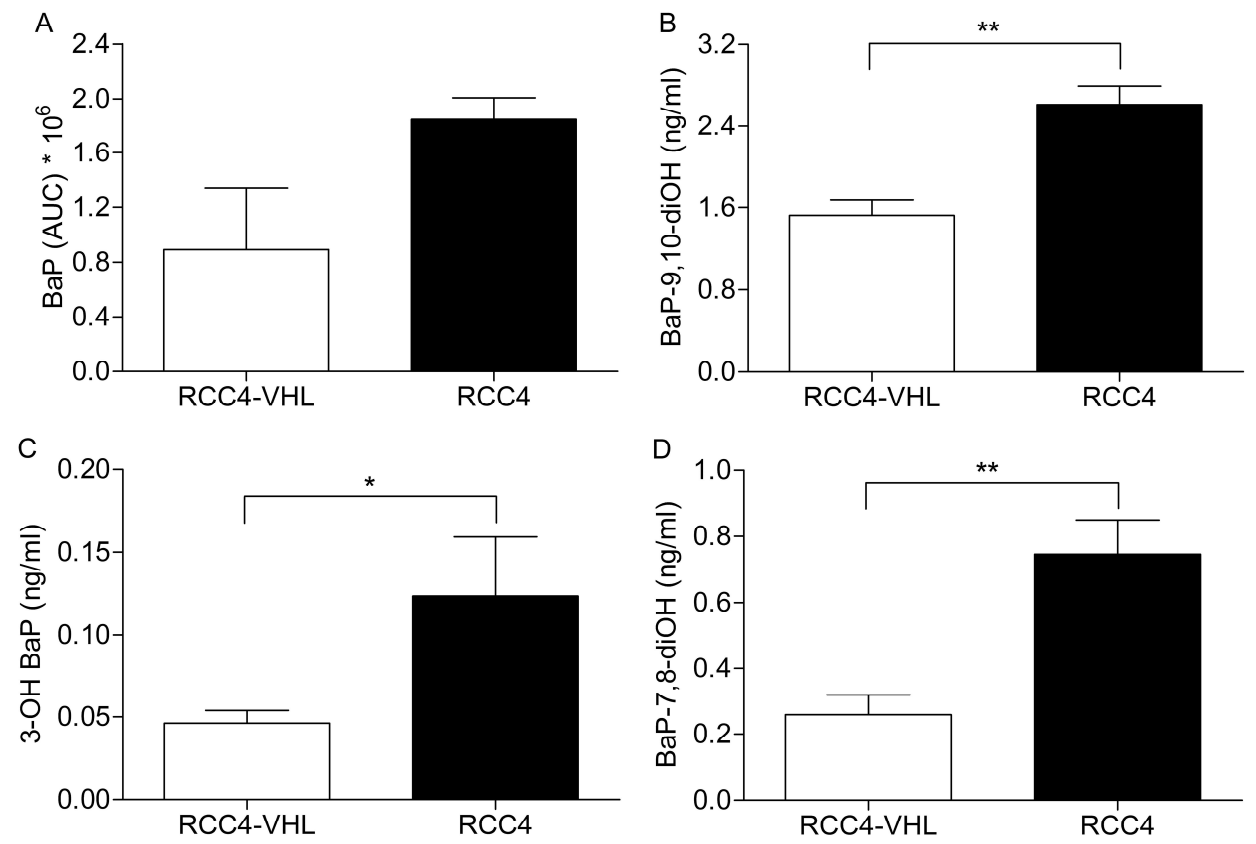

Figure 4.4: Absence of VHL decreased BaP metabolism, but increased BaP metabolites. RCC4VHL ( $\square$ ) and RCC4 cells ( $\square$ ) were incubated with $0.1 \mu \mathrm{M}$ BaP for 18 hours and extracellular unmetabolized BaP (A), BaP-9,10-diOH (B), BaP-7,8-diOH (C), and 3-OH BaP (D) metabolites were measured. Data $(n=5)$ are presented as mean area under the curve \pm standard error $(* p<0.05$, $* * p<0.01)$

Table 4.2: Relative NER gene expression

\begin{tabular}{lllllll}
\hline BaP & & XPA & XPC & ERCC4 & ERCC5 & ERCC1 \\
\hline \multirow{2}{*}{$0 \mu \mathrm{M}$} & RCC4-VHL & $1.00 \pm 0.02$ & $1.00 \pm 0.14$ & $1.00 \pm 0.08$ & $1.00 \pm 0.10$ & $1.00 \pm 0.09$ \\
& RCC4 & $0.94 \pm 0.05$ & $0.98 \pm 0.12$ & $0.98 \pm 0.03$ & $1.16 \pm 0.11$ & $1.09 \pm 0.06$ \\
\multirow{2}{*}{$0.1 \mu \mathrm{M}$} & RCC4-VHL & $1.02 \pm 0.04$ & $1.04 \pm 0.16$ & $0.95 \pm 0.08$ & $0.98 \pm 0.08$ & $1.01 \pm 0.02$ \\
& RCC4 & $1.15 \pm 0.05$ & $1.17 \pm 0.19$ & $0.89 \pm 0.02$ & $1.21 \pm 0.12$ & $1.17 \pm 0.09$ \\
\hline
\end{tabular}

Nucleotide excision repair capacity is reduced in VHL deficient cells

As we have previously reported a down regulation of NER capacity in HIF $\alpha$ stabilized cells, we sought to determine whether diminished DNA repair may also play a role in the observed differences in BPDE-DNA adduct level induction between the RCC4 and RCC4-VHL cells. Firstly, we determined the influence of DNA repair gene expression in the matched cells. The mRNA levels of the critical nucleotide excision repair genes XPA, XPC, ERCC1, ERCC5, and ERCC4 were not altered in the cell lines (Table 4.2). Secondly, as DNA repair is often not regulated at the transcription level, we used a validated modified comet assay to determine the functional NER capacity. Interestingly, a markedly reduced repair capacity was observed in the VHL deficient cells compared to the reconstituted RCC4-VHL cells (Figure 4.5). These results suggest that absence of $\mathrm{VHL}$ is indeed an important mechanism in influencing functional DNA repair. 


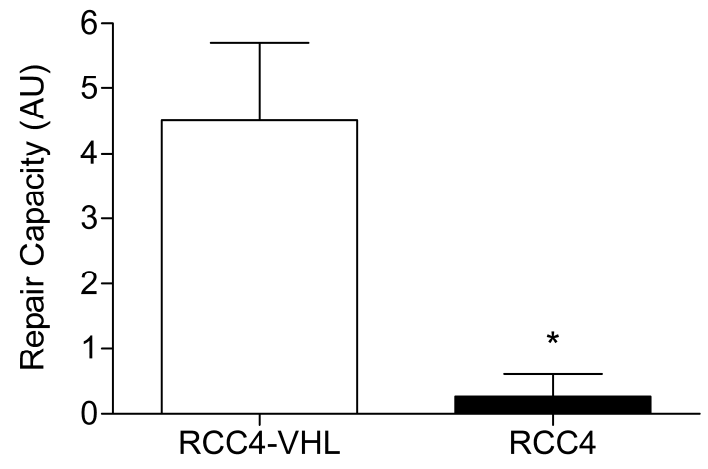

Figure 4.5: NER capacity is decreased in RCC4 cells. The ability to repair BPDE-DNA adducts in RCC4-VHL and RCC4 cells were measured using the modified comet assay (24). Data ( $n=4)$ are presented as mean fold change \pm standard error $(* p<0.05)$.

\section{Discussion}

Since the most frequent observed genetic alteration in RCC is the somatic mutation of the von Hippel-Lindau tumor suppressor gene, understanding how VHL-deficiency leads to genetic instability may prove to be invaluable. To this end, we sought to determine how VHL may impact the carcinogenic capacity of the important environmental carcinogen BaP. Previously we demonstrated that the stabilization of $\mathrm{HIF} \alpha$ by $\mathrm{CoCl}_{2}$ enhances the carcinogenic effect of $\mathrm{BaP}$ in lung cancer cells and reduced repair (21). Furthermore, we have demonstrated that the kinetics of carcinogen metabolism is altered under hypoxic conditions, resulting in a higher amount of BPDEDNA adducts being formed (Schults, M.A. et al, submitted for publication). The aim of the current study was to determine whether similar genetic instability mechanisms hold true in a naturally occurring VHL deficient RCC cells. In this report, we demonstrate that loss of VHL and presumably via the stabilization of HIF $\alpha$ affects both genetic stability related processes of BaP-mediated as well as DNA repair capacity in RCC cells.

Cytochrome P450 enzymatically converts BaP into the active metabolite BPDE, which subsequently binds covalently to DNA forming highly mutagenic DNA adducts (18). To investigate the effect of metabolically activated BaP on RCC4 cells, we focused on the formation of BPDE-DNA adducts. Interestingly, our data demonstrated that VHL deficiency resulted in increased BPDE-DNA adduct levels in RCC4 cells, compared to RCC4-VHL cells, when treated with $0.1 \mu \mathrm{M}$ BaP. This is in agreement with our previously observed results, where the formation of BPDE-DNA adducts was increased due to stabilization of $\mathrm{HIF} \alpha$ by $\mathrm{CoCl}_{2}$ in A549 cells. (21).

We have previously shown that HIF $\alpha$ stabilization by chemicals or reduced oxygen tension changes gene expression of important metabolic enzymes (Schults, M.A. et al, submitted for publication). Therefore, we assessed whether these changes in gene expression also occur in the VHL deficient RCC cells. CYP1A1 and CYP1B1 are two of the most important enzymes in the detoxification and bioactivation of BaP by adding an epoxide group to BaP. $(18,19)$. Furthermore, CYP1A1 is the critical enzyme in the bioactivation of BaP-7,8-diOH to the ultimate carcinogenic BPDE metabolites in human lung cell lines in vitro (26). In this study we demonstrate that CYP1A1 mRNA levels were strongly upregulated in the HIF $\alpha$ stabilized RCC4 cells compared to the 
reconstituted genetically wild type cells. As CYP1B1 mRNA levels were unaffected by VHL loss, CYP1A1 appears to be the critical player in RCC metabolism of BaP in these cells. Induction of CYP1A1 in HIF $\alpha$ stabilized cells may result in an increased level of BPDE formation which may subsequent induce carcinogenicity. This correlates with studies in other cell types where CYP1A1 activity has been positively correlated with pulmonary PAH (BPDE)-associated DNA adduction (27), and high CYP1A1 inducibility in lymphocytes has been related to a high lung cancer risk $(28,29)$.

The resulting BaP metabolites can be converted into hydrophilic products by phase II enzymes. Alterations in these conjugation reactions could result in changed elimination of these compounds and subsequently BPDE-DNA adducts level. No pattern was observed for phase II enzymes, suggesting that they are not likely involved in the observed different BPDE-DNA adduct levels identified between the two cell lines. Nevertheless, measuring BaP metabolites provides a better insight into differences in BaP metabolism between the two RCC4 cell lines. To this end, we focused on the formation of dihydrodiols and phenols; $\mathrm{BaP}-7,8-\mathrm{diOH}$ can be oxidized to BPDE, while BaP-,9,10-diOH leads to the formation of BaP-9,10-diol-7,8-epoxide, which is far less carcinogenic than BPDE, and 3-OH BaP, which is considered one of the major detoxification products. Most abundantly present in the media of both cell lines was $\mathrm{BaP}-9,10-\mathrm{diOH}$. We further observed that the raised levels of metabolites and in particular BaP-7,8-diOH correlates well with the observed increased DNA adducts levels. Together, these data indicate that VHL deficient RCC cells are able to differentially bioactivate BaP as compared to RCC4-VHL cells suggesting a plausible explanation for the increased DNA adduct formation in RCC4 cells.

The level of DNA adducts is influenced by the balance between the induction of the damage and its repair. Therefore, in addition to the formation of adducts, we further analyzed whether loss of VHL is able to affect NER since the bulk of adducts are removed by the NER pathway (30). Our data indicate that the loss of VHL had no effect on DNA repair gene expression. As DNA repair is often regulated in multiple manners in addition to transcriptional control, we sought to determine whether HIF $\alpha$ stabilization impairs overall functional NER. To this end, we used a previously validated modified comet assay, which predominantly assesses the cellular capacity in the recognition and incision phase of NER to remove bulky DNA adducts (24). Interestingly, a dramatically lower repair capacity was observed in the VHL deficient RCC4 cells. Reduced NER capacity under hypoxic conditions has been previously demonstrated in mouse fibroblasts (31) and in HIFa stabilized A549 cells (21). In the present study, we show for the first time that lack of VHL in cells also results in a decreased repair capacity. The reduced NER repair further explains the observed higher BPDE-DNA adduct levels in VHL deficient RCC cells.

In this study, we provide evidence that loss of VHL presumably via the stabilization of HIF affects the BPDE-DNA adduct levels in RCC cells and is in fact a double edged sword. Firstly, the absence of VHL is associated with induced CYP1A1 mRNA levels, which mediated a significant change in BaP-7,8-diOH levels among other metabolites. This could significantly induce the formation of BPDE-DNA adduct levels. Secondly, the capacity to repair DNA by NER is reduced in HIF $\alpha$ stabilized cells, thereby preventing the repair of those BPDE-DNA adducts. Taken together, these data indicate that loss of 
Loss of VHL in RCC increases BaP carcinogenicity

VHL increases carcinogen genotoxicity in renal cell carcinoma in-vitro and provides potential insight in the malignant progression into RCC. 


\section{Reference list}

1 Jemal, A., Siegel, R., Xu, J., and Ward, E. (2010) Cancer statistics, 2010. CA Cancer J Clin, 60, 277-300.

2 Cohen, H.T., and McGovern, F.J. (2005) Renal-cell carcinoma. N Engl J Med, 353, $2477-$ 2490.

3 Baldewijns, M.M., van Vlodrop, I.J., Vermeulen, P.B., Soetekouw, P.M., van Engeland, M., and de Bruine, A.P. (2010) VHL and HIF signalling in renal cell carcinogenesis. J Pathol, 221, 125-138.

4 Nyhan, M.J., O'Sullivan, G.C., and McKenna, S.L. (2008) Role of the VHL (von Hippel-Lindau) gene in renal cancer: a multifunctional tumour suppressor. Biochem Soc Trans, 36, 472478.

5 Jaakkola, P., Mole, D.R., Tian, Y.M., Wilson, M.I., Gielbert, J., Gaskell, S.J., Kriegsheim, A., Hebestreit, H.F., Mukherji, M., Schofield, C.J., Maxwell, P.H., Pugh, C.W., and Ratcliffe, P.J. (2001) Targeting of HIF-alpha to the von Hippel-Lindau ubiquitylation complex by O2regulated prolyl hydroxylation. Science, 292, 468-472.

6 Cockman, M.E., Masson, N., Mole, D.R., Jaakkola, P., Chang, G.W., Clifford, S.C., Maher, E.R., Pugh, C.W., Ratcliffe, P.J., and Maxwell, P.H. (2000) Hypoxia inducible factor-alpha binding and ubiquitylation by the von Hippel-Lindau tumor suppressor protein. $J$ Biol Chem, 275, 25733-25741.

7 Kallio, P.J., Wilson, W.J., O'Brien, S., Makino, Y., and Poellinger, L. (1999) Regulation of the hypoxia-inducible transcription factor 1alpha by the ubiquitin-proteasome pathway. J Biol Chem, 274, 6519-6525.

8 Wang, G.L., Jiang, B.H., Rue, E.A., and Semenza, G.L. (1995) Hypoxia-inducible factor 1 is a basic-helix-loop-helix-PAS heterodimer regulated by cellular $\mathrm{O} 2$ tension. Proc Natl Acad Sci U S A, 92, 5510-5514.

9 Semenza, G.L., Jiang, B.H., Leung, S.W., Passantino, R., Concordet, J.P., Maire, P., and Giallongo, A. (1996) Hypoxia response elements in the aldolase A, enolase 1, and lactate dehydrogenase $A$ gene promoters contain essential binding sites for hypoxia-inducible factor 1. J Biol Chem, 271, 32529-32537.

10 Kondo, K., Kim, W.Y., Lechpammer, M., and Kaelin, W.G., Jr. (2003) Inhibition of HIF2alpha is sufficient to suppress PVHL-defective tumor growth. PLOS Biol, 1, E83.

11 Raval, R.R., Lau, K.W., Tran, M.G., Sowter, H.M., Mandriota, S.J., Li, J.L., Pugh, C.W., Maxwell, P.H., Harris, A.L., and Ratcliffe, P.J. (2005) Contrasting properties of hypoxiainducible factor 1 (HIF-1) and HIF-2 in von Hippel-Lindau-associated renal cell carcinoma. Mol Cell Biol, 25, 5675-5686.

12 Wright, T.M., and Rathmell, W.K. (2010) Identification of Ror2 as a hypoxia-inducible factor target in von Hippel-Lindau-associated renal cell carcinoma. J Biol Chem, 285, 12916-12924.

13 Zhong, H., De Marzo, A.M., Laughner, E., Lim, M., Hilton, D.A., Zagzag, D., Buechler, P., Isaacs, W.B., Semenza, G.L., and Simons, J.W. (1999) Overexpression of hypoxia-inducible factor 1alpha in common human cancers and their metastases. Cancer Res, 59, 5830-5835.

14 Vaupel, P., and Mayer, A. (2007) Hypoxia in cancer: significance and impact on clinical outcome. Cancer Metastasis Rev, 26, 225-239.

15 Maxwell, P.H., Wiesener, M.S., Chang, G.W., Clifford, S.C., Vaux, E.C., Cockman, M.E., Wykoff, C.C., Pugh, C.W., Maher, E.R., and Ratcliffe, P.J. (1999) The tumour suppressor protein VHL targets hypoxia-inducible factors for oxygen-dependent proteolysis. Nature, 399, 271-275. 
16 Kallio, P.J., Pongratz, I., Gradin, K., McGuire, J., and Poellinger, L. (1997) Activation of hypoxia-inducible factor 1alpha: posttranscriptional regulation and conformational change by recruitment of the Arnt transcription factor. Proc Natl Acad Sci U S A, 94, 5667-5672.

17 Reyes, H., Reisz-Porszasz, S., and Hankinson, O. (1992) Identification of the Ah receptor nuclear translocator protein (Arnt) as a component of the DNA binding form of the Ah receptor. Science, 256, 1193-1195.

18 Gelboin, H.V. (1980) Benzo[alpha]pyrene metabolism, activation and carcinogenesis: role and regulation of mixed-function oxidases and related enzymes. Physiol Rev, 60, 11071166.

19 Baird, W.M., Hooven, L.A., and Mahadevan, B. (2005) Carcinogenic polycyclic aromatic hydrocarbon-DNA adducts and mechanism of action. Environ Mol Mutagen, 45, 106-114.

20 Pfeifer, G.P., Denissenko, M.F., Olivier, M., Tretyakova, N., Hecht, S.S., and Hainaut, P. (2002) Tobacco smoke carcinogens, DNA damage and p53 mutations in smokingassociated cancers. Oncogene, 21, 7435-7451.

21 Schults, M.A., Timmermans, L., Godschalk, R.W., Theys, J., Wouters, B.G., van Schooten, F.J., and Chiu, R.K. (2010) Diminished carcinogen detoxification is a novel mechanism for hypoxia-inducible factor 1-mediated genetic instability. J Biol Chem, 285, 14558-14564.

22 Reddy, M.V., and Randerath, K. (1986) Nuclease P1-mediated enhancement of sensitivity of 32P-postlabeling test for structurally diverse DNA adducts. Carcinogenesis, 7, 15431551.

23 Godschalk, R.W., Maas, L.M., Van Zandwijk, N., van 't Veer, L.J., Breedijk, A., Borm, P.J., Verhaert, J., Kleinjans, J.C., and van Schooten, F.J. (1998) Differences in aromatic-DNA adduct levels between alveolar macrophages and subpopulations of white blood cells from smokers. Carcinogenesis, 19, 819-825.

24 Langie, S.A., Knaapen, A.M., Brauers, K.J., van Berlo, D., van Schooten, F.J., and Godschalk, R.W. (2006) Development and validation of a modified comet assay to phenotypically assess nucleotide excision repair. Mutagenesis, 21, 153-158.

25 Knaapen, A.M., Schins, R.P., Borm, P.J., and van Schooten, F.J. (2005) Nitrite enhances neutrophil-induced DNA strand breakage in pulmonary epithelial cells by inhibition of myeloperoxidase. Carcinogenesis, 26, 1642-1648.

26 Uppstad, H., Ovrebo, S., Haugen, A., and Mollerup, S. (2010) Importance of CYP1A1 and CYP1B1 in bioactivation of benzo[a]pyrene in human lung cell lines. Toxicol Lett, 192, 221228.

27 Bartsch, H., Castegnaro, M., Rojas, M., Camus, A.M., Alexandrov, K., and Lang, M. (1992) Expression of pulmonary cytochrome P4501A1 and carcinogen DNA adduct formation in high risk subjects for tobacco-related lung cancer. Toxicol Lett, 64-65 Spec No, 477-483.

28 Kouri, R.E., McKinney, C.E., Slomiany, D.J., Snodgrass, D.R., Wray, N.P., and McLemore, T.L. (1982) Positive correlation between high aryl hydrocarbon hydroxylase activity and primary lung cancer as analyzed in cryopreserved lymphocytes. Cancer Res, 42, 5030-5037.

29 Kiyohara, C., Nakanishi, Y., Inutsuka, S., Takayama, K., Hara, N., Motohiro, A., Tanaka, K., Kono, S., and Hirohata, T. (1998) The relationship between CYP1A1 aryl hydrocarbon hydroxylase activity and lung cancer in a Japanese population. Pharmacogenetics, 8, 315323.

30 Friedberg, E.C. (2001) How nucleotide excision repair protects against cancer. Nat Rev Cancer, 1, 22-33.

31 Yuan, J., Narayanan, L., Rockwell, S., and Glazer, P.M. (2000) Diminished DNA repair and elevated mutagenesis in mammalian cells exposed to hypoxia and low pH. Cancer Res, 60, 4372-4376. 



\section{Chapter 5}

\section{Genetic polymorphisms in catalase and CYP1B1 determine DNA adduct formation by benzo[a]pyrene ex vivo}

Accepted in Mutagenesis

Marten A. Schults

Roland K. Chiu

Peter W. Nagle

Lonneke C. Wilms

Jos C. Kleinjans

Frederik J. van Schooten

Roger W. Godschalk 


\title{
Chapter 5
}

\begin{abstract}
Genetic polymorphisms can partially explain the large inter-individual variation in DNA adduct levels following exposure to polycyclic aromatic hydrocarbons. Effects of genetic polymorphisms on DNA adduct formation are difficult to assess in human studies, because exposure misclassification attenuates underlying relationships. Conversely, ex vivo studies offer the advantage of controlled exposure settings, allowing the possibility to better elucidate genotype-phenotype relationships and gene-gene interactions. Therefore, we exposed lymphocytes of 168 non-smoking volunteers ex vivo to the environmental pollutant benzo[a]pyrene (BaP) and $\mathrm{BaP}-7,8$ dihydrodiol-9,10-epoxide (BPDE)-DNA adducts were quantified. Thirty four genetic polymorphisms were assessed in genes involved in carcinogen metabolism, oxidative stress and DNA repair. Polymorphisms in catalase (CAT, rs1001179) and cytochrome P450 1B1 (CYP1B1, rs1800440) were significantly associated to DNA adduct levels, especially when combined. Moreover, RT-PCR analysis in a subset of 30 subjects revealed that expression of catalase correlated strongly with expression of CYP1B1 $(R=0.92, p<0.001)$. To further investigate the mechanism by which catalase influences CYP1B1 and how they simultaneously affect BPDE-DNA adduct levels, catalase expression was transiently knocked down in the human lung epithelial cell line A549. Although catalase knockdown did not immediately change CYP1B1 gene expression, recovery of catalase expression 8 hours after the knock-down, coincided with a 2.2fold increased expression of CYP1B1 $(p<0.05)$. We conclude that the genetic polymorphism in the promoter region of catalase may determine the amount and activity of catalase, which may subsequently regulate the expression of CYP1B1. As a result, both genetic polymorphisms modulate DNA adduct levels in lymphocytes by $\mathrm{BaP}$ ex vivo.
\end{abstract}




\section{Introduction}

Genetic stability is challenged by many factors, including exposure to genotoxic chemical compounds such as polycyclic aromatic hydrocarbons (PAHs). PAHs such as benzo(a)pyrene $(\mathrm{BaP})$ are widely distributed environmental contaminants that are able to up-regulate a multitude of genes, including the cytochrome P450 isoforms CYP1A1 and CYP1B1. These enzymes metabolize BaP to more soluble and excretable products, but at the same time activate certain metabolites into the highly reactive form BaP7,8-dihydrodiol-9,10-epoxide (BPDE) that is able to bind to DNA to form bulky DNA adducts. When unrepaired, DNA adducts can lead to mutations that initiate carcinogenesis. Therefore, bulky DNA adducts are markers for both exposure to genotoxic aromatic compounds and of the ability of the individual to metabolically activate carcinogens and to repair DNA damage (1). Nevertheless, individuals with similar exposures have highly different DNA adduct levels (2), which may in part be explained by genetic polymorphisms in genes involved in the process of DNA adduct formation and repair. These variations have been studied extensively and multiple genetic polymorphisms affecting BPDE-DNA adducts have been identified, including genes involved in metabolism; CYP1A1, GSTM1, GSTT1 (3-5), DNA repair; ERCC1, XPD (6), and oxidative stress (7).

We previously showed that single genetic polymorphisms are unable to adequately account for the inter-individual variation, but rather by combinations of relevant genetic polymorphisms and the level of exposure (8). The level of exposure is often insufficiently characterized in large epidemiological studies that investigate the impact of genetic variation on DNA damage or disease, leading to misclassification and attenuation of underlying relationships. On the other hand, exposure can be well controlled in in vitro or ex vivo studies, offering the possibility to elucidate genotypephenotype relationships and gene-gene interactions more reliably. Interestingly, the level of BPDE-DNA adduct formation ex vivo in lymphocytes was related to lung cancer risks (9), further offering support for using ex vivo experiments to investigate sources of inter-individual variation in cancer susceptibility. Therefore, lymphocytes of healthy volunteers were incubated with $1 \mu \mathrm{M}$ BaP for 18 hours. We assessed 34 SNPs based on a priori knowledge (10) and determined which SNPs were responsible for differences in BPDE-DNA adduct levels. One SNP in catalase (CAT, rs1001179) and one in CYP1B1 ( $r$ 1800440) had a significant impact on BPDE-DNA adduct formation and further experiments were performed to study genotype-phenotype relationships and genegene interactions in lung epithelial cells (A549) in which catalase was transiently knocked down by siRNA.

\section{Materials and methods}

\section{Study population}

The previously described study population consisted of 114 females and 54 males, aged 18-45 years (10). These healthy volunteers were recruited through advertisements in local newspapers and were non-smokers and did not use medication (except for oral contraceptives) or vitamin supplementation. Subjects were fully 
informed about the details of the study and gave their written informed consent. The Medical Ethical Committee of Maastricht University and the Academic Hospital Maastricht approved the protocol.

Table 5.1: List of SNPs, their position, amino acid change, and polymorphism frequencies.

\begin{tabular}{|c|c|c|c|c|c|}
\hline \multirow{2}{*}{$\begin{array}{l}\text { SNP } \\
\text { CYP1A2 } 1 F\end{array}$} & \multirow[t]{2}{*}{ Change } & \multirow{2}{*}{$\begin{array}{l}\text { SNP ID } \\
\text { rs762551 }\end{array}$} & \multicolumn{3}{|c|}{ Frequencies wt/hz/v* } \\
\hline & & & 86 & 69 & 13 \\
\hline GSTM1 ${ }^{*} 0$ & Deletion & & 90 & - & 78 \\
\hline GSTP1 $^{*} 2$ & I105V & rs947894 & 61 & 85 & 22 \\
\hline GSTP1 ${ }^{*} 3$ & A114V & rs1799811 & 140 & 28 & 0 \\
\hline GSTT1 ${ }^{*} 0$ & Deletion & & 139 & - & 29 \\
\hline NAT2 ${ }_{*}^{*}$ & I114T & rs1801280 & 66 & 76 & 26 \\
\hline NAT2 ${ }^{*} 6$ & R197Q & rs1799930 & 84 & 67 & 17 \\
\hline NAT2 $^{*} 7$ & G286E & rs1799931 & 161 & 7 & 0 \\
\hline $\mathrm{XRCC}^{*} 2$ & R194W & rs1799782 & 147 & 20 & 1 \\
\hline $\mathrm{XRCC}^{*} 3$ & $\mathrm{R} 280 \mathrm{H}$ & rs25489 & 142 & 25 & 1 \\
\hline $\mathrm{XRCC}^{*} 4$ & Q399R & rs25487 & 66 & 77 & 25 \\
\hline $\mathrm{XRCC}^{*} 1$ & $\mathrm{~T} 241 \mathrm{M}$ & rs861539 & 71 & 71 & 26 \\
\hline $\mathrm{XPD}^{*} 5$ & K751Q & rs1052559 & 27 & 85 & 56 \\
\hline $\mathrm{XPD}^{*} 6$ & R156 & rs238406 & 35 & 85 & 48 \\
\hline $\mathrm{OGG}^{*} 2$ & S326C & rs1052133 & 100 & 60 & 8 \\
\hline $\operatorname{BrCA} 2^{*} 1$ & & rs1799943 & 102 & 55 & 11 \\
\hline $\mathrm{BrCA} 2^{*} 3$ & $\mathrm{~N} 372 \mathrm{H}$ & rs144848 & 90 & 57 & 21 \\
\hline GPX $1^{*} 1$ & P198L & rs1050450 & 71 & 80 & 17 \\
\hline $\operatorname{APEX} 1^{*} 1$ & D148E & rs3136820 & 48 & 87 & 33 \\
\hline $\mathrm{mEH}^{*} 2$ & Y113H & rs1051740 & 79 & 77 & 12 \\
\hline $\mathrm{mEH}^{*} 3$ & H139R & rs2234922 & 105 & 55 & 8 \\
\hline CAT $^{*} 1$ & & rs1001179 & 104 & 48 & 16 \\
\hline $\mathrm{MnSOD}^{*}{ }^{*} 1$ & V16A & rs1799725 & 46 & 81 & 41 \\
\hline $\mathrm{NQO}^{*} 2$ & R139W & rs4986998 & 153 & 15 & 0 \\
\hline NQO1 $^{*}{ }^{1}$ & P187S & rs1800566 & 95 & 67 & 6 \\
\hline $\mathrm{CYP} \mathrm{A} 1^{*} 2 \mathrm{~A}$ & & rs5030838 & 145 & 22 & 1 \\
\hline CYP1A1 ${ }^{*} 2 \mathrm{C}$ & $1462 \mathrm{~V}$ & rs1048943 & 159 & 8 & 1 \\
\hline CYP1A1 ${ }^{*} 4$ & T461N & rs1799814 & 160 & 8 & 0 \\
\hline CYP1B1 ${ }^{*} 5$ & V432L & rs1056836 & 55 & 83 & 30 \\
\hline $\mathrm{CYP}^{2}{ }^{*}{ }^{*} 7$ & N453S & rs1800440 & 115 & 46 & 7 \\
\hline CYP2E1 ${ }^{*} 5$ & & rs6413420 & 151 & 16 & 1 \\
\hline CYP3A4 ${ }^{*} 1 \mathrm{~B}$ & & rs2740574 & 154 & 12 & 2 \\
\hline MPO & & rs2333227 & 94 & 64 & 10 \\
\hline COMT $^{*} 1$ & V158M & rs4680 & 41 & 84 & 43 \\
\hline
\end{tabular}

${ }^{*} \mathrm{wt}=$ homozygous wild-type, $\mathrm{hz}=$ heterozygous, $\mathrm{v}=$ homozygous variant. The numbers reflect the numbers of subjects carrying that genotype; a hyphen indicates that the method was not able to distinguish between heterozygous or homozygous wild-type (in case of a deletion), therefore both of these polymorphisms were combined under wt.

\section{Collection and treatment of samples}

Venous blood samples were collected between 8 and $9 \mathrm{AM}$ in $10 \mathrm{ml}$ vacuum lithium heparin tubes (venoject II, Terumo-Europe, Leuren, Belgium). For isolation of lymphocytes, heparinized blood was 1:1 diluted with phosphate-buffered saline (PBS, 
pH 7.4) and layered on Lymphoprep ${ }^{\mathrm{TM}}$ (Axis-shield, Oslo, Norway) in a leucosep tube (Greiner Bio-one, Frickenhausen, Germany). Lymphocytes were separated by 20 minutes $860 \mathrm{~g}$ centrifugation at room temperature and subsequently washed and treated with $25 \mu \mathrm{M}$ hydrogen peroxide for 1 hour at $37^{\circ} \mathrm{C}$ or $1 \mu \mathrm{M} \mathrm{BaP}$ for 18 hours at $37^{\circ} \mathrm{C}$ as described by Wilms et al (10).

\section{Comet assay}

Following incubation with hydrogen peroxide, cell suspensions were diluted 1:4 in $0.5 \%$ low melting point agarose and added to microscope slides pre-coated with a layer of $1.5 \%$ normal melting-point agarose and put at $4^{\circ} \mathrm{C}$ for 45 minutes. Cells were lysed $(0.25 \mathrm{M} \mathrm{NaOH}, 0.1 \mathrm{M}$ EDTA, $0.01 \mathrm{M}$ Tris, $2.5 \mathrm{M} \mathrm{NaCl}, 1 \%$ Triton X-100 and $10 \%$ DMSO, adjusted to $\mathrm{pH} 10$ ) for 1 hour at $4^{\circ} \mathrm{C}$, washed with $\mathrm{PBS}$, placed in electrophoresis buffer (1mM EDTA, 300mM NaOH, pH 13) for 40 minutes for denaturation, and subsequently separated by electrophoresis for 30 minutes at $25 \mathrm{~V}$ and $300 \mathrm{~mA}$. The slides were washed twice with PBS for 10 minutes and stained with ethidium bromide $(10 \mu \mathrm{g} / \mathrm{ml})$ and visualized using a Zeiss Axioskop fluorescence microscope. 50 randomly selected nuclei were analyzed per slide using the Comet assay III software program (Perceptive Instruments, Havervill, UK).

\section{Genotyping}

DNA was isolated from lymphocytes by standard phenol extraction procedures. The Cancer SNP 500 database was used to obtain DNA sequences and allele frequencies (http://snp500cancer.nci.nih.gov) of 34 SNPs (Table 5.1). SNPs were analyzed using a multiplex polymerase chain reaction method developed by Knaapen et al. (11) and further refined by Ketelslegers et al. (8).

\section{${ }^{32}$ P-postlabeling of BPDE-DNA adducts}

DNA adduct levels were determined according to the nuclease P1 enrichment technique originally reported by Reddy and Randerath (12) with the modifications described by Godschalk et al (13). Three BPDE-DNA standards with known BPDE-DNA adduct levels were analyzed in parallel for quantification purposes. Adducts spots that chromatographed at the same position as the BPDE-DNA adducts standards were considered to be derived from BPDE, and were quantified using Phosphor-Imaging technology (Fujifilm FLA-3000, Rotterdam, The Netherlands).

\section{Cell culture and siRNA transfection}

The human epithelial lung carcinoma cell line A549 obtained from the American Tissue Culture Collection (ATCC, Rockville, MD, USA) were cultured in DMEM (Sigma, St. Louis, MO, USA), supplemented with $10 \%$ heat inactivated fetal calf serum (FCS, Invitrogen, Breda, The Netherlands) and $1 \%$ penicillin/streptomycin (Sigma), and maintained at $37^{\circ} \mathrm{C}$ in a $5 \% \mathrm{CO}_{2}$ atmosphere. Cells were seeded at $10 \%$ confluence one day before treatment in antibiotic free medium and maintained at $37^{\circ} \mathrm{C}$ in a $5 \% \mathrm{CO}_{2}$ atmosphere. Cells were transfected with $10 \mathrm{nM}$ siGENOME SMARTpool siRNA specific for human catalase (Dharmacon, Lafayette, CO, USA) using DharmaFECT (Dharmacon). The 
transfections were performed according to manufacturer's instructions. After 24 hours, the medium was removed and replaced with regular culture medium for a further 8 hours.

\section{Real-Time Quantitative PCR}

RNA for real-time quantitative PCR was isolated from lymphocytes or A549 cells by standard phenol extraction procedures. The RNA samples were spectrophotometrically quantified using Nanodrop 1000 (Thermo Scientific, Waltham, MA, USA). cDNA synthesis was performed using the iScript cDNA Synthesis kit (Biorad, Veenendaal, The Netherlands) starting with $1 \mu \mathrm{g}$ of RNA. The generated cDNA was diluted 25x in RNase free water. Real-time PCR was performed using the MyiQ Single Color RT-PCR detection system (Biorad) and Sensimix Sybr Green (Quantace, London, UK). $5 \mu$ l diluted CDNA and $0.3 \mu \mathrm{M}$ primers (Table 5.2) in a total volume of $25 \mu \mathrm{l}$ were used. Samples were amplified under the following conditions: $95^{\circ} \mathrm{C}$ for 3 minutes, followed by 40 cycles of $95^{\circ} \mathrm{C}$ for 15 second and $60^{\circ} \mathrm{C}$ for 45 seconds. The PCR was checked for nonspecific products by performing a melting curve analysis $\left(65^{\circ} \mathrm{C}-95^{\circ} \mathrm{C}\right)$. Data were analyzed using the MyiQ Software system (Biorad) and were expressed as relative gene expression (fold increase) using the $2^{-\Delta \Delta C t}$ method. The stably expressed gene, $\beta$-actin was included as reference.

Table 5.2: Primer sequences for real time RT-PCR

\begin{tabular}{lll}
\hline Gene & Forward primer $\left(5^{\prime}-3^{\prime}\right)$ & Reverse primer $\left(5^{\prime}-3^{\prime}\right)$ \\
\hline Actin & CCTGGCACCCAGCACAAT & GCCGATCCACACGGAGTACT \\
Catalase & GACTGACCAGGGCATCAAAAA & CGGATGCCATAGTCAGGATCTT \\
CYP1B1 & AGTGCAGGCAGAATTGGATCA & GCGCATGGCTTCATAAAGGA \\
NQ01 & GGTGGAGTCGGACCTCTATGC & CCTTCAGTTTACCTGTGATGTCCTT \\
\hline
\end{tabular}

\section{Statistical analysis}

Results are expressed as means \pm standard error of the mean. SPSS was used for statistical analysis. BPDE-DNA adducts were not normally distributed and were therefore log-transformed before statistical analysis. To examine differences between the three groups of polymorphic genotypes (i.e. homozygous wildtype, heterozygotes and homozygous variant), a one-way analysis of variance test with Bonferroni post-hoc multiple comparison correction was used. Linear regression was used to assess relations. The two-way analysis of variance test with Bonferroni post-hoc multiple comparison correction was used to examine the effect of catalase knockdown. Differences were considered to be statistically significant when $p<0.05$.

\section{Results}

SNPs in CYP1B1 and catalase are linked to ex vivo BPDE-DNA adducts formation

Of the 34 SNPs we obtained (Table 5.1); only two were related to BPDE-DNA adduct levels ex vivo. These were the polymorphisms in CYP1B1 ( $\mathrm{s} 1800440$ ) and catalase (rs1001179). Individuals carrying one or both variant allele of CYP1B1-N453S showed a statistically significant lower amount of BPDE-DNA adducts compared to individuals 
that were homozygous for the wild-type allele (Figure 5.1A). Individuals carrying one or both variant alleles of CAT $-262 \mathrm{C} / \mathrm{T}$ had higher levels of BPDE-DNA adducts compared to individuals that were homozygous for the wild-type allele (Figure 5.1B). Lowest BPDE-DNA adduct levels were observed in subjects that carried the combined homozygous CYP1B1 variant alleles and the homozygous wild type alleles for CAT.
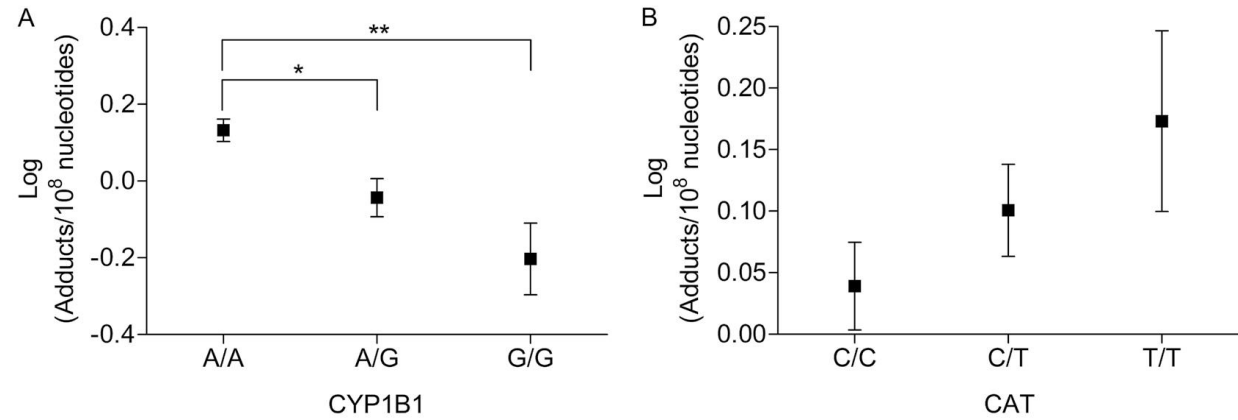

Figure 5.1: Modulation of ex vivo induced BPDE-DNA adduct levels by SNPs in catalase and CYP1B1. Lymphocytes of 166 volunteers were incubated with $1 \mu \mathrm{M}$ BaP for 18 hours and DNA adducts were measured using ${ }^{32} \mathrm{P}$-postlabeling. The effect of the A. CYP1B1-N453S polymorphism and the B. CAT $-262 \mathrm{C} / \mathrm{T}$ polymorphism on BPDE-DNA adduct formation was determined. DNA adduct data were log transformed and presented as mean \pm S.E. $(n=167$ $* p<0.05, * * p<0.01)$

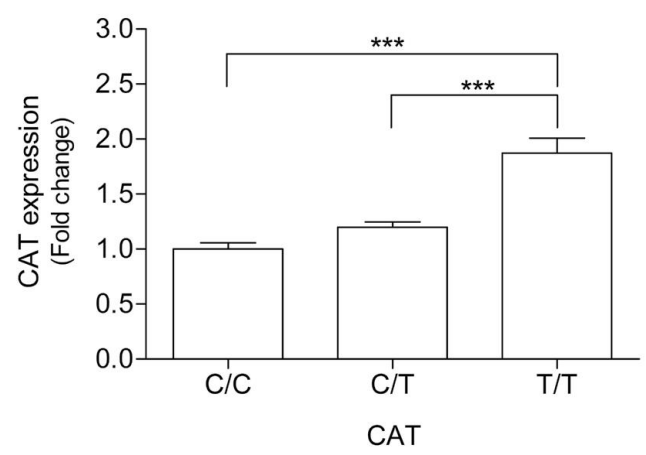

Figure 5.2: SNP in the promoter region of catalase affects CAT expression. The effect of the CAT $-262 \mathrm{C} / \mathrm{T}$ polymorphism on catalase gene expression was determined in unexposed lymphocytes. Data are presented as fold increase compared to the $\mathrm{C} / \mathrm{C}$ genotype. $(n=30,10$ in each group, $* * * p<0.001)$

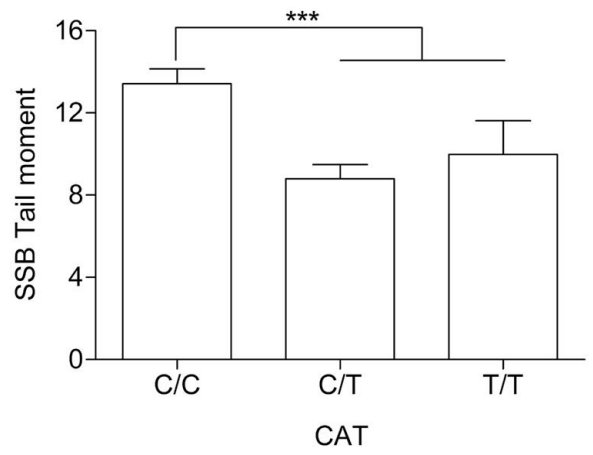

Figure 5.3: CAT polymorphism reduces $\mathrm{H}_{2} \mathrm{O}_{2}$ induced single strand breaks. The effect of CAT -262 C/T polymorphism on catalase gene expression was determined in unexposed lymphocytes. Lymphocytes were incubated with $25 \mu \mathrm{M} \mathrm{H}_{2} \mathrm{O}_{2}$ for 1 hour and single strand breaks were measured using the comet assay. Data are presented as mean \pm S.E. $(\mathrm{n}=135 * * * \mathrm{p}<0.001)$ 
Phenotypic effect of SNP in promoter region of CAT

As the SNP in catalase was found in the promoter region, we sought to determine whether gene-expression would be affected. Therefore, mRNA levels were determined (Figure 5.2) in unexposed peripheral blood lymphocytes of 30 subjects selected on basis of their genotype (10 of each genotype). Individuals homozygous for the wildtype allele of CAT $(C C)$ had $\approx 1.9$ fold lower catalase mRNA levels than individuals that were homozygous for the variant allele $(p<0.001)$. To assess whether this increased expression of CAT also resulted in a concomitant increased catalase activity, the ability to prevent single strand breaks (SSB) induced by $\mathrm{H}_{2} \mathrm{O}_{2}$ was determined (Figure 5.3). To this end, lymphocytes were incubated with $\mathrm{H}_{2} \mathrm{O}_{2}$ and a comet assay was performed to measure SSB. Samples from individuals that were homozygous for the wild-type allele of CAT (CC) had $\approx 1.5$ fold higher amount of SSB than samples from subjects carrying at least one $T$ allele $(p<0.001)$. This is consistent with the lower mRNA expression levels observed in lymphocytes of subjects carrying at least one T allele.

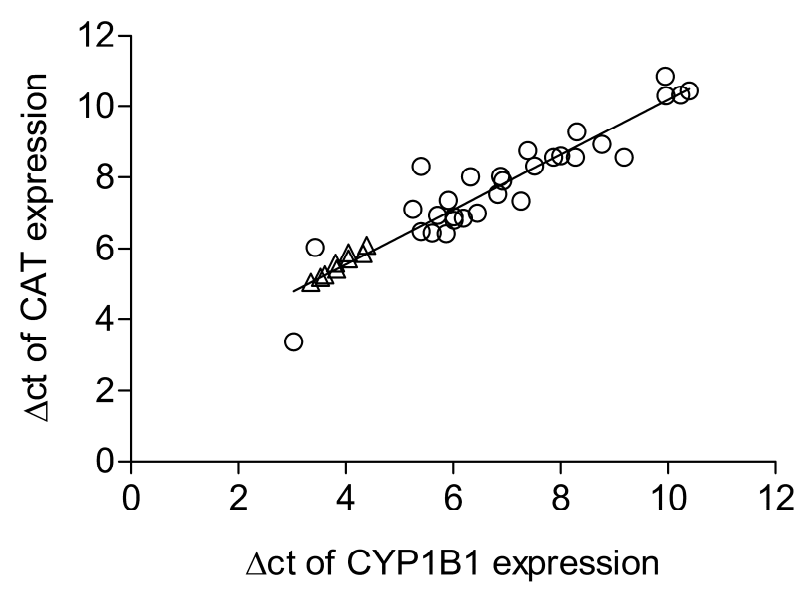

Figure 5.4: Expression of catalase correlates strongly with expression of CYP1B1. mRNA levels of catalase and CYP1B1 were measured in unexposed lymphocytes $n=30$ (circle) and A549 cells $n=9$ (triangle). Data are presented as Ct value difference between CAT and the housekeeping gene. Regression line shown belongs to gene expression of lymphocytes, but also fits the results in A549 cells.

\section{Expression of catalase strongly correlated with expression of CYP1B1}

To further define how catalase expression effects BPDE-DNA adduct levels, catalase mRNA levels were correlated with the expression of CYP1B1 and a strong significant correlation was observed ( $p<0.001, R=0.92$, Figure 5.4 ). The genetic polymorphism in CAT, which regulates the level of gene expression of CAT, thus seems to co-regulate the expression of CYP1B1 in human lymphocytes. Indeed, the expression of CYP1B1 was approximately 2-fold higher in carriers of the CAT TT-genotype than in the CCgenotype subjects, but this did not reach statistical significance $(p=0.08)$.

\section{In vitro modulation of catalase expression alters CYP1B1 mRNA levels}

To further investigate the mechanism by which catalase affects CYP1B1 gene expression, A549 lung epithelial cell line was used to investigate the effect of changing catalase gene expression on CYP1B1. A similar statistically significant correlation in the expression of catalase and CYP1B1 was observed in unexposed cells $(p<0.001, R=0.96$, 
Figure 5.4). From the ex vivo observation, we hypothesized that knocking down the expression of catalase, would also down regulate the expression of CYP1B1. After knock down of catalase expression, only $15 \%$ of the catalase mRNA remained following 24 hours of siRNA treatment (Figure 5.4). The expected simultaneous down regulation of CYP1B1 gene expression was not observed. On the other hand, the removal of the siRNA resulted in the recovery of CAT expression which coincided with a 2.2 fold upregulation of CYP1B1 expression ( $p<0.001)$.

Down regulation of catalase is expected to increase intracellular oxidative stress, the resulting activation of the Nrf2 pathway may be a potential explanation for the initial lack of response in CYP1B1 expression since CYP1B1 is known to be modulated by Nrf2 (14). Therefore, gene expression of the reporter gene NADPH quinine oxidoreductase (NQO1), which is regulated via the Nrf2 pathway, was determined and interestingly, a significant upregulation of NQO1 ( $\approx 1.4$ fold) was observed during catalase knock down. This suggests that an activation of the Nrf2 pathway prevents CYP1B1 to be downregulated in parallel with catalase after its knock down. On the other hand, the subsequent removal of the siRNA and resultant restoration of catalase expression coincided with an upregulation of CYP1B1 expression. These in vitro studies confirm that catalase may affect CYP1B1 gene expression.

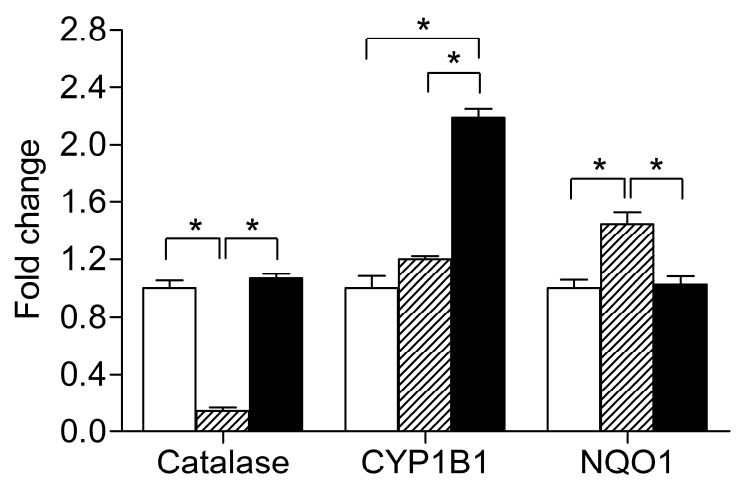

Figure 5.5: CYP1B1 mRNA levels are increased upon recovery of catalase mRNA levels 8 hours after a transient knock down. mRNA levels of catalase, CYP1B1 and NQO1 in A549 were measured after no treatment (white), 24 hours of catalase siRNA (striped), or 24 hours of catalase siRNA followed by 8 hours recovery without siRNA (black). Data are presented as mean \pm S.E. fold increase compared to no treatment. ( $n=3$ for each bar, $* p<0.001$ )

\section{Discussion}

PAHs such as BaP are carcinogens that humans are unknowingly and/or unavoidably exposed to on a daily basis. The ability of an individual to cope with these carcinogens, determines the risk of developing cancer. This intrinsic risk varies within the population and genetic polymorphisms in genes such as those involved in BaP metabolism may be a source of this disparity. To this end, previous studies showed that certain genetic polymorphisms are related to an increase in adduct formation $(3,15)$. However, phenotypic effects of certain genetic polymorphisms are difficult to assess in epidemiological studies, because exposure misclassification attenuates underlying relationships. Therefore, we exposed cells to a single compound to further elucidate genotype-phenotype relationships and report that genetic polymorphisms in catalase and CYP1B1 interact in determining the levels of BPDE-DNA adducts ex vivo. 
Of the 34 polymorphisms investigated, only two resulted in a difference in BPDE-DNA adduct formation. The CYP1B1-N453S polymorphism has previously been linked to altered cancer risks and aggressiveness of hormone dependent cancers $(16,17)$, most likely by influencing estrogen metabolism. Interestingly, estrogen metabolism shows large overlap with the metabolism of PAH, such as BaP. CYP1B1 is also capable of metabolizing $\mathrm{BaP}$ to its reactive metabolites. This metabolic activation is usually ascribed to CYP1A1, but the expression of CYP1A1 is minimal in lymphocytes. In our sample population, expression of CYP1A1 was more than 18-fold lower than the expression of CYP1B1 (data not shown). The CYP1B1-N453S variant alleles appear to be protective since individuals carrying one or two variant alleles had lower levels of BPDE-DNA adducts after ex vivo exposure to BaP (Figure 5.1).

The other polymorphism that influenced BPDE-DNA adduct formation in our population was catalase $\mathrm{C}-262 \mathrm{~T}$ in the promoter region (rs1001179). Catalase reduces oxidative stress by catalyzing the conversion of $\mathrm{H}_{2} \mathrm{O}_{2}$ into water and oxygen. The location of this polymorphism in the promoter suggests that it is involved in the regulation of catalase gene expression. Therefore, we measured catalase mRNA levels in lymphocytes from individuals carrying different alleles. The subjects carrying the variant allele had higher expression of CAT compared to subjects with the wild-type allele. This finding is in concordance with Forsberg et al who showed that the $\mathrm{C} / \mathrm{T}$ polymorphism, in the promoter region of the CAT gene induced the transcriptional activity of the promoter (18). The induced catalase gene expression also coincide with induced activity of catalase in subjects carrying at least one T-allele, since they had lower levels of SSB breaks induced by $\mathrm{H}_{2} \mathrm{O}_{2}$.

The observation that the expression of CYP1B1 was approximately 2-fold higher in carriers of the CAT TT-genotype than in the CC-genotype subjects and because a strong correlation was observed between the expression of CAT and the expression of CYP1B1, led to the hypothesis that the genetic polymorphism in CAT would affect DNA adduct formation induced by BaP via its effect on CYP1B1 expression. Previous studies in hepatoma cells have shown that oxidative stress decreased the expression of CYP1A1, which like CYP1B1, is a member of the CYP1 family (19-21). This oxidative stress-mediated repression was mediated by a nuclear factor 1 (NF1) binding to the promoter region of these CYPs (20). The expression of CYP1A1 and CYP1B1 is activated by binding of a ligand, such as $\mathrm{BaP}$, to the aryl hydrocarbon receptor (AhR). Upon ligand binding, AhR translocates into the nucleus and dimerizes with the aryl hydrocarbon receptor nuclear translocator (ARNT), which can bind to the TNGCGTG consensus sequence in the xenobiotic- responsive elements of target genes (22). This AhR-ARNT complex synergizes with other transcription factors including NF1 thereby activating gene expression, suggesting that high levels of $\mathrm{H}_{2} \mathrm{O}_{2}$ could result in reduced transcription of CYP1B1. We indeed found a strong correlation between catalase expression and CYP1B1 expression ( $>0.92)$ in lymphocytes and A549 cells. Thus, we hypothesized that the SNP in catalase determines the amount of CYP1B1 and the SNP in CYP1B1 subsequently determines the activity of the enzyme.

To further study the combined effect of CAT and CYP1B1 polymorphisms on BPDE-DNA adduct formation; we transiently knocked down catalase by siRNA. Indeed, the recovery of CAT expression after removal of the siRNA coincided with increasing levels 
of CYP1B1 mRNA levels. However, the effective knock down of catalase expression to less than $15 \%$ of the original level, did not result in the expected decrease of CYP1B1 gene expression. This suggests that under circumstances of oxidative stress, other mechanisms are capable of keeping CYP1B1 gene expression intact. A likely candidate was the nuclear erythroid 2-related factor 2 (Nrf2), which when activated, significantly induced AhR, CYP1A1 and CYP1B1 transcription in mouse embryonic fibroblasts (14). In response to oxidative stress, $\mathrm{Nfr} 2$ is activated and upregulates antioxidant and detoxifying genes, including $\mathrm{NAD}(\mathrm{P}) \mathrm{H}$ dehydrogenase quinone 1 (NQO1) (23). In our study, the increase in NQO1 mRNA levels suggests that the knock down of catalase is indeed related to increased oxidative stress levels and activation of $\mathrm{Nfr} 2$. The opposing effects of both NF1 and Nfr2 eventually resulted in an initial unchanged CYP1B1 gene expression. However, when catalase mRNA levels started to increase after removal of the siRNA, oxidative stress quickly decreased and the Nfr2 was deactivated (since NQO1 expression went back to baseline levels). We speculate that as a result of the restored expression of catalase, CYP1B1 expression further increased and was overcompensated (>2 fold increased expression). Our in vitro studies confirm that catalase affects CYP1B1 gene expression.

We propose a model in which the genetic polymorphism in the promotor region of CAT $-262 \mathrm{C} / \mathrm{T}$ determines the amount of intracellular oxidative stress, which co-regulates the expression of CYP1B1 by reducing the amount of $\mathrm{H}_{2} \mathrm{O}_{2}$ present in the cells. This would inactivate or activate relevant transcription factors (NF1 and Nrf2, respectively). The genetic polymorphisms in CYP1B1 subsequently modulates BaP metabolism ex vivo in lymphocytes. Thus, the SNP in CAT determines the amount of CYP1B1, whereas the SNP in CYP1B1 determines its activity. These ex vivo data indicate that interindividual variations in DNA adduct levels depend on gene-gene interactions, which need further attention for application in in vivo studies. Understanding gene-gene interactions allows the identification of relevant combinations of SNP's to assess an individual's cancer susceptibility. 


\section{Reference list}

1 Phillips, D.H. (2005) DNA adducts as markers of exposure and risk. Mutat Res, 577, 284292.

2 Eder, E. (1999) Intraindividual variations of DNA adduct levels in humans. Mutation research, 424, 249-261.

3 Rojas, M., Cascorbi, I., Alexandrov, K., Kriek, E., Auburtin, G., Mayer, L., Kopp-Schneider, A., Roots, I., and Bartsch, H. (2000) Modulation of benzo[a]pyrene diolepoxide-DNA adduct levels in human white blood cells by CYP1A1, GSTM1 and GSTT1 polymorphism. Carcinogenesis, 21, 35-41.

4 Palli, D., Masala, G., Vineis, P., Garte, S., Saieva, C., Krogh, V., Panico, S., Tumino, R., Munnia, A., Riboli, E., and Peluso, M. (2003) Biomarkers of dietary intake of micronutrients modulate DNA adduct levels in healthy adults. Carcinogenesis, 24, 739-746.

5 Besaratinia, A., Kleinjans, J.C., and Van Schooten, F.J. (2002) Biomonitoring of tobacco smoke carcinogenicity by dosimetry of DNA adducts and genotyping and phenotyping of biotransformational enzymes: a review on polycyclic aromatic hydrocarbons. Biomarkers, 7, 209-229.

6 Zhao, H., Wang, L.E., Li, D., Chamberlain, R.M., Sturgis, E.M., and Wei, Q. (2008) Genotypes and haplotypes of ERCC1 and ERCC2/XPD genes predict levels of benzo[a]pyrene diol epoxide-induced DNA adducts in cultured primary lymphocytes from healthy individuals: a genotype-phenotype correlation analysis. Carcinogenesis, 29, 1560-1566.

7 Rojas, M., Godschalk, R., Alexandrov, K., Cascorbi, I., Kriek, E., Ostertag, J., Van Schooten, F.J., and Bartsch, H. (2001) Myeloperoxidase--463A variant reduces benzo[a]pyrene diol epoxide DNA adducts in skin of coal tar treated patients. Carcinogenesis, 22, 1015-1018.

8 Ketelslegers, H.B., Gottschalk, R.W., Godschalk, R.W., Knaapen, A.M., van Schooten, F.J., Vlietinck, R.F., Kleinjans, J.C., and van Delft, J.H. (2006) Interindividual variations in DNA adduct levels assessed by analysis of multiple genetic polymorphisms in smokers. Cancer epidemiology, biomarkers \& prevention, 15, 624-629.

9 Li, D., Wang, M., Cheng, L., Spitz, M.R., Hittelman, W.N., and Wei, Q. (1996) In vitro induction of benzo(a)pyrene diol epoxide-DNA adducts in peripheral lymphocytes as a susceptibility marker for human lung cancer. Cancer Res, 56, 3638-3641.

10 Wilms, L.C., Boots, A.W., de Boer, V.C., Maas, L.M., Pachen, D.M., Gottschalk, R.W., Ketelslegers, H.B., Godschalk, R.W., Haenen, G.R., van Schooten, F.J., and Kleinjans, J.C. (2007) Impact of multiple genetic polymorphisms on effects of a 4-week blueberry juice intervention on ex vivo induced lymphocytic DNA damage in human volunteers. Carcinogenesis, 28, 1800-1806.

11 Knaapen, A.M., Ketelslegers, H.B., Gottschalk, R.W., Janssen, R.G., Paulussen, A.D., Smeets, H.J., Godschalk, R.W., Van Schooten, F.J., Kleinjans, J.C., and Van Delft, J.H. (2004) Simultaneous genotyping of nine polymorphisms in xenobiotic-metabolizing enzymes by multiplex PCR amplification and single base extension. Clin Chem, 50, 1664-1668.

12 Reddy, M.V., and Randerath, K. (1986) Nuclease P1-mediated enhancement of sensitivity of 32P-postlabeling test for structurally diverse DNA adducts. Carcinogenesis, 7, 15431551.

13 Godschalk, R.W., Maas, L.M., Van Zandwijk, N., van 't Veer, L.J., Breedijk, A., Borm, P.J., Verhaert, J., Kleinjans, J.C., and van Schooten, F.J. (1998) Differences in aromatic-DNA adduct levels between alveolar macrophages and subpopulations of white blood cells from smokers. Carcinogenesis, 19, 819-825.

14 Shin, S., Wakabayashi, N., Misra, V., Biswal, S., Lee, G.H., Agoston, E.S., Yamamoto, M., and Kensler, T.W. (2007) NRF2 modulates aryl hydrocarbon receptor signaling: influence on adipogenesis. Mol Cell Biol, 27, 7188-7197. 
15 Godschalk, R.W., Dallinga, J.W., Wikman, H., Risch, A., Kleinjans, J.C., Bartsch, H., and Van Schooten, F.J. (2001) Modulation of DNA and protein adducts in smokers by genetic polymorphisms in GSTM1,GSTT1, NAT1 and NAT2. Pharmacogenetics, 11, 389-398.

16 Ashton, K.A., Proietto, A., Otton, G., Symonds, I., McEvoy, M., Attia, J., Gilbert, M., Hamann, U., and Scott, R.J. (2010) Polymorphisms in genes of the steroid hormone biosynthesis and metabolism pathways and endometrial cancer risk. Cancer Epidemiol, 34, 328-337.

17 Beuten, J., Gelfond, J.A., Byrne, J.J., Balic, I., Crandall, A.C., Johnson-Pais, T.L., Thompson, I.M., Price, D.K., and Leach, R.J. (2008) CYP1B1 variants are associated with prostate cancer in non-Hispanic and Hispanic Caucasians. Carcinogenesis, 29, 1751-1757.

18 Forsberg, L., Lyrenas, L., de Faire, U., and Morgenstern, R. (2001) A common functional C-T substitution polymorphism in the promoter region of the human catalase gene influences transcription factor binding, reporter gene transcription and is correlated to blood catalase levels. Free Radic Biol Med, 30, 500-505.

19 Barouki, R., and Morel, Y. (2001) Repression of cytochrome P450 1A1 gene expression by oxidative stress: mechanisms and biological implications. Biochem Pharmacol, 61, 511516.

20 Morel, Y., and Barouki, R. (1998) Down-regulation of cytochrome P450 1A1 gene promoter by oxidative stress. Critical contribution of nuclear factor 1. J Biol Chem, 273, 26969-26976.

21 Barker, C.W., Fagan, J.B., and Pasco, D.S. (1994) Down-regulation of P4501A1 and P4501A2 mRNA expression in isolated hepatocytes by oxidative stress. J Biol Chem, 269, 3985-3990.

22 Reyes, H., Reisz-Porszasz, S., and Hankinson, O. (1992) Identification of the Ah receptor nuclear translocator protein (Arnt) as a component of the DNA binding form of the Ah receptor. Science, 256, 1193-1195.

23 Itoh, K., Chiba, T., Takahashi, S., Ishii, T., Igarashi, K., Katoh, Y., Oyake, T., Hayashi, N., Satoh, K., Hatayama, I., Yamamoto, M., and Nabeshima, Y. (1997) An Nrf2/small Maf heterodimer mediates the induction of phase II detoxifying enzyme genes through antioxidant response elements. Biochem Biophys Res Commun, 236, 313-322. 



\section{Chapter 6}

\section{Decreased nucleotide excision repair in steatotic livers associates with myeloperoxidase-immunoreactivity}

Mutat Res. 2012 Aug 1;736(1-2):75-81

Marten A. Schults

Peter W. Nagle

Sander S. Rensen

Roger W. Godschalk

Armelle Munnia

Marco Peluso

Sandra M. Claessen

Jan W. Greve

Ann Driessen

Froukje J. Verdam

Wim A. Buurman

Frederik J. van Schooten

Roland K. Chiu 


\begin{abstract}
Chronic inflammation is characterized by the influx of neutrophils and is associated with an increased production of reactive oxygen species that can damage DNA. Oxidative DNA damage is generally thought to be involved in the increased risk of cancer in inflamed tissues. We previously demonstrated that activated neutrophil mediated oxidative stress results in a reduction in nucleotide excision repair (NER) capacity, which could further enhance mutagenesis. Inflammation and oxidative stress are critical factors in the progression of nonalcoholic fatty liver disease that is linked with enhanced liver cancer risk. In this report, we therefore evaluated the role of neutrophils and the associated oxidative stress in damage recognition and DNA repair in steatotic livers of 35 severely obese subjects with either nonalcoholic steatohepatitis (NASH) $(n=17)$ or steatosis alone $(n=18)$. The neutrophilic influx in liver was assessed by myeloperoxidase (MPO) staining and the amount of oxidative DNA damage by measuring M1dG adducts. No differences in M1dG adduct levels were observed between patients with or without NASH and also not between individuals with high or low MPO immunoreactivity. However, we found that high expression of MPO in the liver, irrespective of disease status, reduced the damage recognition capacity as determined by staining for histone $2 \mathrm{AX}$ phosphorylation $(\mathrm{\gamma H} 2 \mathrm{AX})$. This reduction in $\mathrm{YH} 2 \mathrm{AX}$ formation in individuals with high MPO immunoreactivity was paralleled by a significant decrease in NER capacity as assessed by a functional repair assay, and was not related to cell proliferation. Thus, the observed reduction in NER capacity upon hepatic inflammation is associated with and may be a consequence of reduced damage recognition. These findings suggest a novel mechanism of liver cancer development in patients with nonalcoholic fatty liver disease.
\end{abstract}




\section{Introduction}

Hepatic inflammation plays a fundamental role in liver cancer development (1) and is increasingly observed in parallel with the high prevalence of nonalcoholic fatty liver disease (NAFLD). NAFLD is characterized by the accumulation of fat within the liver. Increased levels of hepatic free fatty acids are thought to initiate an inflammatory response culminating in the recruitment of neutrophils and other leukocytes $(2,3)$ and eventually in the progression of the benign steatotic stage of NAFLD to the more advanced stages of nonalcoholic steatohepatitis (NASH), fibrosis, and cirrhosis $(4,5)$. Importantly, there is a link between NASH and the development of hepatocellular carcinoma (HCC), which accounts for more than $80 \%$ of primary liver cancer cases (6). Several groups have suggested that HCC could in fact be the end-point of NASH $(7,8)$. Although the mechanisms by which NASH can lead to the development of HCC are not fully understood, it is known that development of HCC occurs in a significant proportion of people with cirrhosis (6). Oxidative stress caused by reactive oxygen species (ROS) is an important characteristic of cancer development (9). Furthermore, many animal studies have revealed a link between oxidative stress and increased hepatocarcinogenesis by inducing (10) and promoting tumors (11) and causing DNA damage (12).

Inflammation occurs when pro-inflammatory cytokines and chemokines at a site of injury or infection release chemical signals causing an influx of inflammatory cells including neutrophils, monocytes, and eosinophils. The influx of some of these cells results in prolonged production of ROS such as nitric oxide, superoxide, hydrogen peroxide $\left(\mathrm{H}_{2} \mathrm{O}_{2}\right)(13)$, and in the release of myeloperoxidase (MPO). ROS accumulation results in various forms of DNA damage via oxidation, nitration, depurination, or deamination. In addition, it leads to DNA strand breaks and sister chromatid exchanges, all of which can lead to increased mutagenesis and carcinogenesis (14). MPO is an important enzyme abundantly present in neutrophils and involved in the catalysis of $\mathrm{H}_{2} \mathrm{O}_{2}$ to hypochlorous acid $(\mathrm{HOCl})(15)$. $\mathrm{HOCl}$ contributes to host tissue damage at sites of inflammation through reactions with a wide range of biological substrates (16). It damages proteins by causing side-chain modification, backbone fragmentation, and cross-linking (17). Furthermore, Spencer et al. showed that $\mathrm{HOCl}$ is involved in DNA damage in epithelial cells by oxidizing pyrimidine bases and chlorination of cytosine (18). Interestingly, we previously showed that NASH is associated with increased MPO activity (19).

Recently we have also demonstrated that MPO-derived $\mathrm{HOCl}$ mediates the strong inhibition of nucleotide excision repair (NER) capacity in A549 lung cancer cells by activated neutrophils (20). We confirmed that acute lung inflammation caused a $\approx 50 \%$ reduction in NER capacity due to down-regulation of the NER associated genes XPA and ERCC4 in mice. However, Mpo-deficient mice were shown to also have a reduction in NER capacity, suggesting that the suppression of NER in vivo was not dependent on MPO release, but rather due to ROS following the influx of neutrophils (21). Previous studies within our group have also indicated a role for oxidative stress in reduction of NER in colon tissue of newborn piglets, which could be reversed by administration of antioxidants (22). This suggests that release of MPO is not the major cause of 
decreased NER capacity, but it still plays a role in increasing the risk of cancer in inflammation related diseases. Furthermore, reduced expression of NER related genes, such as ERCC1, has been linked to development of lung cancer (23). NER-deficient individuals are at a significantly higher risk of developing certain forms of cancer, including those associated with chronic inflammation $(23,24)$, as there is no 'back-up' pathway for NER malfunction (25).

The mechanisms, by which inflammation and the subsequent influx of neutrophils can cause the inhibition of NER, and how this increases the risk of cancer, are not yet elucidated. Potential mechanisms include a failure to recognise the damage; downregulation of NER related genes, or inhibition of the repair related proteins. Large amounts of ROS are produced during inflammatory NAFLDs such as NASH that put patients at a higher risk of developing HCC, which could be the result of lower NER capacity. In this report, we demonstrate that there is a decrease in damage recognition in subjects with NAFLD and high MPO expression, which correlates with a decrease in NER capacity.

\section{Materials and Methods}

\section{Liver Specimens}

Human liver specimens were obtained during bariatric surgery from 35 severely obese patients (body mass index $>40$ ). None of the patients had suffered from viral hepatitis or autoimmune-related disorders or reported excessive alcohol consumption (>20 $\mathrm{g} /$ day). Biopsies were fixed in formaline stained and analyzed to differentiate liver samples in $<33 \%$ steatosis without inflammation (steatosis group) and NASH as previously described (19). As we have previously shown that there is a clear relation between extracellular MPO activity and neutrophil influx in inflamed tissues (26), MPO in the liver was detected by immunohistochemical staining and was used as a measure for MPO activity. Patient characteristics are summarized in Table 6.1. This study was approved by the Medical Ethical Board of the Maastricht University Medical Centre in line with the ethical guidelines of the 2008 Declaration of Seoul, and informed consent in writing was obtained from each subject.

Table 6.1: Clinical characteristics of patients studied

\begin{tabular}{lllll}
\hline & Low MPO & \multicolumn{3}{l}{ High MPO } \\
\cline { 2 - 5 } & Steatosis & NASH & Steatosis & NASH \\
\hline No. of patients & 9 & 8 & 9 & 9 \\
Sex (female/male) & $5 / 4$ & $3 / 5$ & $7 / 2$ & $9 / 0$ \\
Age (years) & $48 \pm 3.5$ & $41 \pm 3.8$ & $45 \pm 2.4$ & $52 \pm 2.5$ \\
BMI (kg/m ${ }^{2}$ ) & $44 \pm 2.4$ & $51 \pm 3.0$ & $44 \pm 2.8$ & $56 \pm 4.3$ \\
Fasting glucose (mmol/L) & $6.3 \pm 0.4$ & $5.6 \pm 0.1$ & $5.7 \pm 0.2$ & $8.3 \pm 0.4$ \\
ALT (IU) & $26.0 \pm 6.5$ & $21.1 \pm 3.2$ & $23.7 \pm 3.0$ & $25.7 \pm 3.3$ \\
AST (IU) & $22.8 \pm 3.8$ & $26.6 \pm 4.2$ & $8.2 \pm 2.3$ & $27.2 \pm 3.8$ \\
\hline
\end{tabular}




\section{Quantitative Real-Time PCR}

Total RNA was isolated from $50 \mathrm{mg}$ liver tissue by homogenization in Tri-reagent (Sigma), according to the manufacturer's instructions. RNA (750ng) was converted to cDNA using the iScript cDNA synthesis kit (Bio-Rad). Quantitative real-time PCR was performed with the Sensimix Sybr Green (Quantace, London, UK) and the MyiQ Single Color RT-PCR detection system (Biorad). The MyiQ Software system (Biorad) was used for data analysis. Using the $2^{-\Delta \Delta C t}$ method, relative gene expression (fold increase) was calculated. All data were normalized to the housekeeping genes $\beta$-actin and cyclophilin A. Sequences of the used PCR primers are listed in table 6.2.

Table 6.2: Primer sequences for real time RT-PCR

\begin{tabular}{lll}
\hline Gene & Forward primer $\left(5^{\prime}\right.$ - $\left.^{\prime}\right)$ & Reverse primer $\left(5^{\prime}\right.$ - $\left.^{\prime}\right)$ \\
\hline -actin & CCTGGCACCCAGCACAAT & GCCGATCCACACGGAGTACT \\
Cyclophilin A & TTCCTGCTTTCACAGAATTATTCC & GCCACCAGTGCCATTATGG \\
XPA & CCGACAGGAAAACCGAGAAA & TTCCACACGCTGCTTCTTACTG \\
XPC & CCCAGCCCGCTTTACCA & TGCATTAACTGTAAATGTTCCAATGA \\
ERCC4 & CACCTCCCTCGCCGTGTA & CGCAAATATAACACCACCTTGTG \\
ERCC5 & GCATGAAATCTTGACTGATATGAAAGA & TAAGCAAGCCTTTGAGTTGGTACTG \\
ERCC1 & ACCCCTCGACGAGGATGAG & CAGTGGGAAGGCTCTGTGTAGA \\
\hline
\end{tabular}

\section{Quantification of $M_{1} d G$}

After removal of the aqueous phase during RNA isolation using Trizol (Invitrogen), the remaining phases were used for DNA isolation according to the manufacturer's protocol. DNA was resuspended in $100 \mu \mathrm{L} \mathrm{H}_{2} \mathrm{O}$. The quantity and quality of DNA was measured using the Nanodrop 1000 (Thermo Scientific). The ${ }^{32} \mathrm{P}$-postlabelling technique was used to analyze the levels of 3-(2-Deoxy- $\beta$-D-erythropentofuranosyl)pyrimido $[1,2-\alpha]$ purin-10(3H)-one $\left(\mathrm{M}_{1} \mathrm{dG}\right)$ adducts, as previously reported (27). $M_{1} d G$ adduct separation was carried out by PEI-cellulose TLC chromatography according to published conditions (28). Detection and quantification of $\mathrm{M}_{1} \mathrm{dG}$ adducts and total nucleotides were obtained by phosphor imaging technology (Typhoon 9210, Amersham) and ImageQuant software (Molecular Dynamics, Sunnyvale, CA). After background subtraction, the levels of DNA adducts were expressed as relative adduct labelling (RAL = adducted nucleotides/total nucleotides). Standard MDA modified (29) and unmodified DNA were routinely processed in the analysis as controls.

\section{Immunohistochemistry}

MPO abundance was detected by immunohistochemical staining using polyclonal rabbit anti-human MPO antiserum (dilution 1:1000; Dako) as a primary antibody and semi-quantitative evaluation of MPO positive cells was performed on a four-point scale by two independent observers (19). In the present study we used the patients with hardly any MPO positive cells (category 1 ) versus those who contain a large amount of MPO positive cells in their liver (category 4). For the $\mathrm{pH} 2 \mathrm{AX}$ and Ki-67 staining, paraffin embedded tissue sections were deparaffinized and rehydrated 3 times for 10 minutes in xylol, twice for 5 minutes in $100 \% \mathrm{EtOH}$, twice for 5 minutes in $96 \% \mathrm{EtOH}, 5$ minutes 
in $70 \% \mathrm{EtOH}$ and 5 minutes in PBS. Slides were heated 3 times for 5 minutes in $0.01 \mathrm{M}$ citrate buffer $\left(\mathrm{pH}\right.$ 6.0) followed by treatment with $2 \% \mathrm{H}_{2} \mathrm{O}_{2}$ in methanol for 30 minutes at room temperature. Nonspecific binding was blocked with $3 \%$ BSA/PBS for 30 minutes at room temperature and slides were subsequently incubated for 1 hour at room temperature with a 1:1000 dilution of the primary antibody, mouse anti- $\gamma \mathrm{H} 2 \mathrm{AX}$ JBW301 (Upstate, Billerica, MA) or mouse anti-human Ki-67 (Dako). The secondary antibody, biotinylated Rabbit anti Mouse P0161 (Dako) was diluted in 1\% BSA/PBS for 1 hour at $37^{\circ} \mathrm{C}$ followed by BrightVision+ (Immunologic, the Netherlands) according to the manufacturer's instructions. Slides were incubated with $D A B(0.7 \mathrm{mg} / \mathrm{ml})$ and urea $(2 \mathrm{mg} / \mathrm{ml})$ for 7 minutes and counterstained with haematoxylin for 1 minute. Slides were dehydrated for 5 minutes in $70 \% \mathrm{EtOH}$ after washing with tap water, twice for 5 minutes in $96 \% \mathrm{EtOH}$, twice for 5 minutes in $100 \% \mathrm{EtOH}$ and twice for 10 minutes in xylol. Finally the slides were mounted in Entellan (Merck). At least 100 randomly selected cells per slide were microscopically scored blindly. For the $\mathrm{yH} 2 \mathrm{AX}$ staining, cells were graded on a gradual scale in which 0 was considered no staining (only counterstaining visible) and 4 was considered highly positive in which over $80 \%$ of the nucleus was brown. For the Ki-67 staining, the percentage of positive cells (brown nucleus) was determined.

\section{Measurement of NER capacity}

To measure NER capacity in the liver samples, we applied a previously validated modified comet assay (30) which measures the ability of NER-related enzymes that are present in the "test" extracts, to incise substrate DNA containing BPDE-DNA adducts. The substrate nucleoids were prepared from untreated A549 cells (human epithelial lung carcinoma cells) obtained from the American Tissue Culture Collection (ATCC, Rockville, MD). The cells were cultured in DMEM supplemented with $10 \%$ heatinactivated FCS and $1 \%$ penicillin/streptomycin and maintained at $37^{\circ} \mathrm{C}$ in a $5 \% \mathrm{CO}_{2}$ atmosphere. A549 cells were embedded in LMP agarose on glass microscope slides and subsequently lysed overnight in cold $\left(4^{\circ} \mathrm{C}\right)$ lysis buffer $(2.5 \mathrm{M} \mathrm{NaCl}, 0.1 \mathrm{M}$ EDTA, $0.01 \mathrm{M}$ Tris, $0.25 \mathrm{M} \mathrm{NaOH}$ plus $1 \%$ Triton X-100 and $10 \%$ DMSO). The resulting nucleoids were then either exposed to $1 \mu \mathrm{M}$ BPDE ( $\mathrm{NCl}$ Chemical Carcinogen Reference Standard Repository, Midwest Research Institute, Kansas City, MO) in PBS or vehicle control (DMSO, 0.5\%) for 30 minutes at $4^{\circ} \mathrm{C}$. To prepare protein/enzyme extracts, ground frozen liver tissues were thawed and resuspended in $45 \mathrm{mM}$ HEPES, $0.4 \mathrm{M} \mathrm{KCl}, 1 \mathrm{mM}$ EDTA, $0.1 \mathrm{mM}$ dithiothreitol, $10 \%$ glycerol, adjusted to $\mathrm{pH} 7.8$ using $\mathrm{KOH}$. Resulting aliquots were snap-frozen, thawed again and $30 \mu \mathrm{l}$ of $1 \%$ Triton X-100 in buffer A per $100 \mu \mathrm{l}$ of extract was added. Protein concentrations were determined by the BioRAD DC protein assay using bovine serum albumin as a standard. Tissue extracts were diluted to a concentration of $1 \mathrm{mg} / \mathrm{ml}$. Next, 4 volumes of $45 \mathrm{mM}$ HEPES, $0.25 \mathrm{mM}$ EDTA, $2 \%$ glycerol, $0.3 \mathrm{mg} / \mathrm{ml} \mathrm{BSA}$, adjusted to $\mathrm{pH} 7.8$ with $\mathrm{KOH}$ were added and $50 \mu \mathrm{l}$ of the mixture was added to the gel-embedded nucleoids and incubated for 20 minutes at $37^{\circ} \mathrm{C}$. Alkaline treatment (40 minutes) and electrophoresis (30 minutes) were conducted as in the standard comet assay (31). Comets were visualized using a Zeiss Axioskop fluorescence microscope and quantified as tail moment and percentage DNA in tail (tail intensity). Samples were tested in two independent incubations within each 
single experiment. On every slide, 50 cells were analyzed randomly using the Comet assay III software program (Perspective Instruments, Haverhill, UK). The increased DNA strand breakage in the BPDE-modified nucleoids vs. the DMSO-treated nucleoids is indicative of the NER capacity of the cell extracts. The final repair capacity was calculated according to the method previously described (30) using both tail moment as well tail intensity.

\section{Statistical Analysis}

Results are expressed as means \pm S.E. SPSS 15.0 was used for statistical analysis. The two-way ANOVA was used to determine the influence of MPO and NASH. To assess differences between four groups, a one-way analysis of variance test with Dunnet's post-hoc multiple comparison correction was used. Differences were considered to be statistically significant when $\mathrm{p}<0.05$.

\section{Results}

Inflammation in steatotic livers did not increase $M_{1} d G$ adduct levels

To characterize the effect of NASH and/or MPO abundance, on the amount of ROSinduced DNA damage in the liver and $\mathrm{M}_{1} \mathrm{dG}$ adduct levels were determined. We were able to isolate DNA from 22 patients with steatosis. MPO expression in the liver tissue was determined and patients were divided into groups of low versus high MPO staining or steatosis alone versus NASH. There were no differences between the four groups regarding $M_{1} d G$ adduct levels (Figure 6.1). This suggests that inflammation, as determined by the presence of MPO had no effect on hepatic DNA damage in NAFLD.

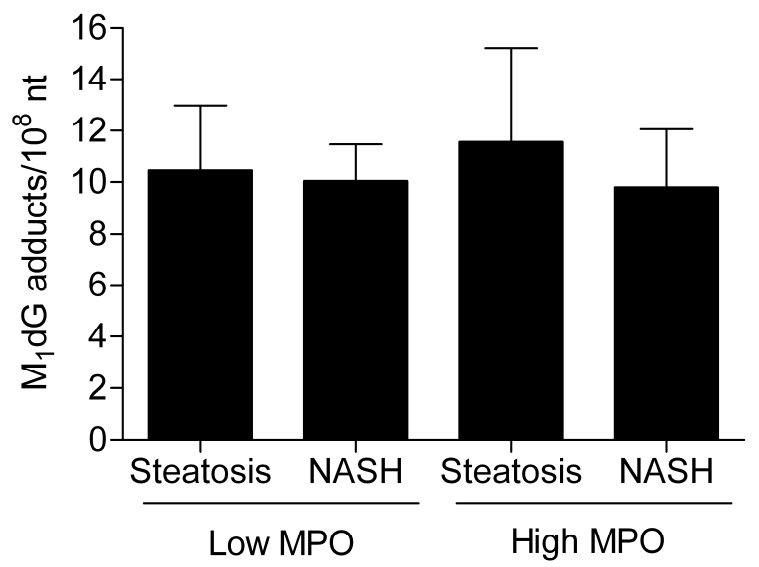

Figure 6.1: Inflammation has no effect on $M_{1} d G$ DNA adduct levels. $M_{1} d G$ DNA adducts levels in human livers with low MPO levels and steatosis $(n=6)$ or NASH $(n=6)$ and high MPO levels and steatosis $(n=6)$ or NASH $(n=4)$ were determined by ${ }^{32}$ P-postlabeling and data was presented as amount of $M_{1} d G$ adducts per $10^{8}$ nucleotides. Values are mean \pm S.E.

Decreased phosphorylated H2AX under high MPO expression in the liver

Next, we stained for histone 2AX phosphorylation $(\gamma \mathrm{H} 2 \mathrm{AX})$. Of 18 patients we were able to obtain liver samples for staining. Patients without NASH and low MPO expression had the highest $\mathrm{\gamma H} 2 \mathrm{AX}$ levels. $\mathrm{A} \approx 52 \%$ decrease in semi-quantitative $\mathrm{\gamma H} 2 \mathrm{AX}$ levels was observed in the liver samples of patients with NASH and low MPO 
expression. Patients with high MPO expression had a further decrease towards $\approx 26 \%$ and $\approx 28 \%$, of the semi-quantitative $\mathrm{\gamma H} 2 \mathrm{AX}$ levels observed in patients with steatosis and NASH, respectively (Figure 6.2). The patients with high MPO immunoreactivity showed a statistically significant decrease of $\approx 59 \%$ compared to the patients with low MPO staining, while patients with NASH had $\approx 19 \%$ lower semi-quantitative $\mathrm{pH} 2 \mathrm{AX}$ levels compared to patients without NASH.
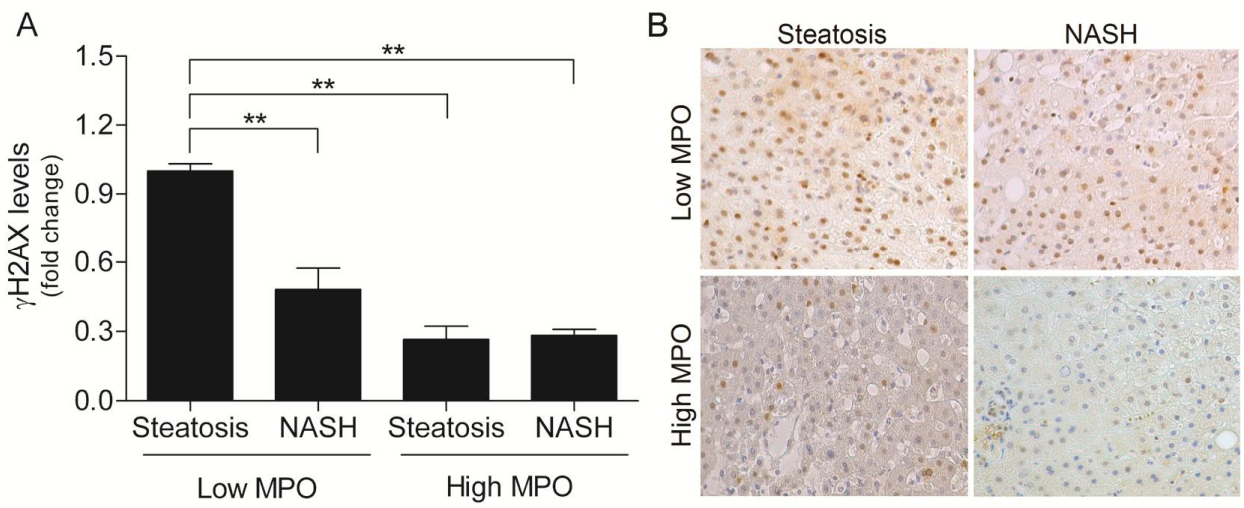

Figure 6.2: $\gamma \mathrm{H} 2 \mathrm{AX}$ is decreased under inflammatory conditions. Phosphorylation of $\mathrm{H} 2 \mathrm{AX}$ in human livers with low MPO levels and steatosis $(n=3)$ or NASH $(n=6)$ and high MPO levels and steatosis $(n=6)$ or NASH $(n=3)$ was microscopically evaluated. A: Data is presented as fold increase compared to patients with low MPO levels without NASH. Values are mean \pm S.E. ${ }^{* * p}<$ 0.01. B: Representative images within the four groups for $\mathrm{yH} 2 \mathrm{AX}$ staining (magnification 400x) were equally post-microscopically enhanced to increase contrast for the brown $\mathrm{\gamma H} 2 \mathrm{AX}$ staining.

\section{Proliferation is unaltered in steatotic livers upon inflammation}

One possible explanation for the differences found in phosphorylation of H2AX is changes in proliferation of cells. Ki-67 staining of the same liver samples stained for $\mathrm{YH} 2 \mathrm{AX}$ showed no difference between the four groups (Figure 6.3). This suggests that the differences found for the $\mathrm{YH} 2 \mathrm{AX}$ staining were unlikely to be the direct result of differences in proliferation status.

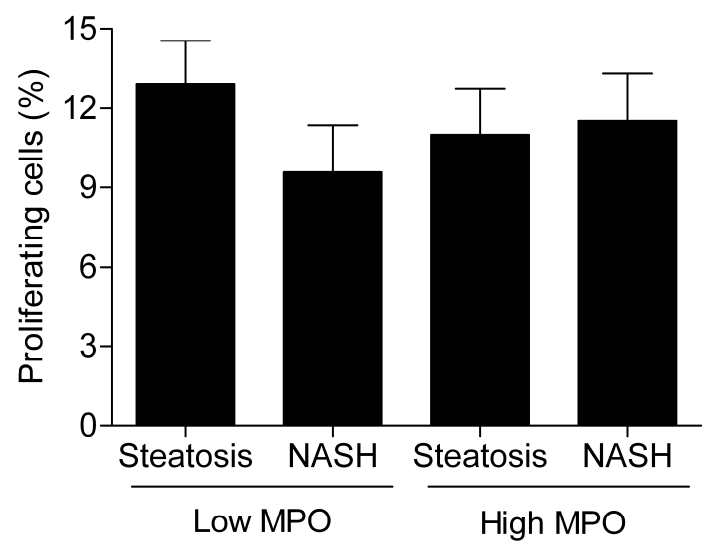

Figure 6.3: No changes in proliferation under inflammatory conditions. Human liver samples of patients with low MPO levels and steatosis $(n=3)$ or NASH $(n=6)$ and high MPO levels and steatosis $(n=6)$ or NASH $(n=3)$ were stained for $\mathrm{Ki}-67$ and percentage of proliferating cells was determined. 
Decreased NER gene expression in the liver of patients with high MPO immunoreactivity

To investigate potential differences in DNA repair gene expression, the effect of MPO and NASH on the mRNA levels of 5 NER genes (XPA, XPC, ERCC4, ERCC5, and ERCC1) was determined (Table 6.3). Of 32 patients, mRNA levels could be determined. For both XPA and ERCC4 gene expression, the highest mRNA levels were found in patients with low MPO staining without NASH. The relative amount of mRNA of these NER related genes decreased in patients with NASH and high MPO immunoreactivity; however the differences between the groups were only statistically significant for ERCC4. Patients with low MPO immunoreactivity were observed to have generally higher NER gene expression compared to patients with high MPO immunoreactivity. ERCC4 mRNA relative expression levels were significantly lower with $\approx 17 \%$. Patients with NASH also displayed a lower gene expression compared to patients without NASH. However, the difference in ERCC4 mRNA levels was not as large as compared to the differences in expression related to MPO.

Table 6.3: Relative NER gene expression in human livers

\begin{tabular}{lllllll}
\hline & & XPA & XPC & ERCC4 & ERCC5 & ERCC1 \\
\hline Low MPO & Steatosis & $1.00 \pm 0.10$ & $1.00 \pm 0.09$ & $1.00 \pm 0.05$ & $1.00 \pm 0.06$ & $1.00 \pm 0.08$ \\
& NASH & $0.84 \pm 0.06$ & $1.05 \pm 0.07$ & $0.91 \pm 0.09$ & $1.24 \pm 0.08$ & $1.14 \pm 0.09$ \\
High MPO & Steatosis & $0.80 \pm 0.05$ & $0.93 \pm 0.07$ & $0.88 \pm 0.06$ & $1.11 \pm 0.06$ & $1.15 \pm 0.11$ \\
& NASH & $0.81 \pm 0.07$ & $0.84 \pm 0.10$ & $0.73 \pm 0.05^{*}$ & $0.84 \pm 0.09$ & $0.91 \pm 0.12$ \\
\hline
\end{tabular}

Data are presented as mean \pm SE. Differences between low MPO levels and steatosis $(n=8)$ or NASH $(n=8)$ and high MPO levels and steatosis $(n=7)$ or NASH $(n=9)$ were determined. ${ }^{*} p<0.05$.

\section{Decreased NER activity correlates with high MPO in the liver}

To investigate if the decreased $\mathrm{YH} 2 \mathrm{AX}$ levels in patients with high MPO staining translated into a reduced functional NER capacity, we next studied NER capacity using a modified comet assay. NER capacity could be measured in liver samples isolated from 33 patients. Patients with low MPO expression without NASH had the highest repair capacity. $A \approx 26 \%$ and $\approx 30 \%$ lower repair capacity was observed in the liver of patients with low MPO immunoreactivity and NASH, when using tail moment and tail intensity values, respectively. The repair capacity further decreased in patients with high MPO expression to only $\approx 58 \%$ of the repair capacity of patients without NASH and low MPO staining (Figure 6.4). The group with high MPO immunoreactivity showed a statistically significant decrease of $\approx 33 \%(p=0.02)$ and $\approx 30 \%(p=0.05)$ compared to the patients with low MPO expression, when using tail moment and tail intensity values, respectively. On the other hand, patients with NASH had $a \approx 14 \%(p=0.31)$ and $\approx 20 \%$ $(p=0.20)$ lower repair capacity compared to patients without NASH (irrespective of MPO abundance), when using tail moment and tail intensity values, respectively. This difference was not statistically significant, suggesting that the presence of high levels of MPO-immunoreactive cells had the largest contribution to the observed lower levels of DNA repair. 
A

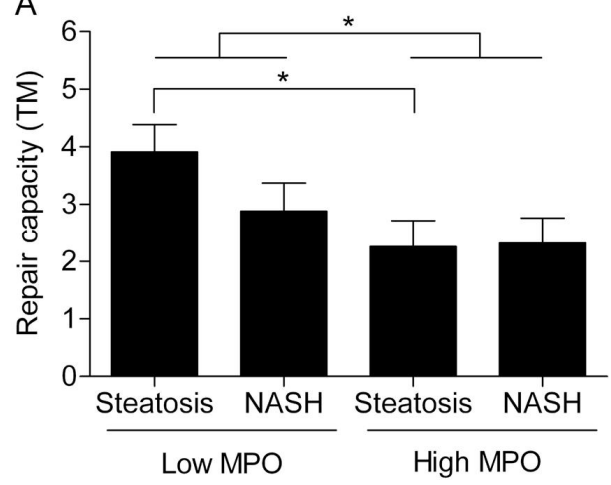

B

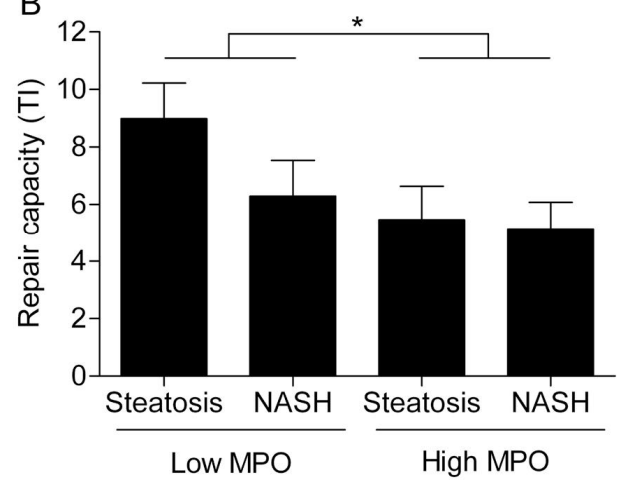

Figure 6.4: NER capacity is decreased under inflammatory conditions. Repair capacity (A: calculated by using tail moment. B: calculated by using tail intensity) of cell extracts isolated from human livers was measured and differences between low MPO levels and steatosis $(n=8)$ or NASH $(n=8)$ and high MPO levels and steatosis $(n=9)$ or NASH $(n=8)$ were determined. Values are mean \pm S.E. $* p<0.05$.

\section{Discussion}

Chronic inflammation has been shown to play a role in the development of cancer in various organs, in part due to the recruitment of neutrophils at the site of inflammation resulting in enhanced levels of oxidative stress $(14,32)$. This oxidative stress may result in more DNA damage, a subsequent induction of mutation prone cells and ultimately increase in development in $\operatorname{HCC}(7,8,33-35)$. Indeed, we have previously shown that NER activity was significantly impaired by neutrophil activation in lung cells (20). There is circumstantial evidence that individuals with a reduced NER pathway capacity are at greater risk to develop cancer $(23,24)$. Therefore, we proposed that NER inhibition upon neutrophil activation and accumulation of mutations over time due to oxidative stress may play a role in the development of hepatocellular carcinomas associated with NASH.

To determine the amount of ROS induced DNA damage, $M_{1} d G$ adducts, a marker for oxidative damage, were measured. NER is the primary pathway that removes the damage caused by DNA helix distorting lesions, including $M_{1} d G$ adducts $(36,37)$. When DNA damage is not effectively removed, these lesions can be highly mutagenic $(25,38,39)$. In general, increased oxidative stress is seen as a trigger for the development of NASH from steatosis. However, several studies have observed similarly elevated levels of oxidative stress in steatosis and NASH (40-42). Indeed, in this study, no significant differences in $\mathrm{M}_{1} \mathrm{dG}$ adduct levels were observed in relation to the presence of NASH neither to the inflammation as determined by MPO expression.

The phosphorylation of histone H2AX by the PI-3 kinases ATM, ATR and DNA-PK, is a well described marker for DNA damage. This occurs rapidly in response to double strand breaks (DSBs) (43), V(D)J recombination (44), replication fork blockage (45) and NER dependent DNA damage (46). In liver cells, the observation of $\mathrm{\gamma H} 2 \mathrm{AX}$ is not likely linked to somatic recombination events. We therefore suggest that the reduced $\mathrm{YH} 2 \mathrm{AX}$ 
is related to impairment of the recognition of DNA damage rather than absolute amount of damage, as the tissues showed similar DNA damage levels as inferred from the $M_{1} d G$ adducts (Figure 6.1). Furthermore, $\mathrm{YH} 2 \mathrm{AX}$ is also observed in $\mathrm{S}$ phase cells most likely due to DSBs or endogenous damage leading to stalled replication forks (47). To determine whether the decrease in $\mathrm{YH} 2 \mathrm{AX}$ that we observed with increased MPO (Figure 6.2) resulted simply from changes in proliferation rate, we stained for Ki-67. As all groups showed similar levels of Ki-67 staining (Figure 6.3), proliferation rates are unlikely to be the source of the differences in $\mathrm{pH} 2 \mathrm{AX}$ staining.

To investigate whether MPO immunoreactivity in the liver or the NASH phenotype altered NER gene expression, the mRNA levels of XPA, XPC, ERCC1, ERCC4 and ERCC5, were determined. There was a consistent trend that repair genes were decreased in patients with high MPO immunoreactivity, but only ERCC4 showed significantly lower levels of expression in combination with conditions of high MPO expression. This is in agreement with previous studies on the regulation of NER genes in response to inflammation, where ERCC4 was down regulated in the presence of high MPO levels (21).

As DNA repair is often regulated in multiple manners in addition to transcriptional control, we sought to determine whether either NASH and/or higher MPO immunoreactivity impair overall functional NER. To this end, we used a previously validated modified comet assay, which predominantly assesses the cellular capacity in the recognition and incision phase of NER to remove bulky DNA adducts (30) and used both tail moment and tail intensity to assess repair capacity. Steatotic liver samples with higher MPO expression had a significant decrease in the activity of this part of the NER pathway compared to the livers with lower expression of MPO using both the tail moment and tail intensity. Although the repair capacity was further reduced in the liver samples taken from NASH patients, the contribution of MPO appears to dominate. A small decrease in NER capacity was also observed in patients with NASH compared with subjects with steatosis alone; however this was not statistically significant. These results suggest that in human liver samples, NER is inhibited by increased MPO in vivo, similar to what we have previously described for lung cells in vitro (20). The level of DNA adducts is the result of a balance between damage induction and its repair. Therefore, one would expect that the lower NER activity in patients with high MPO is accompanied by higher levels of the $M_{1} d G$ adducts. However, in this study we observed comparable levels between the four groups. Human data of both in vivo and in vitro models have demonstrated that cell death, particularly apoptosis, is increased in NAFLD and NASH patients (48). If DNA repair is decreased in these patients as observed in our study, cell death of highly damaged cells could prevent DNA adduct levels to accumulate.

In this study, we have demonstrated that increased expression of MPO in the liver correlates with decreased NER capacity within the liver. Although the amount of inflammatory cells is much lower than the structural liver cells, a limitation of the study is that the differences found in DNA repair may partly be due to differences in the proportion of inflammatory cells that contribute to the tissue lysate, since whole tissue was used for the analysis. The observed decrease in $\mathrm{YH} 2 \mathrm{AX}$ appears to be related to impairment of the recognition of DNA damage when MPO expression is high, as no 
significant reduction of cell proliferation and only a small change in NER gene expression transcription, was observed. Although in patients with NASH there is a decrease in both NER capacity and H2AX phosphorylation, the major component determining the repair capacity appears to be MPO-immunoreactivity. This suggests that increased influx of neutrophils and their activation, which is often associated with $\mathrm{NASH}$, may play an important role in the development of HCC. 


\section{Reference list}

1 Farazi, P.A., and DePinho, R.A. (2006) Hepatocellular carcinoma pathogenesis: from genes to environment. Nat Rev Cancer, 6, 674-687.

2 Boden, G. (2008) Obesity and free fatty acids. Endocrinol Metab Clin North Am, 37, 635646, viii-ix.

3 Yamaguchi, K., Yang, L., McCall, S., Huang, J., Yu, X.X., Pandey, S.K., Bhanot, S., Monia, B.P., Li, Y.X., and Diehl, A.M. (2007) Inhibiting triglyceride synthesis improves hepatic steatosis but exacerbates liver damage and fibrosis in obese mice with nonalcoholic steatohepatitis. Hepatology, 45, 1366-1374.

4 Maher, J.J., Leon, P., and Ryan, J.C. (2008) Beyond insulin resistance: Innate immunity in nonalcoholic steatohepatitis. Hepatology, 48, 670-678.

5 Tilg, H., and Hotamisligil, G.S. (2006) Nonalcoholic fatty liver disease: Cytokine-adipokine interplay and regulation of insulin resistance. Gastroenterology, 131, 934-945.

6 Bugianesi, E. (2007) Non-alcoholic steatohepatitis and cancer. Clin Liver Dis, 11, 191-207, xxi.

7 Bugianesi, E., Leone, N., Vanni, E., Marchesini, G., Brunello, F., Carucci, P., Musso, A., De Paolis, P., Capussotti, L., Salizzoni, M., and Rizzetto, M. (2002) Expanding the natural history of nonalcoholic steatohepatitis: from cryptogenic cirrhosis to hepatocellular carcinoma. Gastroenterology, 123, 134-140.

8 Ong, J.P., and Younossi, Z.M. (2002) Is hepatocellular carcinoma part of the natural history of nonalcoholic steatohepatitis? Gastroenterology, 123, 375-378.

9 Toyokuni, S., Okamoto, K., Yodoi, J., and Hiai, H. (1995) Persistent oxidative stress in cancer. FEBS Lett, 358, 1-3.

10 Sanchez-Perez, Y., Carrasco-Legleu, C., Garcia-Cuellar, C., Perez-Carreon, J., HernandezGarcia, S., Salcido-Neyoy, M., Aleman-Lazarini, L., and Villa-Trevino, S. (2005) Oxidative stress in carcinogenesis. Correlation between lipid peroxidation and induction of preneoplastic lesions in rat hepatocarcinogenesis. Cancer Lett, 217, 25-32.

11 Dewa, Y., Nishimura, J., Muguruma, M., Jin, M., Kawai, M., Saegusa, Y., Okamura, T., Umemura, T., and Mitsumori, K. (2009) Involvement of oxidative stress in hepatocellular tumor-promoting activity of oxfendazole in rats. Arch Toxicol, 83, 503-511.

12 Nishimura, J., Dewa, Y., Muguruma, M., Kuroiwa, Y., Yasuno, H., Shima, T., Jin, M., Takahashi, M., Umemura, T., and Mitsumori, K. (2007) Effect of fenofibrate on oxidative DNA damage and on gene expression related to cell proliferation and apoptosis in rats. Toxicol Sci, 97, 44-54.

13 Maeda, H., and Akaike, T. (1998) Nitric oxide and oxygen radicals in infection, inflammation, and cancer. Biochemistry (Mosc), 63, 854-865.

14 Knaapen, A.M., Gungor, N., Schins, R.P., Borm, P.J., and Van Schooten, F.J. (2006) Neutrophils and respiratory tract DNA damage and mutagenesis: a review. Mutagenesis, 21, 225-236.

15 Klebanoff, S.J. (2005) Myeloperoxidase: friend and foe. J Leukoc Biol, 77, 598-625.

16 Davies, M.J., Hawkins, C.L., Pattison, D.I., and Rees, M.D. (2008) Mammalian heme peroxidases: from molecular mechanisms to health implications. Antioxid Redox Signal, 10, 1199-1234.

17 Pattison, D.I., and Davies, M.J. (2001) Absolute rate constants for the reaction of hypochlorous acid with protein side chains and peptide bonds. Chem Res Toxicol, 14, 1453-1464.

18 Spencer, J.P., Whiteman, M., Jenner, A., and Halliwell, B. (2000) Nitrite-induced deamination and hypochlorite-induced oxidation of DNA in intact human respiratory tract epithelial cells. Free Radic Biol Med, 28, 1039-1050. 
19 Rensen, S.S., Slaats, Y., Nijhuis, J., Jans, A., Bieghs, V., Driessen, A., Malle, E., Greve, J.W., and Buurman, W.A. (2009) Increased hepatic myeloperoxidase activity in obese subjects with nonalcoholic steatohepatitis. Am J Pathol, 175, 1473-1482.

20 Gungor, N., Godschalk, R.W., Pachen, D.M., Van Schooten, F.J., and Knaapen, A.M. (2007) Activated neutrophils inhibit nucleotide excision repair in human pulmonary epithelial cells: role of myeloperoxidase. FASEB J, 21, 2359-2367.

21 Gungor, N., Haegens, A., Knaapen, A.M., Godschalk, R.W., Chiu, R.K., Wouters, E.F., and van Schooten, F.J. (2010) Lung inflammation is associated with reduced pulmonary nucleotide excision repair in vivo. Mutagenesis, 25, 77-82.

22 Langie, S.A., Kowalczyk, P., Tudek, B., Zabielski, R., Dziaman, T., Olinski, R., van Schooten, F.J., and Godschalk, R.W. (2010) The effect of oxidative stress on nucleotide-excision repair in colon tissue of newborn piglets. Mutat Res, 695, 75-80.

23 Cheng, L., Spitz, M.R., Hong, W.K., and Wei, Q. (2000) Reduced expression levels of nucleotide excision repair genes in lung cancer: a case-control analysis. Carcinogenesis, 21, 1527-1530.

24 Latimer, J.J., Johnson, J.M., Kelly, C.M., Miles, T.D., Beaudry-Rodgers, K.A., Lalanne, N.A., Vogel, V.G., Kanbour-Shakir, A., Kelley, J.L., Johnson, R.R., and Grant, S.G. (2010) Nucleotide excision repair deficiency is intrinsic in sporadic stage I breast cancer. Proc Natl Acad Sci U S A.

25 Lindahl, T., and Wood, R.D. (1999) Quality control by DNA repair. Science, 286, 1897-1905.

26 Van Schooten, F.J., Boots, A.W., Knaapen, A.M., Godschalk, R.W., Maas, L.M., Borm, P.J., Drent, M., and Jacobs, J.A. (2004) Myeloperoxidase (MPO) -463G->A reduces MPO activity and DNA adduct levels in bronchoalveolar lavages of smokers. Cancer Epidemiol Biomarkers Prev, 13, 828-833.

27 Munnia, A., Saletta, F., Allione, A., Piro, S., Confortini, M., Matullo, G., and Peluso, M. (2007) 32P-Post-labelling method improvements for aromatic compound-related molecular epidemiology studies. Mutagenesis, 22, 381-385.

28 Munnia, A., Bonassi, S., Verna, A., Quaglia, R., Pelucco, D., Ceppi, M., Neri, M., Buratti, M., Taioli, E., Garte, S., and Peluso, M. (2006) Bronchial malondialdehyde DNA adducts, tobacco smoking, and lung cancer. Free Radic Biol Med, 41, 1499-1505.

29 Seto, H., Seto, T., Takesue, T., and Ikemura, T. (1986) Reaction of malonaldehyde with nucleic acid. III. Studies of the fluorescent substances released by enzymatic digestion of nucleic acids modified with malonaldehyde. Chem Pharm Bull (Tokyo), 34, 5079-5085.

30 Langie, S.A., Knaapen, A.M., Brauers, K.J., van Berlo, D., van Schooten, F.J., and Godschalk, R.W. (2006) Development and validation of a modified comet assay to phenotypically assess nucleotide excision repair. Mutagenesis, 21, 153-158.

31 Knaapen, A.M., Schins, R.P., Borm, P.J., and van Schooten, F.J. (2005) Nitrite enhances neutrophil-induced DNA strand breakage in pulmonary epithelial cells by inhibition of myeloperoxidase. Carcinogenesis, 26, 1642-1648.

32 Coussens, L.M., and Werb, Z. (2002) Inflammation and cancer. Nature, 420, 860-867.

33 Bugianesi, E., Vanni, E., and Marchesini, G. (2007) NASH and the risk of cirrhosis and hepatocellular carcinoma in type 2 diabetes. Curr Diab Rep, 7, 175-180.

34 Powell, E.E., Cooksley, W.G., Hanson, R., Searle, J., Halliday, J.W., and Powell, L.W. (1990) The natural history of nonalcoholic steatohepatitis: a follow-up study of forty-two patients for up to 21 years. Hepatology, 11, 74-80.

35 Zen, Y., Katayanagi, K., Tsuneyama, K., Harada, K., Araki, I., and Nakanuma, Y. (2001) Hepatocellular carcinoma arising in non-alcoholic steatohepatitis. Pathol Int, 51, 127-131.

36 VanderVeen, L.A., Hashim, M.F., Shyr, Y., and Marnett, L.J. (2003) Induction of frameshift and base pair substitution mutations by the major DNA adduct of the endogenous carcinogen malondialdehyde. Proc Natl Acad Sci U S A, 100, 14247-14252. 
37 Johnson, K.A., Fink, S.P., and Marnett, L.J. (1997) Repair of propanodeoxyguanosine by nucleotide excision repair in vivo and in vitro. J Biol Chem, 272, 11434-11438.

38 Gillet, L.C., and Scharer, O.D. (2006) Molecular mechanisms of mammalian global genome nucleotide excision repair. Chem Rev, 106, 253-276.

39 Sancar, A., Lindsey-Boltz, L.A., Unsal-Kacmaz, K., and Linn, S. (2004) Molecular mechanisms of mammalian DNA repair and the DNA damage checkpoints. Annu Rev Biochem, 73, 3985.

40 Kojima, H., Sakurai, S., Uemura, M., Fukui, H., Morimoto, H., and Tamagawa, Y. (2007) Mitochondrial abnormality and oxidative stress in nonalcoholic steatohepatitis. Alcohol Clin Exp Res, 31, S61-66.

41 Loguercio, C., De Girolamo, V., de Sio, I., Tuccillo, C., Ascione, A., Baldi, F., Budillon, G., Cimino, L., Di Carlo, A., Di Marino, M.P., Morisco, F., Picciotto, F., Terracciano, L., Vecchione, R., Verde, V., and Del Vecchio Blanco, C. (2001) Non-alcoholic fatty liver disease in an area of southern Italy: main clinical, histological, and pathophysiological aspects. J Hepatol, 35, 568-574.

42 Seki, S., Kitada, T., Yamada, T., Sakaguchi, H., Nakatani, K., and Wakasa, K. (2002) In situ detection of lipid peroxidation and oxidative DNA damage in non-alcoholic fatty liver diseases. J Hepatol, 37, 56-62.

43 Rogakou, E.P., Pilch, D.R., Orr, A.H., Ivanova, V.S., and Bonner, W.M. (1998) DNA doublestranded breaks induce histone $\mathrm{H} 2 \mathrm{AX}$ phosphorylation on serine 139. J Biol Chem, 273, 5858-5868.

44 Chen, H.T., Bhandoola, A., Difilippantonio, M.J., Zhu, J., Brown, M.J., Tai, X., Rogakou, E.P., Brotz, T.M., Bonner, W.M., Ried, T., and Nussenzweig, A. (2000) Response to RAGmediated VDJ cleavage by NBS1 and gamma-H2AX. Science, 290, 1962-1965.

45 Gagou, M.E., Zuazua-Villar, P., and Meuth, M. (2010) Enhanced H2AX phosphorylation, DNA replication fork arrest, and cell death in the absence of Chk1. Mol Biol Cell, 21, 739752.

46 Marti, T.M., Hefner, E., Feeney, L., Natale, V., and Cleaver, J.E. (2006) H2AX phosphorylation within the G1 phase after UV irradiation depends on nucleotide excision repair and not DNA double-strand breaks. Proc Natl Acad Sci U S A, 103, 9891-9896.

47 Ward, I.M., and Chen, J. (2001) Histone H2AX is phosphorylated in an ATR-dependent manner in response to replicational stress. J Biol Chem, 276, 47759-47762.

48 Machado, M.V., and Cortez-Pinto, H. (2011) Cell death and nonalcoholic steatohepatitis: where is ballooning relevant? Expert Rev Gastroenterol Hepatol, 5, 213-222. 



\section{Chapter 7}

Summary and general discussion 
Understanding the molecular mechanisms of benzo[a]pyrene (BaP) mediated carcinogenesis can be of great importance in the discovery of preventive measures or treatments against carcinogen-induced carcinogenesis. BaP is an environmental agent capable of forming bulky DNA adducts following a complex process of metabolic activation. When unrepaired, these adducts have the potential to form mutations and ultimately cancer. Increased induction of these DNA adducts and decreased repair are two important factors in the carcinogenicity of BaP. When people are exposed to similar amounts of carcinogens like BaP, large inter-individual differences are observed in, for instance, the formation of DNA adducts (1). There are different endogenous factors such as polymorphisms and oxidative stress that might influence carcinogenicity of carcinogens and determine someone's susceptibility to carcinogens. Understanding these factors gives us a better insight in carcinogen-induced tumorigenesis.

One important endogenous factor we explored is the lack of oxygen in the human body, better known as hypoxia. Significantly, hypoxia or more specifically hypoxia inducible factor $\alpha$ (HIF $\alpha$ ) stabilization has been strongly associated with multiple forms of cancer including lung (2), liver (3), cervix and breast cancers (4) and affect the clinical outcome. There are several reasons behind this phenomenon, including the capacity of HIF $\alpha$ stabilization to drive genomic instability and alter DNA damage repair pathways. Cells exposed to low oxygen levels activate the transcription factor HIF $\alpha$ as an adaptive response, which results in changes in gene expression. These alterations in gene expression are crucial in mediating cellular adaptation and survival of the cell.

In this thesis we investigated several pathways for hypoxia-induced mutagenesis. The major pathway is a mechanism where HIF $\alpha$ stabilization induces BaP mutagenicity due to crosstalk between the HIF-pathway and the aryl hydrocarbon receptor (AhR)pathway. Secondly, we investigated the effect of HIF $\alpha$ stabilization on repair of BaPinduced damage by nucleotide excision repair (NER). Finally, as changes in oxygen levels results in alterations in oxidative stress, $(5,6)$, we sought to determine if this oxidative stress could be a second factor influencing carcinogen metabolism

\section{Hypoxia and BaP-induced DNA damage}

In this thesis, we propose a novel mechanism that HIF $\alpha$ stabilization modulates carcinogen metabolism. This may be an important mechanism in carcinogenicity, since HIF $\alpha$ stabilization may already occur in the early phases of disease development, since growth factors (7), oncogene activation and tumorsuppressor gene inactivation (8) as well as reactive oxygen species (9) are able to activate the HIF pathway. Also, alterations in the metabolism of carcinogens, to which we are continuously exposed, can have an important influence on carcinogenesis. Therefore, our proposed mechanism of HIF $\alpha$ altered carcinogen metabolism could be of major relevance for the pre-clinical stages of carcinogenesis. In the first three chapters of this thesis, we investigated gene expression, BaP metabolism, BaP metabolite formation and DNA damage induction and determined the effect of three different modes of HIF $\alpha$ stabilization: $\mathrm{CoCl}_{2}$ (chapter 2), hypoxia (chapter 3), and von Hippel-Lindau (VHL) deficiency (chapter 4) on them. 
In chapter 2, A549 lung carcinoma cells were simultaneously incubated with BaP for 18 hours, to induce the AhR-pathway, and with $\mathrm{CoCl}_{2}$ to induce the HIF-pathway. Analysis indicated that induction of the HIF-pathway significantly reduces the mRNA levels of AhR downstream targets CYP1A1 and CYP1B1. Furthermore, the lower levels of AhR bound to the aryl hydrocarbon nuclear transporter (ARNT) upon HIF $\alpha$ induction indicated competition for ARNT. These results demonstrated that induction of the HIFpathway leads to downstream effects in the AhR-pathway.

Besides the examination of the level of crosstalk between the two pathways as other studies have done before $(10,11)$, importantly, we also investigated the biological significance of this crosstalk, which to our knowledge has not been demonstrated before. Therefore, the effect on genetic instability by measuring mutation frequencies, DNA strand breaks, and BaP-7,8-dihydroxy-9,10-epoxide (BPDE)-DNA adduct formation was determined. The results presented in this thesis showed that the amount of BaPinduced mutant cells and DNA strand breaks were significantly higher when the HIFpathway was induced, suggesting that modulation of carcinogen metabolism may be an important mechanism for the observed HIF mediated genetic instability $(12,13)$.

Other mechanisms besides competition for ARNT may also be involved in HIF modulated BaP genotoxicity. To explain for instance why the BPDE-DNA adduct levels were only $20-50 \%$ increased under HIF1 induction as compared to BaP alone, while the amount of BaP induced mutations were 10-20 fold increased when the HIF1 pathway was activated. Therefore, to further investigate mechanisms involved in the crosstalk, in chapter 3, the role of oxygen in the activation and detoxification of BaP was examined. A549 were treated in a manner similar to the previous chapter with $0.1 \mu \mathrm{M}$ $\mathrm{BaP}$ for 18 hours, but this time under different oxygen concentrations. Oxygen concentrations in the human body vary widely between different tissues, but largely fall in the $2-9 \%$ oxygen range. However, it can get as low as $1 \%$ in for instance the thymus and retina (14). Therefore, $0.2 \%$ oxygen was considered to be hypoxic conditions.

In our experiments we observed induced phase I enzyme gene expression suggesting an increased BaP metabolism under hypoxia, while the observed decreased phase II enzyme gene expression suggests less detoxification of the BaP metabolites. Overall, this implies a possible increased metabolism towards the formation of BPDE. However, our data showed that cells under hypoxic conditions have a reduced capacity to metabolize $\mathrm{BaP}$, resulting in lower metabolite levels. The pre-cursor metabolite (BaP7,8-dihydrodiol) of the reactive metabolite BPDE was however formed in higher concentrations. This shows that the determined gene expression patterns do not completely explain the observed metabolic changes. Nonetheless, the reduced $\mathrm{BaP}$ metabolism, but induced BaP-7,8-dihydrodiol formation, resulted in BPDE-DNA adducts accumulation over a period of 168 hours under hypoxia, whereas adducts were efficiently removed in $20 \%$ oxygen conditions. Ross et al showed that the extended time in which BPDE-DNA adducts are present in the cells, is associated with increased tumorigenesis (15). Since we observe this extended time in our experiment, it suggests that there is an increased risk of BaP-induced carcinogenesis under hypoxic conditions. Besides competition for ARNT, as shown in chapter 2, hypoxia itself directs carcinogen metabolism towards a more toxic metabolic pattern and alter kinetics of 
metabolism leading to longer exposure to these metabolites. Subsequently, resulting in an increased adduct formation. These data further support the idea that modulation of carcinogen metabolism is an important additional mechanism for the observed HIF $\alpha$ mediated genetic instability.

In chapter 4, we sought to determine whether the previously established mechanism holds true in a HIFa stabilized cell line. Therefore, naturally occurring renal cell carcinoma (RCC) cells deficient in VHL were used and compared with a functionally wild type RCC cells line with a reconstituted VHL present to investigate the effect of HIF $\alpha$ stabilization on carcinogen metabolism. Loss of VHL tumor suppressor protein function is associated with stabilization of HIFa regardless of oxygen tension and it is known that mutations in VHL are present in the majority of sporadic RCCs (16). To understand the mechanism by which defective VHL induces carcinogenicity will give better insight in the development of renal cancer. Data presented in this thesis showed that CYP1A1 mRNA levels were strongly diminished in RCC4-VHL cells compared to HIF $\alpha$ stabilized RCC4 cells. CYP1B1 mRNA levels on the other hand were unaffected due to loss of $\mathrm{VHL}$, suggesting that CYP1A1 is the important player in carcinogen metabolism in RCC cells. HPLC analysis indicated that loss of VHL reduces BaP metabolism while increasing BaP-7,8-dihydroxydiol levels, the pre-cursor metabolite of BPDE. This change in carcinogen metabolism resulted in increased BPDE-DNA adduct levels in HIF $\alpha$ stabilized cells. Taken together, these data show that loss of VHL affects $\mathrm{BaP}$-mediated genotoxic responses in RCC and further supports our hypothesis that HIF $\alpha$ stabilization affects carcinogen metabolism.

These three studies demonstrate in different ways that HIF $\alpha$ stabilization modulates carcinogen metabolism. To further elucidate the mechanisms behind this effect, future studies are needed. First of all, the influence of specific genes involved in $\mathrm{BaP}$ metabolism needs to be better determined, since phase I gene expressions was downregulated under treatment with $\mathrm{CoCl}_{2}$, but upregulated under hypoxic conditions and phase II gene expressions seemed to influence BaP metabolism under real hypoxia, but not under VHL deficiency. Knock-out of these genes should explain the effect of the specific genes involved in carcinogen metabolism under HIF $\alpha$ stabilized conditions. Furthermore, the observation that under hypoxic conditions BaP metabolism is decreased resulting in decreased metabolite levels, except for the precursor of BPDE needs to be clarified. Furthermore, to fully understand the physiological impact of the changed carcinogen metabolism, our results need to be confirmed in an animal model. Finally, future studies should investigate the effect of $\mathrm{HIF} \alpha$ stabilization on other carcinogens as well; starting with other polycyclic hydrocarbons, but from there further expanding towards other carcinogens.

\section{Hypoxia and reduced nucleotide excision repair}

Since BPDE-DNA adduct levels are always a balance between the induction of the damage and its removal, we investigated the effect of HIF $\alpha$ stabilization on the repair of BPDE-DNA adducts by NER, since NER is the most important pathway in removing these DNA adducts. Although, hypoxia is known to inhibit DNA repair mechanisms, surprisingly, not much is known about the effect of hypoxia on NER. In chapter 2 we 
already suggested that HIF $\alpha$ stabilization could result in diminished NER, since our data showed that the amount of single strand breaks, generated during the repair of these adducts, is lower when the HIF-pathway is induced. In chapter 4, the observed changes in NER due to the stabilization of HIF $\alpha$ were further elucidated by investigating the NER capacity, by a previously validated modified comet assay which measures the ability of NER-related enzymes to incise DNA containing BPDE-DNA adducts. Our data from RCC cells deficient in VHL indicated that loss of VHL had no effect on DNA repair gene expression, but importantly the capacity to repair BPDE-DNA adducts in the HIF $\alpha$ stabilized RCC4 cells was markedly reduced. This confirms our initial observation in $\mathrm{CoCl}_{2} \mathrm{HIF \alpha}$-stabilized cells described in chapter 2. Ineffective repair could result in increased cancer susceptibility as has been shown in XPA knock-out mice having enhanced tumorigenesis in the lung after exposure to BaP (17). Furthermore, individuals with a reduced NER capacity are at greater risk to develop cancer such as prostate (18) and breast cancer (19). Since mutations in VHL are present in the majority of RCCs, the reduced NER capacity could be responsible for increased susceptibility of renal cells, with a mutated VHL gene, to carcinogens which subsequently could result in the formation of RCC.

\section{Oxidative stress and increased adduct formation}

Since oxidative stress is an important factor in the hypoxia-induced mutagenicity (5), we investigated if oxidative stress itself could have an effect on the metabolism and carcinogenicity of BaP. As mentioned before, individuals can respond differently to similar exposure of $\mathrm{BaP}$, which results in inter-individual differences in BPDE-DNA adduct levels. These differences can be partially explained by genetic differences (20). Although the effect of polymorphisms on BPDE-DNA adduct levels have been studied extensively and genes involved in carcinogen metabolism (21), DNA repair (22), and oxidative stress (23) have been identified, the level of exposure is often insufficiently characterized in large epidemiological studies that investigate the impact of genetic variation on DNA damage or disease. This could lead to misclassification and attenuation of underlying relationships. Therefore, we performed an ex vivo study assessing 34 SNPs based on a priori knowledge (24) and determined which SNPs were responsible for differences in BPDE-DNA adduct levels. In chapter 5, we present an important genetic polymorphism in catalase (C-262T) which to date has not been associated with altered BPDE-DNA adduct formation.

It was observed that this polymorphism located in the promoter site of catalase resulted in an increased activity of catalase in individuals with the variant catalase allele compared to subjects with the wild-type allele, decreasing the levels of oxidative stress. Interestingly, catalase gene expression was strongly correlated with CYP1B1 expression in lymphocytes and A549 cells. Although we did not fully elucidate the mechanism, knock down experiments indicated that two transcription factors (nuclear factor 1 (NF1) and nuclear erythroid 2-related factor 2 (Nrf2)) may play a role in the observed catalase-dependent CYP1B1 gene expression. Our results suggest a model in which the catalase polymorphism determines the amount of intracellular catalase and (co)regulates the expression of CYP1B1 by reducing the amount of $\mathrm{H}_{2} \mathrm{O}_{2}$ present in the 
cells, which subsequently prevents the downregulation of transcription factors needed to transcribe CYP1B1.

Our data indicate that oxidative stress is involved in the alteration in carcinogen metabolism; the proposed mechanism needs however further research. Nonetheless, the identification of susceptible groups carrying this specific polymorphism, which leads to functional changes, could result in a better risk assessment which could eventually result in lifestyle changes or reduction in exposure to certain carcinogens.

\section{Oxidative stress and reduced nucleotide excision repair}

The effect of oxidative stress on BaP-induced DNA damage may not be limited to the increased BPDE-DNA adduct formation, but, like HIF $\alpha$ stabilization, may also alters its repair by reducing NER capacity. Indeed, it was previously shown that NER activity was significantly impaired by neutrophil activation in lung cells in vitro (25) and that this was probably due to ROS formation following the influx of neutrophils (26). Based on these previous observations, it was speculated that in chronic inflamed livers, enhanced levels of oxidative stress due to the recruitment of neutrophils at the site of inflammation could inhibit NER compared to those with steatosis, an earlier stage of non-alcoholic fatty liver disease.

Therefore, in chapter 6 , the role of oxidative stress, in damage recognition and DNA repair in steatotic livers of 35 severely obese subjects with either nonalcoholic steatohepatitis (NASH) or steatosis alone was evaluated. A reduced damage recognition capacity, determined by staining for histone $2 \mathrm{AX}$ phosphorylation $(\mathrm{\gamma H} 2 \mathrm{AX})$, was observed in livers with higher levels of myeloperoxidase, an indicator for neutrophil influx. This reduction in $\mathrm{\gamma H} 2 \mathrm{AX}$ formation was paralleled by a significant decrease in NER capacity. Our results confirmed the previous findings that increased influx of neutrophils and their activation reduces NER activity and might play a role in carcinogenesis. These patients might benefit from better treatment of the inflammation by for instance specific dietary interventions like vitamin $E$ treatment preventing the development of hepatocellular carcinoma (27). Future research is however needed to investigate if this observed reduction in NER also applies to other inflammatory conditions in the human body.

\section{Overall conclusion}

A lot is known about BaP-induced DNA damage, especially on the effect of polymorphisms involved in carcinogen metabolism. However, there are more endogenous factors that could influence one's susceptibility to carcinogens. Therefore, the main goal of this thesis was to investigate two of these endogenous factors (hypoxia and oxidative stress) and to better understand their effect on BaP-induced DNA damage and repair. Since BaP needs to be metabolic activated towards BPDE, alterations in the metabolism of BaP could eventually result in changed BPDE-DNA adduct levels and altered genetic instability.

The first factor investigated in this thesis was hypoxia and the subsequent HIF $\alpha$ stabilization. At present the knowledge on HIF $\alpha$ stabilization affecting carcinogen 
metabolism was limited to research on crosstalk between these two pathways without showing any phenotypic consequences. In three chapters we showed not only that HIF $\alpha$ stabilization caused changes in gene expression of genes involved in BaP metabolism, but also its effect on altered BaP metabolism, and on increased levels of DNA damage. More importantly, we showed the same effect in naturally occurring HIF $\alpha$ stabilized cells, showing the clinical relevance of this crosstalk and indicating that BaP metabolism can already be affected in the early stages of carcinogenesis. Besides hypoxia, we also determined that oxidative stress could have an effect on carcinogen metabolism by a polymorphism in catalase affecting CYP1B1 gene expression.

Finally, we showed that NER capacity is reduced in HIF $\alpha$ stabilized cells, which prevent the repair of those BPDE-DNA adducts and we confirmed in a human model the inhibition of NER by oxidative stress.

In conclusion, the results presented in this thesis shows different types of impact that hypoxia has on the mutagenicity of BaP. Besides increasing the BaP-induced DNA damage and reducing its repair by hypoxia, oxidative stress, which could be a result of hypoxia, plays also an important role in DNA damage inductions and DNA repair reduction. Overall, this thesis gives a better insight in endogenous mechanisms affecting BaP mutagenicity. In the future, this will offer new opportunities to investigate if it is possible to reduce the mutagenicity of carcinogens by influencing HIF $\alpha$ stabilization and reducing oxidative stress levels. Furthermore, a better understanding of the cause of inter-individual difference can result in a better risk assessment of carcinogens. 


\section{Reference list}

1 Rojas, M., Marie, B., Vignaud, J.M., Martinet, N., Siat, J., Grosdidier, G., Cascorbi, I., and Alexandrov, K. (2004) High DNA damage by benzo[a]pyrene 7,8-diol-9,10-epoxide in bronchial epithelial cells from patients with lung cancer: comparison with lung parenchyma. Cancer Lett, 207, 157-163.

2 Jackson, A.L., Zhou, B., and Kim, W.Y. (2010) HIF, hypoxia and the role of angiogenesis in non-small cell lung cancer. Expert Opin Ther Targets, 14, 1047-1057.

3 Wu, X.Z., Xie, G.R., and Chen, D. (2007) Hypoxia and hepatocellular carcinoma: The therapeutic target for hepatocellular carcinoma. J Gastroenterol Hepatol, 22, 1178-1182.

4 Vaupel, P., and Mayer, A. (2007) Hypoxia in cancer: significance and impact on clinical outcome. Cancer Metastasis Rev, 26, 225-239.

5 Chandel, N.S., and Budinger, G.R. (2007) The cellular basis for diverse responses to oxygen. Free Radic Biol Med, 42, 165-174.

6 Moller, P., Loft, S., Lundby, C., and Olsen, N.V. (2001) Acute hypoxia and hypoxic exercise induce DNA strand breaks and oxidative DNA damage in humans. FASEB journal : official publication of the Federation of American Societies for Experimental Biology, 15, 11811186.

7 Bardos, J.I., and Ashcroft, M. (2004) Hypoxia-inducible factor-1 and oncogenic signalling. Bioessays, 26, 262-269.

8 Semenza, G.L. (2003) Targeting HIF-1 for cancer therapy. Nat Rev Cancer, 3, 721-732.

9 Cash, T.P., Pan, Y., and Simon, M.C. (2007) Reactive oxygen species and cellular oxygen sensing. Free Radic Biol Med, 43, 1219-1225.

10 Gradin, K., McGuire, J., Wenger, R.H., Kvietikova, I., fhitelaw, M.L., Toftgard, R., Tora, L., Gassmann, M., and Poellinger, L. (1996) Functional interference between hypoxia and dioxin signal transduction pathways: competition for recruitment of the Arnt transcription factor. Mol Cell Biol, 16, 5221-5231.

11 Gassmann, M., Kvietikova, I., Rolfs, A., and Wenger, R.H. (1997) Oxygen- and dioxinregulated gene expression in mouse hepatoma cells. Kidney Int, 51, 567-574.

12 Reynolds, T.Y., Rockwell, S., and Glazer, P.M. (1996) Genetic instability induced by the tumor microenvironment. Cancer Res, 56, 5754-5757.

13 Papp-Szabo, E., Josephy, P.D., and Coomber, B.L. (2005) Microenvironmental influences on mutagenesis in mammary epithelial cells. International journal of cancer. Journal international du cancer, 116, 679-685.

14 Simon, M.C., and Keith, B. (2008) The role of oxygen availability in embryonic development and stem cell function. Nat Rev Mol Cell Biol, 9, 285-296.

15 Ross, J.A., Nelson, G.B., Wilson, K.H., Rabinowitz, J.R., Galati, A., Stoner, G.D., Nesnow, S., and Mass, M.J. (1995) Adenomas induced by polycyclic aromatic hydrocarbons in strain A/J mouse lung correlate with time-integrated DNA adduct levels. Cancer Res, 55, 10391044.

16 Cohen, H.T., and McGovern, F.J. (2005) Renal-cell carcinoma. N Engl J Med, 353, $2477-$ 2490.

17 Ide, F., lida, N., Nakatsuru, Y., Oda, H., Tanaka, K., and Ishikawa, T. (2000) Mice deficient in the nucleotide excision repair gene XPA have elevated sensitivity to benzo[a]pyrene induction of lung tumors. Carcinogenesis, 21, 1263-1265.

18 Lockett, K.L., Snowhite, I.V., and Hu, J.J. (2005) Nucleotide-excision repair and prostate cancer risk. Cancer Lett, 220, 125-135.

19 Latimer, J.J., Johnson, J.M., Kelly, C.M., Miles, T.D., Beaudry-Rodgers, K.A., Lalanne, N.A., Vogel, V.G., Kanbour-Shakir, A., Kelley, J.L., Johnson, R.R., and Grant, S.G. (2010) 
Nucleotide excision repair deficiency is intrinsic in sporadic stage I breast cancer. Proc Natl Acad Sci U S A, 107, 21725-21730.

20 Eder, E. (1999) Intraindividual variations of DNA adduct levels in humans. Mutat Res, 424, 249-261.

21 Rojas, M., Cascorbi, I., Alexandrov, K., Kriek, E., Auburtin, G., Mayer, L., Kopp-Schneider, A., Roots, I., and Bartsch, H. (2000) Modulation of benzo[a]pyrene diolepoxide-DNA adduct levels in human white blood cells by CYP1A1, GSTM1 and GSTT1 polymorphism. Carcinogenesis, 21, 35-41.

22 Zhao, H., Wang, L.E., Li, D., Chamberlain, R.M., Sturgis, E.M., and Wei, Q. (2008) Genotypes and haplotypes of ERCC1 and ERCC2/XPD genes predict levels of benzo[a]pyrene diol epoxide-induced DNA adducts in cultured primary lymphocytes from healthy individuals: a genotype-phenotype correlation analysis. Carcinogenesis, 29, 1560-1566.

23 Rojas, M., Godschalk, R., Alexandrov, K., Cascorbi, I., Kriek, E., Ostertag, J., Van Schooten, F.J., and Bartsch, H. (2001) Myeloperoxidase--463A variant reduces benzo[a]pyrene diol epoxide DNA adducts in skin of coal tar treated patients. Carcinogenesis, 22, 1015-1018.

24 Wilms, L.C., Boots, A.W., de Boer, V.C., Maas, L.M., Pachen, D.M., Gottschalk, R.W., Ketelslegers, H.B., Godschalk, R.W., Haenen, G.R., van Schooten, F.J., and Kleinjans, J.C. (2007) Impact of multiple genetic polymorphisms on effects of a 4-week blueberry juice intervention on ex vivo induced lymphocytic DNA damage in human volunteers. Carcinogenesis, 28, 1800-1806.

25 Gungor, N., Godschalk, R.W., Pachen, D.M., Van Schooten, F.J., and Knaapen, A.M. (2007) Activated neutrophils inhibit nucleotide excision repair in human pulmonary epithelial cells: role of myeloperoxidase. Faseb J, 21, 2359-2367.

26 Gungor, N., Haegens, A., Knaapen, A.M., Godschalk, R.W., Chiu, R.K., Wouters, E.F., and van Schooten, F.J. (2010) Lung inflammation is associated with reduced pulmonary nucleotide excision repair in vivo. Mutagenesis, 25, 77-82.

27 Singal, A.K., Jampana, S.C., and Weinman, S.A. (2011) Antioxidants as therapeutic agents for liver disease. Liver Int, 31, 1432-1448. 



\section{Nederlandse samenvatting}


Volgens berekeningen zijn er in 2008 wereldwijd ongeveer 12,7 miljoen nieuwe gevallen van kanker geconstateerd en zijn er dat jaar maar liefst 7,6 miljoen mensen overleden aan deze ziekte. Omdat de wereldbevolking groeit en vergrijst en omdat in opkomende economiën slechte gewoontes zoals roken worden overnemen zal dit aantal de komende jaren alleen maar toenemen (1). Al sinds jaar en dag is bekend dat omgevingsfactoren zoals sigarettenrook, alcohol, voeding en blootstelling aan schadelijke stoffen op het werk de oorzaak zijn van het overgrote deel van het aantal doden als gevolg van kanker (2). Het merendeel van de kankerverwekkende stoffen (carcinogenen) dat aanwezig is in de omgeving moet eerst omgezet (gemetaboliseerd) worden tot een nieuwe stof voordat deze stoffen echt schadelijk zijn (3). Daarom kunnen veranderingen in het metabolisme van deze stoffen van invloed zijn op de carcinogeniciteit (de mate waarin een stof kanker kan veroorzaken) van een stof. Uit onderzoek is gebleken dat wanneer verschillende mensen worden blootgesteld aan dezelfde hoeveelheden van een carcinogene stof, er grote individuele verschillen worden waargenomen in de hoeveelheid schade aan het DNA (4). Er zijn verschillende endogene factoren (factoren aanwezig in het lichaam) die de carcinogeniciteit van carcinogenen kunnen beïnvloeden en zo iemands gevoeligheid bepalen. Zo is er al veel bekend over de effecten die polymorfismen (mutaties in het DNA die bij grote delen van de bevolking voorkomen) hebben op het metabolisme van carcinogenen. Er zijn echter meerdere endogene factoren die van invloed kunnen zijn op iemands gevoeligheid voor die carcinogenen, zoals de aanwezigheid van een ontsteking of oxidatieve stress (een overschot aan vrije radicalen en een tekort aan anti-oxidanten). Bovendien kunnen diezelfde factoren misschien van invloed zijn op het herstel van de schade die veroorzaakt wordt door de carcinogenen.

\section{Introductie en doelstellingen van dit proefschrift}

Benzo[a]pyreen (BaP) is een carcinogeen dat in grote mate om ons heen aanwezig is. Dat komt omdat het ontstaat bij incomplete verbranding. Zo is het aanwezig in uitlaatgassen, sigarettenrook en verbrand vlees. BaP is een lipofiele stof. Hierdoor passeert het gemakkelijk het celmembraan. Eenmaal in het cytoplasma van de cel bindt het zich aan de aryl hydrocarbon receptor (AhR), waarna het zich samen verplaatst naar de celkern. In de celkern bindt het zich aan de aryl hydrocarbon receptor nuclear translocator (ARNT) en activeert het de genexpressie van bepaalde genen door zich te binden aan het DNA. Deze route staat bekend als de AhR-pathway. $\mathrm{BaP}$ staat vooral bekend om zijn vermogen om zijn eigen metabolisme te stimuleren door het induceren van de expressie van de cytochroom P450 isovormen CYP1A1 en CYP1B1, twee van de belangrijkste enzymen in de detoxificatie en activatie van BaP (5). Het detoxificatieproces van BaP kan grofweg verdeeld worden in twee fasen. Tijdens fase I wordt er een epoxide groep aan BaP gebonden door CYP1A1 en CYP1B1. De resulterende metabolieten kunnen dan tijdens fase II geconjugeerd worden doordat er een sulfaat, glutathion of glucuronide zuur aan gebonden wordt. De ontstane metaboliet is oplosbaar in water en kan zo makkelijk verwijderd worden uit het lichaam. Dit proces wordt gestuurd door de zogenoemde fase II-enzymen (6). BaP kan echter ook omgezet worden tot BaP-7,8-dihydroxy-9,10-epoxide (BPDE), wat aan het 
DNA bindt en zogenoemde DNA-adducten vormt. Deze adducten moeten verwijderd worden door het nucleotide excision repair (NER)-mechanisme. Als deze adducten echter niet verwijderd worden, kunnen er mutaties in het DNA ontstaan die uiteindelijk tot kanker kunnen leiden.

In dit proefschrift ligt de focus van het onderzoek op twee endogene zuurstofgerelateerde factoren (hypoxie, ofwel een tekort aan zuurstof, en oxidatieve stress). Uit eerder onderzoek is gebleken dat deze factoren van invloed zouden kunnen zijn op het metabolisme van carcinogenen (7) en het herstel van DNA-schade (8). Ons doel was om deze factoren verder te onderzoeken en de biologische significantie van deze factoren (door het veranderen van het metabolisme van carcinogenen en het herstel van DNA-schade) op het ontstaan van kanker te bewijzen.

De eerste endogene factor die we onderzocht hebben is hypoxie. Hypoxie, of meer specifiek, de stabilisatie van het hypoxia-inducible factor $\alpha(H I F \alpha)$ eiwit is sterk geassocieerd met meerdere vormen van kanker zoals long- (9), lever- (10) en baarmoederhals- en borstkanker (11) en is van invloed is op iemands prognose. Als er voldoende zuurstof aanwezig is, worden hydroxylgroepen aan HIFa gebonden door prolyl-4-hydroxylase (12). Het gehydroxyleerde HIFa wordt daarop herkend door een ubiquitine ligase complex dat het von Hippel-Lindau-eiwit (VHL) bevat. Na binding van VHL wordt HIF $\alpha$ afgebroken (13). Hypoxie voorkomt daarintegen de hydroxylaseactiviteit waardoor HIF $\alpha$ niet wordt afgebroken, maar zich verplaatst naar de celkern, waar het zich aan ARNT bindt en HIF1 vormt (14). HIF1 bindt zich hierna aan het DNA waar het de transcriptie van een groot aantal genen verhoogt. Dit proces staat bekend als de HIF-pathway. Deze veranderingen in genexpressie zijn cruciaal voor om de cel te laten overleven.

In dit proefschrift onderzochten we verschillende manieren van hypoxie-geïnduceerde carcinogeniciteit, maar de belangrijkste focus lag op het feit dat beide pathways ARNT nodig hebben en er dus sprake kan zijn van competitie tussen de twee pathways. Daarnaast onderzochten we het effect van HIF $\alpha$-stabilisatie op de herstel van BaPgeïnduceerde schade door NER. Omdat veranderingen in de zuurstofconcentraties kan resulteren in veranderingen in oxidatieve stress $(15,16)$, hebben we onderzocht of oxidatieve stress een tweede endogene factor kan zijn die van invloed is op het metabolisme van carcinogenen en op het herstel van de carcinogeen-geïnduceerde schade.

\section{Hypoxie en BaP-geïnduceerde DNA-schade}

In dit proefschrift introduceren we een nieuw mechanisme waarbij HIF $\alpha$-stabilisatie het carcinogeenmetabolisme moduleert. Dit kan een belangrijk mechanisme zijn in de carcinogeniteit van carcinogenen, aangezien HIF $\alpha$ al kan stabiliseren in de beginfase van de ontwikkeling van kanker. Dit komt omdat groeifactoren (17), activatie van oncogene en deactivatie van tumorsuppressorgenen (18) en de aanwezigheid van zuurstofradicalen de HIF-pathway kunnen activeren (19). Bovendien kunnen veranderingen in het metabolisme van carcinogenen waar we continu blootgesteld aan worden van grote invloed zijn op het ontstaan van kanker. Daarom kan ons voorgestelde mechanisme van groot belang zijn voor de preklinische stadia van de 
ontwikkeling van kanker. In de eerste drie hoofdstukken van dit proefschrift hebben we genexpressie, BaP-metabolisme, de vorming van BaP-metabolieten en DNA-schade onderzocht en bepaald wat het effect is van drie verschillende manieren van HIF $\alpha$ stabilisatie: $\mathrm{CoCl}_{2}$ (hoofdstuk 2), hypoxie (hoofdstuk 3), en von Hippel-Lindau (VHL)deficiëntie (hoofdstuk 4). In hoofdstuk 2 zijn A549-cellen afkomstig van een longcarcinoom gelijktijdig blootgesteld aan BaP (om de AhR-pathway te activeren), en $\mathrm{CoCl}_{2}$ (om de HIF-pathway te activeren). Analyse gaf aan dat het activeren van de HIFpathway de mRNA niveaus reduceert van de AhR-pathway genen CYP1A1 en CYP1B1. Bovendien is er minder AhR gebonden aan ARNT als de HIF-pathway wordt geïnduceerd. Deze resultaten toonden aan dat de activatie van de HIF-pathway effect heeft op de AhR-pathway. Naast het onderzoek naar het niveau van competitie tussen deze twee pathways zoals andere studies al eerder hebben gedaan $(20,21)$, hebben we ook gekeken naar de biologische significantie van deze competitie. Dit was namelijk tot op heden nog niet aangetoond. Hiervoor hebben we het effect van genetische instabiliteit bepaald door het meten van de hoeveelheid gemuteerde cellen, DNAbreuken en BPDE-DNA adducten. De resultaten zoals beschreven in dit proefschrift laten zien dat de hoeveelheid BaP-geïnduceerde mutante cellen en de hoeveelheid DNA-breuken significant hoger zijn als de HIF-pathway wordt geactiveerd, wat aangeeft dat veranderingen van het metabolisme van carcinogenen een belangrijk mechanisme kunnen zijn voor de in andere onderzoeken waargenomen HIFgemedieerde genetische instabiliteit $(22,23)$.

Behalve de competitie voor ARNT zijn er echter ook andere mechanismen zijn die de HIF gemoduleerde BaP-genotoxiciteit bepalen. Zo zagen wij bijvoorbeeld dat het niveau van het BPDE-DNA-adduct slechts tussen de 20 en $50 \%$ verhoogd was als de HIF-pathway was geïnduceerd ten opzichte van BaP alleen, terwijl de hoeveelheid BaPgeïnduceerde mutaties 10 tot 20 maal hoger waren wanneer de HIF1 pathway was geactiveerd. Om mogelijke andere mechanismen te onderzoeken die betrokken zijn bij HIF-geinduceerde BaP-carcinogeniciteit, hebben we in hoofdstuk $\mathbf{3}$ de rol van zuurstof in de activatie en detoxificatie van BaP onderzocht. A549-cellen werden op vergelijkbare wijze behandeld als in het voorgaande hoofdstuk, maar dit keer werden de cellen blootgesteld aan verschillende concentraties zuurstof. Zuurstofconcentraties in het menselijk lichaam variëren sterk tussen de verschillende weefsels. Over het algemeen liggen ze tussen de 2 tot $9 \%$, met uitzondering van sommige weefsels zoals de thymus en de retina, waar de zuurstofconcentratie op slechts $1 \%$ ligt (24). Daarom hebben we gekozen voor een concentratie van $0,2 \%$ zuurstof. Deze is representatief voor hypoxische omstandigheden.

In deze experimenten zagen we een toename in de genexpressie van fase I-enzymen. Dit is een indicatie voor een verhoogd BaP-metabolisme tijdens hypoxie, terwijl de waargenomen verminderde genexpressie van fase II-enzymen een verminderde verwijdering van de BaP-metabolieten aangeeft. Over het algemeen betekent dit een mogelijk verhoogd metabolisme, wat resulteert in een verhoogde vorming van BPDE. Uit onze gegevens bleek echter dat de cellen onder hypoxische condities een verminderde capaciteit hebben om $\mathrm{BaP}$ te metaboliseren, wat resulteerde in lagere hoeveelheden metabolieten die aanwezig zijn. De precursor metaboliet (BaP-7,8dihydrodiol) van de reactieve metaboliet BPDE was echter in hogere concentraties in 
de cel aanwezig. Dit toont aan dat de vastgestelde genexpressiepatronen de waargenomen metabole veranderingen niet volledig verklaren. Desalniettemin toonden we aan dat het verminderde BaP metabolisme, maar geïnduceerde BaP-7,8dihydrodiol vorming onder hypoxie leidde tot een accumulatie van BPDE-DNAadducten over een periode van 168 uur, terwijl adducten efficiënt werden verwijderd bij $20 \%$ zuurstof.

Ross et al. toonden aan dat de tijd waarin BPDE-DNA-adducten aanwezig zijn in de cellen geassocieerd wordt met een verhoogde tumorvorming (25). Omdat in ons experiment de adducten onder hypoxische condities voor een langere tijd aanwezig zijn in vergelijking met niet-hypoxische condities, suggereert dit dat er een verhoogd risico is op BaP-geïnduceerde carcinogenese onder hypoxische condities. Naast de competitie voor ARNT, zoals aangetoond in hoofdstuk 2, tonen we in hoofdstuk $\mathbf{3}$ aan dat hypoxie het carcinogeenmetabolisme in de richting van een meer toxische metaboolpatroon stuurt en dat de veranderde kinetiek van het metabolisme leidt tot meer blootstelling aan deze metabolieten. Dit resulteert vervolgens in een verhoogde adductvorming. Deze gegevens ondersteunen het idee dat de modulatie van het carcinogeenmetabolisme een belangrijk extra mechanisme is in de waargenomen HIF $\alpha$-gemedieerde genetische instabiliteit.

In hoofdstuk 4 hebben we geprobeerd te bepalen of het eerder vastgestelde mechanisme ook geldt in een HIF $\alpha$-gestabiliseerde cellijn. Daarom hebben we cellen van een niercelcarcinoom (RCC) gebruikt die een niet-functionerend VHL-gen hebben. Deze werden vergeleken met RCC-cellen waar een functionerend VHL-gen in terug was gebracht (RCC4-VHL-cellen). Het niet-functioneren van het VHL-tumorsuppressoreiwit resulteert in de stabilisatie van HIFa ongeacht de zuurstofconcentratie en het is bekend dat de meeste RCCs een mutatie hebben in het VHL-gen (26). De resultaten uit dit proefschrift laten zien dat CYP1A1 mRNA-niveaus sterk zijn afgenomen in de RCC4VHL-cellen in vergelijking met HIF $\alpha$-gestabiliseerde RCC4-cellen. De mRNA-niveaus van CYP1B1 werden daarentegen niet beïnvloed door het verlies van VHL. Dit geeft aan dat CYP1A1 de belangrijkste speler is in het carcinogeenmetabolisme in RCC-cellen. HPLCanalyse toonde aan dat door het verlies van VHL het BaP-metabolisme vermindert, terwijl er wel hogere niveaus van BaP-7,8-dihydroxydiol aanwezig zijn (de precursormetaboliet van BPDE). Deze verandering in het carcinogeenmetabolisme resulteert in een verhoogd aantal BPDE-DNA-adduct in HIF $\alpha$ gestabiliseerde cellen. Al deze gegevens tonen aan dat het verlies van VHL van invloed is op BaP-gemedieerde genotoxische reacties in RCC. Dit ondersteunt onze hypothese dat HIF $\alpha$-stabilisatie carcinogeenmetabolisme beïnvloedt.

De drie studies uitgevoerd in dit proefschrift tonen op verschillende manieren aan dat HIF $\alpha$-stabilisatie carcinogeenmetabolisme moduleert. Om dit mechanisme verder te ontrafelen, zijn er uiteraard meer studies nodig. Omdat we in ons onderzoek zagen dat de genexpressie van fase I-enzymen verminderd was na behandeling met $\mathrm{CoCl}_{2}$, maar geïnduceerd onder hypoxische omstandigheden, moet allereerst de invloed van specifieke genen in het BaP-metabolisme beter worden bepaald. Bovendien leek veranderde genexpressie van fase II-enzymen onder echte hypoxie het BaPmetabolisme te beïnvloeden, maar was dat niet het geval toen er sprake was van VHLdeficiëntie. Het uitschakelen van specifieke genen zal meer inzicht geven in de werking 
van deze genen en hun invloed op het carcinogeenmetabolisme onder omstandigheden waarin HIF $\alpha$ gestabiliseerd is. Voorts hebben we waargenomen dat onder hypoxische omstandigheden het BaP-metabolisme vermindert. Dit resulteerde in verminderde metabolietvormen (behalve bij de voorloper van BPDE). Om bovendien volledig te begrijpen wat de fysiologische impact is van het gewijzigde carcinogeenmetabolisme, moeten onze resultaten bevestigd worden in een diermodel. Ten slotte kunnen toekomstige studies onderzoek doen naar het effect van HIF $\alpha$ stabilisatie op andere carcinogenen, te beginnen bij andere polycyclische koolwaterstoffen en dat verder uitbreiden naar andere carcinogenen.

\section{Hypoxie en verminderde nucleotide excision repair}

Adduct-niveaus van BPDE-DNA zijn altijd een evenwicht tussen het ontstaan van de schade en het herstel ervan. Daarom onderzochten we het effect van HIF $\alpha$ stabilisering op het herstel van BPDE-DNA-adducten door NER; de belangrijkste route voor het verwijderen van deze DNA-adducten. Hoewel het bekend is dat hypoxie DNAherstelmechanismen kan remmen, is er verrassend weinig bekend over het effect van hypoxie op NER. In hoofdstuk 2 hebben we al gesuggereerd dat HIF $\alpha$-stabilisatie zou kunnen leiden tot verminderde NER, omdat uit onze gegevens bleek dat het niveau van enkelstrengsbreuken die tijdens het herstel van deze adducten ontstaan, lager is wanneer de HIF-pathway wordt geïnduceerd. In hoofdstuk 4 werden de waargenomen veranderingen in NER als gevolg van de stabilisatie van HIF $\alpha$ verder bekeken. De gegevens toonden in RCC-cellen met een niet werkend VHL-eiwit aan dat het verlies van VHL-functie geen effect heeft op de genexpressie van NER-genen, maar dat het vermogen om BPDE-DNA adducten te herstellen in de HIF $\alpha$-gestabiliseerde RCC4cellen aanmerkelijk verminderd is. Dit bevestigt onze eerdere observatie in cellen waarin $\mathrm{HIF} \alpha$-is gestabiliseerd door $\mathrm{CoCl}_{2}$ beschreven in hoofdstuk 2. Ineffectief herstel van adducten kan leiden tot een verhoogde gevoeligheid van kanker, zoals is aangetoond in een muizensoort waarin NER niet meer werkte. In deze muizen werd een verhoogde tumorvorming in de longen waargenomen nadat ze blootgesteld waren aan $\mathrm{BaP}$ (27). Bovendien lopen mensen met een verminderde NER-capaciteit een groter risico om kanker te ontwikkelen, zoals prostaat-(28) en borstkanker (29). Aangezien mutaties in VHL aanwezig zijn in de meeste niercarcinoma, kan de beperkte capaciteit van NER verantwoordelijk zijn voor verhoogde gevoeligheid van niercellen met een gemuteerd VHL-gen aan carcinogenen. Dit kan vervolgens leiden tot (de vorming van) nierkanker.

\section{Oxidatieve stress en een verhoogde adductvorming}

Omdat oxidatieve stress een belangrijke factor is in hypoxie-geïnduceerde carcinogenese (15), hebben wij onderzocht of oxidatieve stress zelf een effect kan hebben op het metabolisme en de carcinogeniteit van BaP. Zoals eerder aangegeven kunnen individuen verschillend reageren op dezelfde blootstelling aan $\mathrm{BaP}$, waardoor individuele verschillen in BPDE-DNA adductniveaus waargenomen worden. Deze verschillen kunnen gedeeltelijk verklaard worden door genetische verschillen (30). 
Hoewel het effect van polymorfismen op BPDE-DNA adduct-niveaus uitgebreid is bestudeerd en genen die betrokken zijn bij carcinogeen metabolisme (31), DNA herstel (32), en oxidatieve stress (33) zijn geïdentificeerd, wordt het niveau van blootstelling vaak onnauwkeurig bepaald in grote epidemiologische studies die de impact van de genetische variatie onderzoeken op DNA-schade of ziekte. Dit kan leiden tot misclassificatie en verzwakking van de onderliggende relaties. Daarom hebben we een ex vivo-studie uitgevoerd naar 34 polymorfismen op basis van a prior-kennis (34). We hebben polymorfismen geïdentificeerd die verantwoordelijk waren voor verschillen in BPDE-DNA adductniveaus. In hoofdstuk 5 presenteren we een belangrijk genetisch polymorfisme in catalase (C-262T), die tot op heden niet is in verband gebracht met veranderde BPDE-DNA adductvorming. Dit polymorfisme in de promotor van catalase zorgde voor een verhoogde activiteit van catalase in individuen met het homozygote variante catalase allel in tegenstelling tot personen met het wild-type allel, wat resulteerde in verminderde oxidatieve stress. Interessant is dat de genexpressie van catalase sterk gecorreleerd is aan CYP1B1-expressie in lymfocyten en A549-cellen. Hoewel we niet volledig het mechanisme hebben kunnen verklaren, toonden knockdownexperimenten aan dat twee transcriptiefactoren (nuclear factor 1 (NF1) en nucleaire erytroïde 2-gerelateerde factor 2 (Nrf2) mogelijk een rol spelen in de waargenomen catalase-afhankelijke CYP1B1 genexpressie. Onze resultaten suggereren een model waarbij het polymorfisme in catalase de hoeveelheid intracellulaire catalase bepaalt en zo de expressie van CYP1B1 beïnvloedt door de hoeveelheid $\mathrm{H}_{2} \mathrm{O}_{2}$ in de cellen te verminderen. Dit voorkomt vervolgens de afname van transcriptiefactoren die nodig zijn om genexpressie van CYP1B1-enzymen te induceren. Deze gegevens tonen aan dat oxidatieve stress van invloed kan zijn op verandering in het carcinogeenmetabolisme. Het voorgestelde mechanisme moet echter verder onderzocht worden. Wel kan de identificatie van gevoelige groepen die dit specifieke polymorfisme hebben, leiden tot een betere risicobeoordeling. Dit kan uiteindelijk resulteren in specifiek advies over leefstijlveranderingen of verlaging van blootstelling van deze specifieke groepen aan bepaalde carcinogenen.

\section{Oxidatieve stress en een verminderd herstel van DNA adducten}

Het effect van oxidatieve stress op BaP-geïnduceerde DNA-schade kan niet alleen resulteren in verhoogde BPDE-DNA adduct vorming, maar net als bij HIF $\alpha$-stabilisatie leiden tot verminderde NER-capaciteit. Er is eerder aangetoond binnen onze afdeling dat NER-activiteit aanzienlijk werd verminderd door in vitro-activatie van neutrofielen in longcellen (35) en dat dit vermoedelijk veroorzaakt werd door het ontstaan van oxidatieve stress na de influx van neutrofielen in het weefsel (8). Op basis van deze eerdere observaties wilden we onderzoeken of dit ook het geval was bij chronisch ontstoken lever. Daarom werd in hoofdstuk 6 de rol van oxidatieve stress in schadeherkenning en DNA-herstel in steatotische levers van 35 ernstig obese patiënten met ofwel non-alcoholische steatohepatitis (NASH; ontstoken lever) of steatose (leververvetting) vergeleken met elkaar. Door gebruik te maken van een kleuring voor histon-2AX-fosforylering $(\mathrm{\gamma H} 2 \mathrm{AX})$ toonden we aan dat er sprake is van een verminderde herkenning van de schade in levers met hogere niveaus van 
myeloperoxidase, een indicator voor influx van neutrofielen. Deze verminderde $\mathrm{YH} 2 \mathrm{AX}$-vorming ging gepaard met een significante afname van de NER-capaciteit. Onze resultaten bevestigen dus de eerdere bevindingen dat de influx van neutrofielen leidt tot een verminderde NER-activiteit. Dit zou een rol kunnen spelen bij het ontstaan van kanker. Deze patiënten zouden kunnen profiteren van een betere behandeling van de ontsteking of van specifieke aanpassingen in hun dieet, zoals extra vitamine $E$ die de ontwikkeling van hepatocellulair carcinoom kan beperken (36). Nader onderzoek is echter nodig om te bevestigen of deze waargenomen verlaging in NER ook geldt voor andere ontstekingsaandoeningen in het menselijk lichaam.

\section{Algemene conclusie}

$\mathrm{Er}$ is al veel bekend over BaP-geïnduceerde DNA-schade en welke factoren hierop van invloed kunnen zijn, in het bijzonder over het effect van polymorfismen die betrokken zijn bij het metabolisme van carcinogenen. Er zijn echter meer endogene factoren die de gevoeligheid voor carcinogenen kunnen beïnvloeden. Daarom was het doel van dit proefschrift om twee van deze endogene factoren (hypoxie en oxidatieve stress) verder te onderzoeken om zo meer inzicht te krijgen in het effect dat ze hebben op de BaP-geïnduceerde DNA-schade en het herstel van die schade. Omdat BaP gemetaboliseerd moet worden tot BPDE voordat het kan reageren met het DNA, kunnen veranderingen in het metabolisme van BaP uiteindelijk resulteren in een veranderd BPDE-DNA adduct niveau en veranderde genetische instabiliteit. De eerste endogene factor die is onderzocht in dit proefschrift was hypoxie en de daaropvolgende HIF $\alpha$-stabilisatie. Momenteel is de kennis over de invloed van HIF $\alpha$ stabilisatie op carcinogeenmetabolisme beperkt tot de competitie tussen de HIFpathway en de AhR-pathway. Echter is nog nooit aangetoond of dat deze competitie ook daadwerkelijk klinische gevolgen heeft. In drie hoofdstukken hebben we laten zien dat niet alleen $\mathrm{HIF} \alpha$-stabilisatie veranderingen veroorzaakt in genexpressie van genen die betrokken zijn bij BaP-metabolisme, maar dat dit ook leidt tot een veranderd BaPmetabolisme en tot verhoogde DNA-schade. Hetzelfde effect toonden we aan in de in het lichaam voorkomende door HIF $\alpha$ gestabiliseerde cellen, wat de klinische relevantie van deze competitie aangeeft. Dit toont aan dat BaP-metabolisme al kan worden beïnvloed in de vroege stadia van carcinogenese.

Behalve de invloed vanhypoxie hebben we ook vastgesteld dat oxidatieve stress een effect kan hebben op het carcinogeenmetabolisme. We hebben een relatie kunnen leggen tussen een polymorfisme in catalase dat invloed heeft op de genexpressie van CYP1B1. Tot slot toonden we aan dat de NER-capaciteit wordt verminderd in HIF $\alpha$ gestabiliseerde cellen, waardoor het herstel van BPDE-DNA adducten wordt verminderd. Bovendien hebben we in een humaan model bevestigd dat oxidatieve stress in staat is om NER te remmen.

Kortom, de resultaten van dit proefschrift tonen de verschillende soorten impact aan die hypoxie heeft op de mutageniteit van BaP. Naast het verhogen van de BaPgeïnduceerde DNA-schade en het verminderen van het herstel door hypoxie, speelt ook oxidatieve stress een belangrijke rol in het veroorzaken van DNA-schade en het verminderde herstel van deze schade. Over het geheel genomen geeft dit proefschrift 
een beter inzicht in de endogene mechanismen die van invloed kunnen zijn op de BaPmutageniteit. Dit kan in de toekomst leiden tot onderzoek dat bekijkt of het mogelijk is om de mutageniteit van kankerverwekkende stoffen te verminderen door HIF $\alpha$ stabilisatie te beïnvloeden en oxidatieve stress te verminderen. Het begrijpen van de moleculaire mechanismen die de carcinogeniciteit van BaP bepalen kan bovendien van groot belang zijn in het bepalen van preventieve maatregelen of het ontdekken van nieuwe behandelingen tegen carcinogeen-geïnduceerde tumoren. Bovendien kan een beter idee over de oorzaken van de interindividuele verschillen leiden tot een betere risico-evaluatie van kankerverwekkende stoffen. 
1 Jemal, A., Bray, F., Center, M.M., Ferlay, J., Ward, E., and Forman, D. (2011) Global cancer statistics. CA Cancer J Clin, 61, 69-90.

2 Lichtenstein, P., Holm, N.V., Verkasalo, P.K., Iliadou, A., Kaprio, J., Koskenvuo, M., Pukkala, E., Skytthe, A., and Hemminki, K. (2000) Environmental and heritable factors in the causation of cancer--analyses of cohorts of twins from Sweden, Denmark, and Finland. $N$ Engl J Med, 343, 78-85.

3 Luch, A. (2005) Nature and nurture - lessons from chemical carcinogenesis. Nat Rev Cancer, 5, 113-125.

4 Rojas, M., Marie, B., Vignaud, J.M., Martinet, N., Siat, J., Grosdidier, G., Cascorbi, I., and Alexandrov, K. (2004) High DNA damage by benzo[a]pyrene 7,8-diol-9,10-epoxide in bronchial epithelial cells from patients with lung cancer: comparison with lung parenchyma. Cancer Lett, 207, 157-163.

5 Gelboin, H.V. (1980) Benzo[alpha]pyrene metabolism, activation and carcinogenesis: role and regulation of mixed-function oxidases and related enzymes. Physiol Rev, 60, 11071166.

6 Baird, W.M., Hooven, L.A., and Mahadevan, B. (2005) Carcinogenic polycyclic aromatic hydrocarbon-DNA adducts and mechanism of action. Environ Mol Mutagen, 45, 106-114.

7 Chan, W.K., Yao, G., Gu, Y.Z., and Bradfield, C.A. (1999) Cross-talk between the aryl hydrocarbon receptor and hypoxia inducible factor signaling pathways. Demonstration of competition and compensation. J Biol Chem, 274, 12115-12123.

8 Gungor, N., Haegens, A., Knaapen, A.M., Godschalk, R.W., Chiu, R.K., Wouters, E.F., and van Schooten, F.J. (2010) Lung inflammation is associated with reduced pulmonary nucleotide excision repair in vivo. Mutagenesis, 25, 77-82.

9 Jackson, A.L., Zhou, B., and Kim, W.Y. (2010) HIF, hypoxia and the role of angiogenesis in non-small cell lung cancer. Expert Opin Ther Targets, 14, 1047-1057.

10 Wu, X.Z., Xie, G.R., and Chen, D. (2007) Hypoxia and hepatocellular carcinoma: The therapeutic target for hepatocellular carcinoma. J Gastroenterol Hepatol, 22, 1178-1182.

11 Vaupel, P., and Mayer, A. (2007) Hypoxia in cancer: significance and impact on clinical outcome. Cancer Metastasis Rev, 26, 225-239.

12 Jaakkola, P., Mole, D.R., Tian, Y.M., Wilson, M.I., Gielbert, J., Gaskell, S.J., Kriegsheim, A., Hebestreit, H.F., Mukherji, M., Schofield, C.J., Maxwell, P.H., Pugh, C.W., and Ratcliffe, P.J. (2001) Targeting of HIF-alpha to the von Hippel-Lindau ubiquitylation complex by O2regulated prolyl hydroxylation. Science, 292, 468-472.

13 Kallio, P.J., Wilson, W.J., O'Brien, S., Makino, Y., and Poellinger, L. (1999) Regulation of the hypoxia-inducible transcription factor 1alpha by the ubiquitin-proteasome pathway. $J$ Biol Chem, 274, 6519-6525.

14 Wang, G.L., Jiang, B.H., Rue, E.A., and Semenza, G.L. (1995) Hypoxia-inducible factor 1 is a basic-helix-loop-helix-PAS heterodimer regulated by cellular $\mathrm{O} 2$ tension. Proc Natl Acad Sci US A, 92, 5510-5514.

15 Chandel, N.S., and Budinger, G.R. (2007) The cellular basis for diverse responses to oxygen. Free Radic Biol Med, 42, 165-174.

16 Moller, P., Loft, S., Lundby, C., and Olsen, N.V. (2001) Acute hypoxia and hypoxic exercise induce DNA strand breaks and oxidative DNA damage in humans. FASEB journal : official publication of the Federation of American Societies for Experimental Biology, 15, 11811186.

17 Bardos, J.I., and Ashcroft, M. (2004) Hypoxia-inducible factor-1 and oncogenic signalling. Bioessays, 26, 262-269.

18 Semenza, G.L. (2003) Targeting HIF-1 for cancer therapy. Nat Rev Cancer, 3, 721-732. 
19 Cash, T.P., Pan, Y., and Simon, M.C. (2007) Reactive oxygen species and cellular oxygen sensing. Free Radic Biol Med, 43, 1219-1225.

20 Gradin, K., McGuire, J., Wenger, R.H., Kvietikova, I., fhitelaw, M.L., Toftgard, R., Tora, L., Gassmann, M., and Poellinger, L. (1996) Functional interference between hypoxia and dioxin signal transduction pathways: competition for recruitment of the Arnt transcription factor. Mol Cell Biol, 16, 5221-5231.

21 Gassmann, M., Kvietikova, I., Rolfs, A., and Wenger, R.H. (1997) Oxygen- and dioxinregulated gene expression in mouse hepatoma cells. Kidney Int, 51, 567-574.

22 Reynolds, T.Y., Rockwell, S., and Glazer, P.M. (1996) Genetic instability induced by the tumor microenvironment. Cancer Res, 56, 5754-5757.

23 Papp-Szabo, E., Josephy, P.D., and Coomber, B.L. (2005) Microenvironmental influences on mutagenesis in mammary epithelial cells. International journal of cancer. Journal international du cancer, 116, 679-685.

24 Simon, M.C., and Keith, B. (2008) The role of oxygen availability in embryonic development and stem cell function. Nat Rev Mol Cell Biol, 9, 285-296.

25 Ross, J.A., Nelson, G.B., Wilson, K.H., Rabinowitz, J.R., Galati, A., Stoner, G.D., Nesnow, S., and Mass, M.J. (1995) Adenomas induced by polycyclic aromatic hydrocarbons in strain A/J mouse lung correlate with time-integrated DNA adduct levels. Cancer Res, 55, 10391044.

26 Cohen, H.T., and McGovern, F.J. (2005) Renal-cell carcinoma. N Engl J Med, 353, 2477 2490.

27 Ide, F., lida, N., Nakatsuru, Y., Oda, H., Tanaka, K., and Ishikawa, T. (2000) Mice deficient in the nucleotide excision repair gene XPA have elevated sensitivity to benzo[a]pyrene induction of lung tumors. Carcinogenesis, 21, 1263-1265.

28 Lockett, K.L., Snowhite, I.V., and Hu, J.J. (2005) Nucleotide-excision repair and prostate cancer risk. Cancer Lett, 220, 125-135.

29 Latimer, J.J., Johnson, J.M., Kelly, C.M., Miles, T.D., Beaudry-Rodgers, K.A., Lalanne, N.A., Vogel, V.G., Kanbour-Shakir, A., Kelley, J.L., Johnson, R.R., and Grant, S.G. (2010) Nucleotide excision repair deficiency is intrinsic in sporadic stage I breast cancer. Proc Natl Acad Sci U S A, 107, 21725-21730.

30 Eder, E. (1999) Intraindividual variations of DNA adduct levels in humans. Mutat Res, 424, 249-261.

31 Rojas, M., Cascorbi, I., Alexandrov, K., Kriek, E., Auburtin, G., Mayer, L., Kopp-Schneider, A., Roots, I., and Bartsch, H. (2000) Modulation of benzo[a]pyrene diolepoxide-DNA adduct levels in human white blood cells by CYP1A1, GSTM1 and GSTT1 polymorphism. Carcinogenesis, 21, 35-41.

32 Zhao, H., Wang, L.E., Li, D., Chamberlain, R.M., Sturgis, E.M., and Wei, Q. (2008) Genotypes and haplotypes of ERCC1 and ERCC2/XPD genes predict levels of benzo[a]pyrene diol epoxide-induced DNA adducts in cultured primary lymphocytes from healthy individuals: a genotype-phenotype correlation analysis. Carcinogenesis, 29, 1560-1566.

33 Rojas, M., Godschalk, R., Alexandrov, K., Cascorbi, I., Kriek, E., Ostertag, J., Van Schooten, F.J., and Bartsch, H. (2001) Myeloperoxidase--463A variant reduces benzo[a]pyrene diol epoxide DNA adducts in skin of coal tar treated patients. Carcinogenesis, 22, 1015-1018.

34 Wilms, L.C., Boots, A.W., de Boer, V.C., Maas, L.M., Pachen, D.M., Gottschalk, R.W., Ketelslegers, H.B., Godschalk, R.W., Haenen, G.R., van Schooten, F.J., and Kleinjans, J.C. (2007) Impact of multiple genetic polymorphisms on effects of a 4-week blueberry juice intervention on ex vivo induced lymphocytic DNA damage in human volunteers. Carcinogenesis, 28, 1800-1806. 
Nederlandse samenvatting

35 Gungor, N., Godschalk, R.W., Pachen, D.M., Van Schooten, F.J., and Knaapen, A.M. (2007) Activated neutrophils inhibit nucleotide excision repair in human pulmonary epithelial cells: role of myeloperoxidase. Faseb J, 21, 2359-2367.

36 Singal, A.K., Jampana, S.C., and Weinman, S.A. (2011) Antioxidants as therapeutic agents for liver disease. Liver Int, 31, 1432-1448. 




\section{Dankwoord}


Zo aan het einde van dit proefschrift is het tijd om de mensen te bedanken die ervoor gezorgd hebben dat hetgeen nu voor $\mathrm{u}$ ligt ook daadwerkelijk zo geworden is. Ik wil niet alleen de mensen bedanken die er daadwerkelijk voor hebben gezorgd dat er data kwam om artikelen mee te vullen, maar ik wil ook de mensen bedanken die de afgelopen vier jaar voor de sfeer en het plezier hebben gezorgd op de afdeling.

Allereerst wil ik mijn co-promotor Dr. Roland Chiu bedanken. Toen ik in 2008 begon, had een oud-GRAT-medewerker ervoor gezorgd dat er geld was om mij aan te nemen als Phd-student. Hij was echter bij zijn vertrek vergeten te vermelden dat het onderzoeksvoorstel dat hij geschreven had al werd uitgevoerd door een collega-aio. Daar zit je dan zonder begeleiding en zonder onderwerp als beginnend aio. Het enige wat je kunt doen is een beetje literatuur lezen waarvan je maar hoopt dat je die nog nodig zult hebben. Achteraf gezien heb ik dus inderdaad vier maanden lang artikelen gelezen die ik nooit meer heb hoeven te gebruiken, maar er is dankzij jou wel een enorm leuk onderwerp voor in de plaats gekomen. Je zorgde tijdens mijn aio-periode voor de perfecte combinatie: je liet mij het initiatief nemen, maar verschafte ook hulp en ideeën als ik die nodig had. Ik heb me in de afgelopen vier jaar kunnen ontwikkelen als onderzoeker en hoewel ik nu niet meer in het onderzoek zit, kan ik wat ik geleerd heb nog steeds toepassen in mijn huidige werk. Heel erg bedankt hiervoor.

Daarnaast wil ik mijn tweede copromoter Dr. Roger Godschalk bedanken. Je maakte altijd al deel uit van de projectgroep, maar ging me echt begeleiden toen Roland tijdelijk in het buitenland zat. Ik kan zeggen dat jij je rol als begeleider met verve vervuld hebt. Ik kon altijd bij je terecht met vragen en je hulp met de statistiek heb ik erg gewaardeerd. Bovendien was je altijd zeer geïnteresseerd in mijn onderzoek. Ook mijn promotor Prof. Dr. Frederik-Jan van Schooten verdient woorden van lof. Ik heb je interesse in mijn onderzoek en je inbreng zeer gewaardeerd. Dat mijn promotieperiode in Maastricht binnen vier jaar afgerond kon worden, is aan jullie alle drie te danken. Heren, dank voor alles.

De beoordelingscommissie, bestaande uit Prof. Dr. Bast, Prof. Dr. Ramaekers, Prof. Dr. Vooijs en Dr. Langen, wil ik graag bedanken voor het beoordelen van mijn proefschrift.

Ook mijn oud-collega's verdienen een woord van dank. Leen wil ik graag bedanken voor het mogelijk maken van mijn eerste artikel. Toen het de eerste keer terug kwam moest er nog behoorlijk wat extra onderzoek verricht worden. Zonder jou was dat niet in die drie maanden gelukt. Sandra wil ik graag bedanken voor het uitvoeren van de kleuringen voor het leverartikel. Je deed dit helemaal vrijwillig tussen je al drukke schema door en daar ben ik je zeer dankbaar voor. Lou wil ik graag bedanken voor het ${ }^{32} \mathrm{P}$-postlabellen van mijn samples en Edwin voor zijn hulp met de HPLC. Daarnaast wil ik alle analisten inclusief de hierboven al genoemden ook bedanken voor de gezelligheid op het lab.

In totaal heb ik ook zeven stagairs gehad waarvan er eentje vrijwillig na zijn studie nog wat bijbeunde. In 2010 had ik het geluk dat drie stagairs voor mij werkten, Kathleen, 
Sarah en Yvonne. Een jaar later waren er opnieuw drie stagiairs, namelijk Constance, Pratiksha en Tom die me hielpen met mijn onderzoek. Uit die stageperiodes zijn uiteindelijk twee artikelen gerold die de basis vormen van dit proefschrift. Ik wil Peter nog even apart bedanken. Je bent vrijwillig naar Nederland gekomen om na je studie ervaring op te doen om uiteindelijk te promoveren. Dit boekje was niet mogelijk geweest zonder jou. Het is niet voor niets dat jouw naam bij twee artikelen staat. Ik wil jullie allemaal bedanken voor jullie hulp, de gezelligheid en ik wil jullie heel veel succes wensen met het vervolg van jullie carrières. Thanks a lot to you all and good luck with your futures.

Ik wil ook mijn medelotgenoten bedanken voor de gezelligheid en de leuke dingen die we gedaan hebben, zoals de reis naar Florence en de GPS-zoektocht door Maastricht. Mijn oud roomies; Christina, Marlon, Hilda, Maria, Lize en Wim. Ik heb het altijd erg leuk gevonden om met jullie samen op een kamer te zitten. Bedankt hiervoor. Daarnaast mijn buren; Marieke, Linda, Dennie, Joost, Karen en Kevin bedankt voor de leuke tijd en lunches samen. Ik had het voor geen goud willen missen.

Verder wil ik ook mijn paranimfen bedanken, ten eerste mijn promoveersoulmate Kimberly. Ongeveer tegelijkertijd beginnen, meer dan drie jaar samen op een kamer zitten, deels dezelfde begeleiders hebben, en van dezelfde slechte muziek houden schept een band. We hebben het altijd erg goed kunnen vinden samen en ik ben blij dat je mijn paranimf wil zijn. Marike, jou heb ik leren kennen toen je nog een student was en we samen in het bodemhok zaten. Sinds die tijd zijn we goede vrienden en we hebben veel leuke dingen samen gedaan. Mijn tijd in Maastricht is door jou extra leuk geworden en daar ben ik je dankbaar voor.

Ten slotte wil ik mijn lieve Lori bedanken. Een paar maanden nadat we verliefd op elkaar werden verhuisde ik alweer naar Maastricht en dan nog wel voor vier jaar. Het voordeel was dan wel dat ik zo een hele week de tijd had om me erop te verheugen dat ik jou weer zou zien. Jij hebt ervoor gezorgd dat deze vier jaar zijn omgevlogen. Ik weet dat ik het altijd erg druk had en ik ben blij dat je daar begrip voor had. Nu is de tijd aangebroken dat we het relaxter aan kunnen doen en ik weet zeker dat we samen een mooie toekomst voor de boeg hebben.

Allen bedankt!

Marten 



\section{Curriculum Vitae}





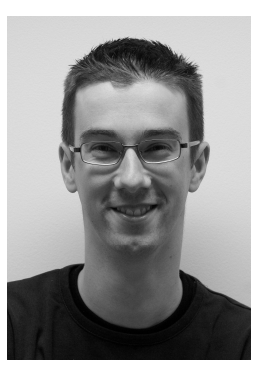

Marten Schults was born on July $25^{\text {th }}, 1983$ in Tilburg, the Netherlands. He graduated from the Odulphuslyceum in Tilburg in 2001 and started his academic education at the Technical University Eindhoven in 2001, where he studied Mechanical Engineering. After one year, he decided to make a switch to Biomedical Sciences at the Radboud University Nijmegen. As part of his Master, he followed two majors; toxicology and pathobiology. Furthermore, he obtained the license for working with laboratory animals (according to art. 9 of the Dutch law on experimental animals) and the license to work with radioactive material (Health physics 5B). In 2006 he did an internship for his major in pathobiology at the department of Dermatology and Allergology at UMC Utrecht, where he studied how certain apoptotic-related genes were linked to atopic dermatitis. In 2007 he did an internship for his major in toxicology at the department of Pharmacology at the University of Melbourne. There he studied whether the flavonoid 3'4'dihydroxyflavonol could prevent doxorubicin-induced cardiotoxicity. He graduated the same year and then started his PhD at the department of Health Risk Analysis and Toxicology at Maastricht University (since 2011 named the department of Toxicology). Under the supervision of Prof. Dr. FJ van Schooten, Dr. R. Chiu and Dr. R. Godschalk he investigated the influence of hypoxia and oxidative stress on the carcinogenicity of benzo[a]pyrene. The results are presented in this thesis. Currently, he is working as a toxicologist and registration specialist at TNO Triskelion in Zeist. 



\section{List of publications}



Schults MA, Timmermans L, Godschalk RW, Theys J, Wouters BG, van Schooten FJ, Chiu RK. Diminished carcinogen detoxification is a novel mechanism for hypoxia-inducible factor 1-mediated genetic instability. J Biol Chem. 2010 May 7;285 (19): 14558-64.

Schults MA, Sanen K, Godschalk RW, Theys J, van Schooten FJ, Chiu RK. Hypoxia diminishes the detoxification of the environmental mutagen benzo[a]pyrene. Submitted.

Schults MA, Oligschläger Y, Godschalk RW, van Schooten FJ, Chiu RK. Loss of VHL affects benzo[a]pyrene-induced genotoxic responses in renal-cell carcinoma in-vitro. Submitted.

Schults MA, Nagle PW, Rensen SS, Godschalk R.W, Munnia A, Peluso M, Claessen SM, Greve JW, Driessen A, Verdam FJ, Buurman WA, van Schooten FJ, Chiu RK, Decreased nucleotide excision repair in steatotic livers: associates with myeloperoxidaseimmunoreactivity. Mutat Res. 2012 Aug 1;736(1-2):75-81

Schults MA, Chiu RK, Nagle PW, Wilms LC, Kleinjans JC, van Schooten FJ, Godschalk RW. Interaction between genetic polymorphisms in catalase and CYP1B1 determines DNA adduct formation by benzo[a]yrene ex vivo. Accepted in Mutagenesis. 
